\title{
ipen
}

AUTARQUIA ASSOCIADA À UNIVERSIDADE DE SÃO PAULO

\section{ANÁLISE DOSIMÉTRICA DE FONTES DE RADIAÇÃO PARA USO EM LESÕES DERMATOLÓGICAS}

\author{
Ariane Tada
}

Dissertação apresentada como parte dos requisitos para obtenção do Grau de Mestre em Ciências na Área de Tecnologia Nuclear - Reatores

Orientador:

Prof. Dr. Hélio Yoriyaz 
ARIANE TADA

\section{ANÁLISE DOSIMÉTRICA DE FONTES DE RADIAÇÃO PARA USO EM LESÕES DERMATOLÓGICAS}

Dissertação apresentada como parte dos requisitos para obtenção do grau de mestre em Ciências na Área de Tecnologia de Aplicações Nucleares.

Área de Concentração: Tecnologia Nuclear - Reatores Orientador: Dr. Hélio Yoriyaz

São Paulo 
A minha Familia!

Aos meus queridos pais Maria Fátima e Sérgio Tada, pelo amor, pela confiança que sempre me deram, pelas palavras de incentivo e motivação, pelos conselhos, por serem exemplos de luta e por abrirem as portas do meu futuro, iluminando-o com a luz mais brilhante que puderam me dar: o estudo. Por terem sacrificado muitas vezes seus sonhos a favor dos meus, por me apoiarem mesmo nas horas em que meus ideais pareciam distantes e inatingíveis, por compartilhar meu cansaço e minhas preocupações, que me incentivava a prosseguir.

Aos meus queridos irmãos Taís e Serginho, que me incentivam, me erguem, me alegram, por serem minhas raízes e simplesmente fazerem parte da minha vida sempre. E a pessoa mais sábia que conheço Tereza Mussato. Obrigada Pai e Mãe e irmãos, dedico este meu trabalho a vocês.

AMO VOCÊS!! "É na família que nasce o primeiro passo de uma grande caminhada." 


\section{AGRADECIMENTOS}

\section{"Se eu vi mais longe, foi por estar de pé sobre ombros de gigantes."}

\section{Isaac Newton}

À Deus toda honra e toda glória; pela vida, saúde, força e por sempre colocar pessoas boas no meu caminho!

Ao orientador Prof. Dr. Hélio Yoriyaz, pela orientação, compreensão ao deixar conciliar o mestrado com meu trabalho, por ter me aceito como sua orientanda, pelos ensinamentos transmitidos durante esses dois anos. Muito Obrigada!!

Ao pesquisador e amigo Prof. Dr. Marco Antonio Rodrigues Fernandes, por ter me presenteado com esse plano de trabalho, pelas palavras de incentivo e motivação durante essa trajetória. Por transmitir seus conhecimentos, pelos valiosos ensinamentos e pela inesgotável dedicação e co-orientação em mais uma etapa acadêmica. Muito Obrigada!

Ao Departamento de Radioterapia do Hospital das Clínicas da Faculdade de Medicina de Botucatu-UNESP, por nos ter possibilitado o acesso para realização dos experimentos, em especial ao Técnico Natanael Izidoro por estar sempre disposto a nos ajudar, pela paciência de nos esperar em várias madrugadas de experimentos. Muito Obrigada!

A Maíra do Laboratório de Calibração de Instrumentos do IPEN pela ajuda no experimento com tubo de raios-X. 


\section{Ao departamento de Radioterapia do Hospital das Clínicas da Universidade de São}

Paulo-USP/Inrad, pelo acesso a leitora dos TLDS. Muito Obrigada.

As Famílias Tada-Marcussi; Tada-Kawata; Tada-Ikuno; Tada-Vieira; Tada-Nakaya; Tada-Santos, Marcussi-Mussato que são meus tios e primos pelas variadas formas de demonstração de carinho e união, pelas incontáveis formas de apoio, cuidado, preocupação e apoio indiretamente ou diretamente. Eternamente Grata!

A querida Família Minhoto Élen, Fabrício, Dili e Tia Elza(in memorian), pelo apoio e abrigo no início dessa jornada. Jamais esquecerei. Obrigada de todo meu coração!

Ao Instituto de Pesquisas Tecnológicas do Estado de São Paulo - IPT que me concedeu disponibilidade para o mestrado, pela oportunidade de emprego, por me realizar profissionalmente como engenheira, por estar sendo uma escola e que se tornou para mim uma família IPT. Agradeço as pessoas que fazem parte desse renomado instituto pela boa convivência, oportunidade, troca de conhecimentos são eles: Antônio Gentil; Júlio Carlos Teixeira; Raul Leone; Roberto Romano; Rose Mazzo, Samuel Freitas, Evangelina Paiva; Kleber Jesus; Simone Paizovan, Mário Leite, Eduardo Berruezo, José Pucci, Jane Gouveia e Nabil Alameddine.

Ao meu colega de trabalho e amigo Gabriel Paiva Fonseca, pelas inúmeras discussões e críticas que agregaram muito ao meu trabalho e por ser uma pessoa sempre prestativa comigo. Muito Obrigada!

Ao Douglas Borges Domingos, pelas inúmeras formas de ajuda e pela boa convivência. Muito Obrigada!

Ao Instituto de Pesquisas Energéticas e Nucleares -IPEN, pela oportunidade de realizar este trabalho Mestrado, pelo apoio financeiros nas participações dos congressos. Em especial aos Pesquisadores Gaianê Sabundjian e Paulo Tarso pelos conselhos e dicas que sempre agregam.

Aos meus colegas de Pós-Graduação do IPEN, Paulinha Antunes, Gregório, Léo, Milena, Pedro, Rafael, Felipe Cintra, Felipe Massicano, Cesinha pela troca de conhecimentos e por tornarem o caminho percorrido mais prazeroso, e em especial a Talita Salles Coelho, pelas 
histórias da nossa convivência na USP e nas viagens para Botucatu.

A Família Salesiana de Araçatuba por fazer parte da minha formação acadêmica e pessoal.

Aos meus amigos de São Paulo, Everton Menezes, Bruno Corcioli, Jeferson Carvalho, Dalila, Miréia Maio. E aos meus amigos de Araçatuba que mesmo na distância me acompanham Juliana Dias, Denise Mattos, Jessica Gon, Daniel Lorenzetti, Marquinho Alves.

Aos primos Gustavo e Kátia Marcussi por estarem me acompanhando nessa jornada e sempre estarem torcendo por mim.

A minha prima e amiga Daniela Beccaria, pelas palavras de incetivo constante pelo carinho e amizade.

E a todos aqueles que, de uma forma ou de outra, contribuiram para que este trabalho fosse desenvolvido. 
"O que faz você feliz?"

"A Educação é o que resta depois de ter esquecido tudo o que se aprendeu na escola"

Albert Einstein

"Aprendi a viver contente em todas as circunstâncias"

Filipenses 4:11

"Clama a mim, e responder-te-ei, e anunciar-te-ei coisas grandes e firmes que não sabes."

Jeremias 33:3 


\title{
ANÁLISE DOSIMÉTRICA DE FONTES DE RADIAÇÃO PARA USO EM LESÕES DERMATOLÓGICAS
}

\author{
ARIANE TADA
}

\section{RESUMO}

As lesões dermatológicas submetidas à terapia com fontes de radiação podem apresentar diferentes padrões de malignidade. Os tumores de pele mais comumente encontrados nos serviços de radioterapia são os carcinomas.

A radioterapia de lesões dermatológicas é realizada com feixes de radiação de baixa penetração como os raios- $X$ de ortovoltagem, feixes de elétrons e fontes radioativas $\left({ }^{192} \mathrm{Ir},{ }^{198} \mathrm{Au}\right.$, e ${ }^{90} \mathrm{Sr}$ ) arranjadas em moldes superficiais ou aplicadores metálicos. O presente trabalho teve como objetivo analisar o perfil de distribuição de dose terapêutica produzida por fontes de radiação utilizadas em procedimentos radioterápicos em lesões superficiais da pele. As medidas experimentais, para as análises dosimétricas das fontes de radiação, foram comparadas com cálculos obtidos no sistema computacional baseado no Método de Monte Carlo. Os resultados obtidos com os cálculos computacionais através do código MCNP-4C apresentaram uma boa concordância com as medidas experimentais. As comparações das medidas experimentais com os cálculos obtidos através do código MCNP-4C, foram utilizadas para validar os cálculos e assim possibilitar o uso de dados de simulação para aplicação em casos clínicos de rotina. A comparação entre diferentes modalidades podem fornecer um indicativo dos procedimentos mais adequados em cada caso clínico. 


\title{
DOSIMETRIC ANALYSIS OF RADIATION SOURCES FOR USE DERMATOLOGICAL LESIONS
}

\author{
ARIANE TADA
}

\begin{abstract}
Skin lesions undergoing therapy with radiation sources may have different patterns of malignancy. Malignant lesions or cancer most commonly found in radiotherapy services are carcinomas. Radiation therapy in skin lesions is performed with low penetration beams and orthovoltage $\mathrm{X}$-rays, electron beams and radioactive sources $\left({ }^{192} \mathrm{Ir},{ }^{198} \mathrm{Au}, \mathrm{e}^{90} \mathrm{Sr}\right)$ arranged on a surface mold or in metal applicator. This study aims to analyze the therapeutic radiation dose profile produced by radiation sources used in skin lesions radiotherapy procedures. Experimental measurements for the analysis of dosimetric radiation sources were compared with calculations obtained from a computer system based on the Monte Carlo Method. Computational results had a good agreement with the experimental measurements. Experimental measurements and computational results by the MCNP4C code were both physically consitent as expected. These experimental measurements compared with calculations using the MCNP-4C code have been used to validate the calculations obtained by MCNP code and to provide a reliable medical application for each clinical case.
\end{abstract}




\section{Lista de Figuras}

2.1 Desenho ilustrativo de uma simulação computacional utilizando transporte de radiação ionizante para tratamento de paciente. . . . . . . . . . . . 25

2.2 Equipamentos dos Primórdios da Radioterapia a) Equipamento de Cobalto -60, El Dorado, b) Equipamento ortovoltagem - Stabilipan. . . . . . . . . . . 27

2.3 Configurações: a) Distância Fonte-superfície (DFS), b) Distância Fonte-isocentro

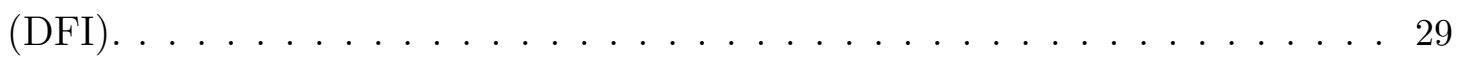

2.4 Conceitos a) Definição de planura e simetria de feixes clínicos, b) Definição de penumbra de feixes clínicos. . . . . . . . . . . . . . . 30

2.5 Distribuição terapêutica de dose em profundidade com as definições de parâmetros $\mathrm{R}_{100}, \mathrm{R}_{85}, \mathrm{R}_{50}$ e $\mathrm{R}_{p} \ldots \ldots \ldots \ldots \ldots \ldots \ldots \ldots \ldots \ldots \ldots \ldots \ldots \ldots \ldots \ldots \ldots \ldots$

3.1 Anatomia da Pele. . . . . . . . . . . . . . . . . . . . 34

3.2 Carcinomas Basocelulares: a) CBC nódulo ulcerativo; b) CBC forma super-

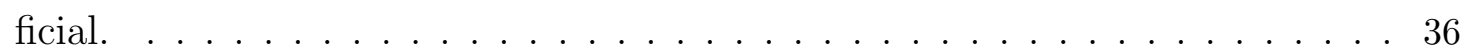

3.3 Carcinomas Espinocelulares: a) CEC nodular , b) CEC ulcerado. . . . . . . . . . . 37

3.4 Desenho ilustrativo da profundidade dos tumores de pele. . . . . . . . . . . . 38

3.5 Exemplos de curvas de porcentagem de dose para feixe de elétrons de megavoltagem. . . . . . . . . . . . . . . . . . . . . . 40

3.6 Exemplos de curvas de porcentagem de dose para feixe de fótons de quilovoltagem e megavoltagem. . . . . . . . . . . . . . . . . 41

4.1 Acelerador linear Varian, modelo Clinac 2100C . . . . . . . . . . . . . . . . 43

4.2 a) Tubo de raios-X IPEN, b) Sala de controle do tubo de raios-X . . . . . . 45

4.3 a) Aplicador dermatológico de ${ }^{90} \mathrm{Sr}+{ }^{90} \mathrm{Y}$, b) Proteção do Aplicador dermatológico ${ }^{90} \mathrm{Sr}+{ }^{90} \mathrm{Y} \ldots \ldots \ldots \ldots \ldots \ldots \ldots \ldots$. . . . . . . . . . . . 46 
4.4 Camâras de Ionização a) CI de Placas Paralelas, b) Câmara de Ionização . . . 47

4.5 Eletrômetros a) Eletrômetro CDX -2000B, b) Eletrômetro PTW Unidos. . . . 48

4.6 a) Dosímetros termoluminescente TDL LiF-100; b) Leitora dos TLDs Harshaw, modelo 3500 pertecente ao HC/USP. . . . . . . . . . . . . . . . . . . . 49

4.7 a) Objeto simulador de água, b) Placas de água sólida . . . . . . . . . . . . . 49

4.8 Exemplo de arquivo de entrada contendo as variáveis iniciais e seus valores designados para simulação com o código MCNP4C. Estrutura do arquivo de entrada do MCNP4C basicamente dividida em três blocos. . . . . . . . . . . . 53

4.9 Arranjo experimental da caracterização dos feixes - Parte Axial a) Acelerador Linear e objeto simulador, b) Eletrômetro, c) Posicionamento e alinhamento

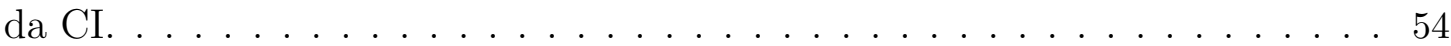

4.10 Geometria utilizada para caracterização do feixe de elétrons $4 \mathrm{MeV}$ e $9 \mathrm{MeV}$. 55

4.11 Ilustração da Geometria típica dos componentes do modelo de um CLINAC utilizados em simulação pelo método de Monte Carlo. . . . . . . . . . . . . . . 56

4.12 Janela ilustrativa da distribuição energética da fonte de elétrons no código

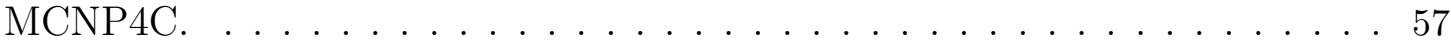

4.13 a) Arranjo experimental para medidas de perfis radiais dos feixes de elétrons,

b) Sistema de Medição de deslocamento da Planura. . . . . . . . . . . . . . . . . 57

4.14 Geometria utilizada para a reconstrução da distribuição espacial dos feixes de elétrons de $4 \mathrm{MeV}$ e $9 \mathrm{MeV}$ do Acelerador Linear de Botucatu. . . . . . . . 58

4.15 Janela ilustrativa com a especificações da distribuição espacial da fonte de elétrons no código MCNP4C . . . . . . . . . . . . . . . . . . . 59

4.16 Arranjo experimental da atenuação dos feixes de elétrons em função das espessuras de atenuadores a) Posicionamento da CI no objeto simulador, b) posicionamento das placas atenuadoras no aplicador. . . . . . . . . . . . . . 60

4.17 Exemplo de duas geometrias utilizadas no MCNP para análise do perfil de atenuação de dose dos feixes de elétrons em função de placas atenuadoras a) arquivo de entrada sem placa, b) arquivo de entrada com 20 placas. . . . . . . 61

4.18 Arranjo experimental da atenuação dos feixes de elétrons de $4 \mathrm{MeV}$ em função das espessuras de atenuadores utilizando TLD: 01) Configuração experimental, 02) Placas de Polietileno e suporte de acrílico e 03) TLDs no suporte. . . 62

4.19 Configuração experimental utilizado nas medidas do feixe de elétrons de 4 MeV com TLD, Setup DFI $=100 \mathrm{~cm}$, Setup DFS $=100 \mathrm{~cm} . \ldots \ldots \ldots 2$ 
4.20 a) Arranjo das medidas experimentais das Planuras; b) Geometria utilizada para planura do feixe de elétrons $4 \mathrm{MeV}$ e $9 \mathrm{MeV} \ldots \ldots$. . . . . . . . . . . 63

4.21 Configuração experimental utilizada para as medidas com o equipamento de Raios-X de 90 kVp - Laboratório de Calibração de Instrumentos do IPEN. . . 64

4.22 Geometria modelada no MCNP4C referente ao arranjo experimental das medidas com equipamento de raios-X de $90 \mathrm{kVp} \ldots$. . . . . . . . . . . . . . . . 65

4.23 Espectro do feixe de raios-X de $90 \mathrm{kVp}$ usado no MCNP4C para simulação 66

4.24 a) Desenho ilustrativo de uma lesão de pele, b) Geometria do tumor de pele

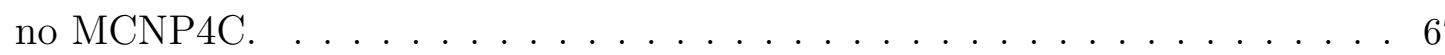

5.1 Curvas de PDPs a) $4 \mathrm{MeV}$, b) $9 \mathrm{MeV} \ldots \ldots \ldots \ldots$

5.2 Espectro reconstruído do feixe clínico de elétrons de $4 \mathrm{MeV}$ no MCNP4C. . . 69

5.3 Espectro reconstruído do feixe clínico de elétrons de $9 \mathrm{MeV}$ no MCNP4C. . . 69

5.4 a) Comparação entre PDP obtida com a câmara de ionização e a simulada com espectro energético reconstruído para energia de $4 \mathrm{MeV}$, b) Diferença percentual entre a curva de PDP obtida experimentalmente e simulada no MCNP4C para energia de $4 \mathrm{MeV} \ldots \ldots \ldots \ldots$. . . . . . . . . 70

5.5 a) Comparação entre PDP obtida com a câmara de ionização e a simulada com espectro energético reconstruído para energia de $9 \mathrm{MeV}$; b) Diferença percentual entre a curva de PDP obtida experimentalmente e simulada no MCNP4C para energia de $9 \mathrm{MeV} \ldots \ldots \ldots \ldots \ldots$. . . . . . . . . . . . 71

5.6 PDP $9 \mathrm{MeV}$ - Curva de PDP experimental versus PDP considerando o feixe monoenergético versus PDP com espetro energético reconstruído no MCNP. . 72

5.7 Caracterização geométrica do campo de radiação com 3 regiões com pesos distintos . . . . . . . . . . . . . . . . . . . . . . . . 73

5.8 Curvas da planura obtida experimentalmente e reconstruída com MCNP do feixe $4 \mathrm{MeV}$ na profundidade de dose máxima do feixe. . . . . . . . . . . . . . 74

5.9 Curvas da planura obtida experimentalmente e reconstruída com MCNP4C do feixe $9 \mathrm{MeV}$ na profundidade de dose máxima do feixe. . . . . . . . . . . 74

5.10 Intensidade de dose relativa obtida com câmara de ionização em função das espessuras de placas atenuadoras para o feixe de elétrons de $4 \mathrm{MeV}$. . . . . 76

5.11 Intensidade de dose relativa obtida com câmara de ionização e TLD em função das espessuras de placas atenuadoras para o feixe de elétrons de 4

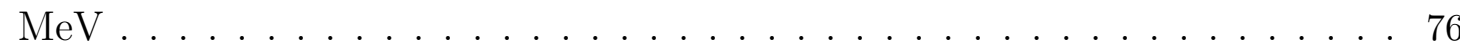


5.12 Intensidade de dose relativa obtida com câmara de ionização em função das espessuras de placas atenuadoras para o feixe de elétrons de $9 \mathrm{MeV}$. . . . . 77

5.13 Medidas experimentais da planura do campo $10 \mathrm{~cm} \mathrm{X} 10 \mathrm{~cm}$ do feixe de 4 $\mathrm{MeV}$ em 4 profundidades. . . . . . . . . . . . . . . . . . 78

5.14 Medidas experimentais da planura do campo $10 \mathrm{~cm} \mathrm{X} 10 \mathrm{~cm}$ do feixe de 9 $\mathrm{MeV}$ em 4 profundidades. . . . . . . . . . . . . . . . . . . 79

5.15 Planura do feixe de $4 \mathrm{MeV}$ na profundidade de $0 \mathrm{~mm}$ sem placas atenuadoras. 80

5.16 Planura do feixe de $4 \mathrm{MeV}$ na profundidade de $1,2 \mathrm{~mm}$ referente à 2 placas

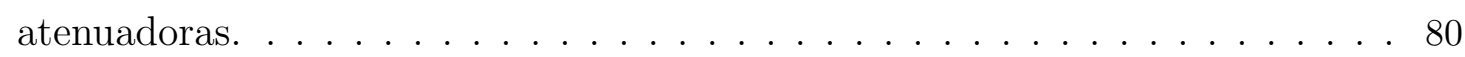

5.17 Planura do feixe de $9 \mathrm{MeV}$ na profundidade de $0 \mathrm{~mm}$ sem placas atenuadoras. 82

5.18 Planura do feixe de $9 \mathrm{MeV}$ na profundidade de $3 \mathrm{~mm}$ referente à 5 placas atenuadoras. . . . . . . . . . . . . . . . . . 82

5.19 Planura do feixe de $9 \mathrm{MeV}$ na profundidade de $6 \mathrm{~mm}$ referente à 10 placas

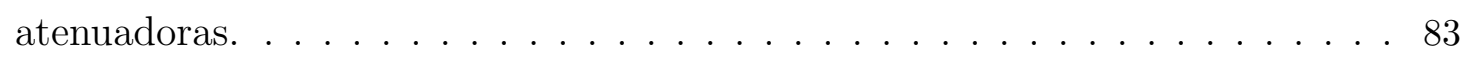

5.20 Planura do feixe de $9 \mathrm{MeV}$ na profundidade de $9 \mathrm{~mm}$ referente à 15 placas

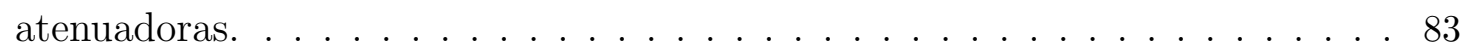

5.21 Intensidade de dose relativa obtida com câmara de ionização em função das espessuras de placas atenuadoras para o feixe de raios-X de $90 \mathrm{kVp}$. . . . . . 86

5.22 Análise dosimétrica entre as curvas experimentais dos feixes de elétrons de 4 $\mathrm{MeV}$ e $9 \mathrm{MeV}$, Raios-X de $90 \mathrm{kVp}$ e fonte de ${ }^{90} \mathrm{Sr}+{ }^{90} \mathrm{Y} . \ldots . . . . . . .88$

5.23 Resultado da simulação no MCNP4C do Caso clínico 1 - Lesão de pele com dimensões $6 \mathrm{~cm}$ X $6 \mathrm{~cm}$ X 0,75 cm; Energia de tratamento $4 \mathrm{MeV}$; Tamanho de campo $10 \mathrm{~cm} \mathrm{X} 10 \mathrm{~cm}$ e DFS $100 \mathrm{~cm}$. . . . . . . . . . . . . . . 89

5.24 Resultado da simulação no MCNP4C do Caso clínico 2 - Lesão de pele com dimensões $6 \mathrm{~cm}$ X 6 cm X 2,1 cm; Energia de tratamento $9 \mathrm{MeV}$; Tamanho de campo $10 \mathrm{~cm}$ X $10 \mathrm{~cm}$ e DFS $103 \mathrm{~cm}$. . . . . . . . . . . . . . 89

5.25 Resultado da simulação no MCNP4C do Caso clínico 3 - Lesão de pele com dimensões $9 \mathrm{~cm}$ X $6 \mathrm{~cm}$ X 2,1 cm; Energia de tratamento $9 \mathrm{MeV}$; Tamanho de campo $10 \mathrm{~cm}$ X $10 \mathrm{~cm}$ e DFS $100 \mathrm{~cm}$. . . . . . . . . . . . . . 90

5.26 Resultado da simulação no MCNP4C do Caso clínico 4 - Tumor de pele com dimensões $6 \mathrm{~cm}$ X 6 cm X 2,1 cm; Feixe de Tratamento Raios-X de 90 kVp; Tamanho de campo $6,8 \mathrm{~cm}$ e DFS $50 \mathrm{~cm}$ (Caso Fictício). . . . . . . . . . . 90 
5.27 Medidas experimentais das fontes de radiação para uso de lesões dermatológicas e simulações no MCNP4C, mostrando a porcentagem de dose absorvida em cada região da camada da pele até $6 \mathrm{~mm} . \quad \ldots \ldots$. . . . . . . . 91 


\section{Lista de Tabelas}

3.1 Regiões anatômicas onde os carcinomas são mais comuns e suas respectivas espessuras de pele. . . . . . . . . . . . . . . . . . 34

3.2 Relação entre a energia dos elétrons, faixa clínica (PDP 85\%) e alcance prático dos feixes. . . . . . . . . . . . . . . . . . 39

4.1 Propriedades de alguns materiais constituintes de objetos simuladores . . . . 50

4.2 Configurações utilizadas no experimento com feixes de elétrons. . . . . . . . 60

4.3 Características e configurações do experimento com raios-X de $90 \mathrm{kVp}$. . . . 65

4.4 Casos Clínicos de tratamento de lesões de pele com feixes de elétrons. . . . . 67

5.1 Valores das dimensões de cada região do campo de radiação e os respectivos pesos obtidos pelo MCNP4C para o feixe de $4 \mathrm{MeV}$. . . . . . . . . . . . 73

5.2 Valores das dimensões de cada região do campo de radiação e os respectivos pesos obtidos pelo MCNP4C para o feixe de $9 \mathrm{MeV} \ldots \ldots \ldots$. . . . . . . 73

5.3 Dados normalizados obtidos da planura do feixe de $4 \mathrm{MeV}$ e a diferença Percentual para profundidade $0 \mathrm{~mm}$ referente a $100 \%$ de dose relativa. . . . . 81

5.4 Dados normalizados obtidos da planura do feixe de $4 \mathrm{MeV}$ e a diferença Percentual para profundidade 1,2 mm referente a $71 \%$ de dose relativa. . . . . 81

5.5 Dados normalizados obtidos da planura do feixe de $9 \mathrm{MeV}$ e a diferença percentual para profundidade $0 \mathrm{~mm}$ referente a $100 \%$ de dose relativa. . . . . 84

5.6 Dados normalizados obtidos da planura do feixe de $9 \mathrm{MeV}$ e a diferença percentual para profundidade $3 \mathrm{~mm}$ referente a $92 \%$ de dose relativa. . . . . . 84

5.7 Dados normalizados obtidos da planura do feixe de $9 \mathrm{MeV}$ e a diferença percentual para profundidade $6 \mathrm{~mm}$ referente a $80 \%$ de dose relativa. . . . . . 85 
5.8 Dados normalizados obtidos da planura do feixe de $9 \mathrm{MeV}$ e a diferença percentual para profundidade $9 \mathrm{~mm}$ referente a $63 \%$ de dose realativa. . . . . 85 


\section{Sumário}

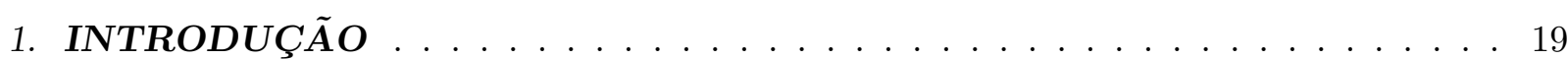

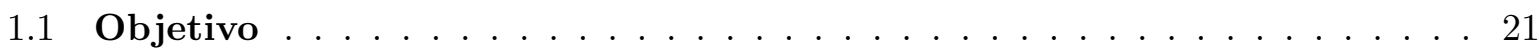

2. FUNDAMENTOS TEÓRICOS EM RADIOTERAPIA . . . . . . . . . . . 22

2.1 Evolução da Radioterapia . . . . . . . . . . . . . . . . . . . . . 22

2.1.1 Descobertas e as Primeiras Aplicações . . . . . . . . . . . . . . 22

2.1.2 Desenvolvimento da Dosimetria em Radioterapia . . . . . . . . . . . 23

2.1.3 Desenvolvimento dos Equipamentos de Radioterapia . . . . . . . . . 26

2.2 Formalismo da Dosimetria Clínica e Física . . . . . . . . . . . . . . . . 27

2.2 .1 Dose Absorvida . . . . . . . . . . . . . . . . 27

2.2.2 Porcentagem de Dose Profunda - PDP _ . . . . . . . . . . 27

2.2 .3 Build-up e Equilíbrio Eletrônico . . . . . . . . . . . . . . . . 28

2.2.4 Distância Fonte-Superfície (DFS) e Distância Fonte-Isocentro (DFI) 28

2.2.5 Tamanho de Campo do Feixe de Radiação . . . . . . . . . . . . . . . 29

2.2.6 Perfil do Feixe (Simetria e Planura) f . . . . . . . . . . . . . . 30

2.2.7 Profundidade para $100 \%$ da Dose $\mathbf{R}_{100} \ldots \ldots \ldots \ldots$

2.2 .8 Alcance à meia Profundidade $\mathbf{R}_{50} \ldots \ldots \ldots \ldots$. . . . . . . . . 31

2.2.9 Profundidade de Referência $\mathbf{Z}_{r e f} \ldots \ldots \ldots \ldots$

2.2 .10 Alcance Terapêutico $\mathbf{R}_{85} \ldots \ldots \ldots \ldots$. . . . . . . . . . . . . . .

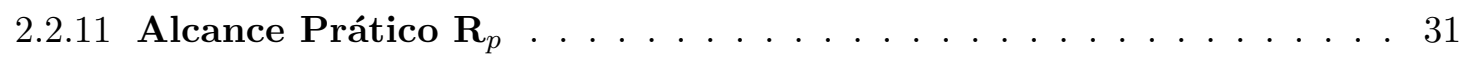

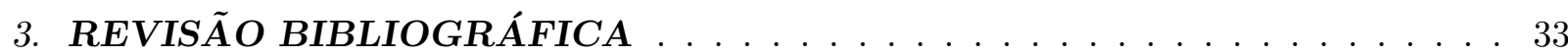

3.1 Pele - Anatomia . . . . . . . . . . . . . . . . . 33

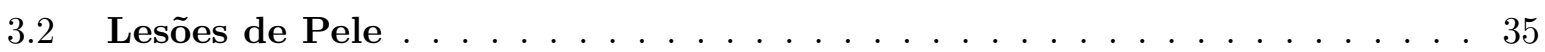

3.2.1 Carcinomas Basocelulares . . . . . . . . . . . . . . 35 
3.2.2 Carcinomas Espinocelulares . . . . . . . . . . . 36

3.2.3 Etiologia dos Tumores de Pele . . . . . . . . . . . . . . 37

3.2.4 Características dos CBC e CEC (Formas Geométricas, Tamanho e Profundidade $\ldots \ldots \ldots \ldots$. . . . . . . . . . . . . . . . . . . .

3.3 Procedimentos Terapêuticos . . . . . . . . . . . . . . . 38

3.3.1 Tratamento com Feixe de Elétrons . . . . . . . . . . . . . . . 39

3.3.2 Tratamento com Raios-X de Ortovoltagem . . . . . . . . . . . . . 40

3.3.3 Procedimento com Betaterapia e Braquiterapia . . . . . . . . . . . 41

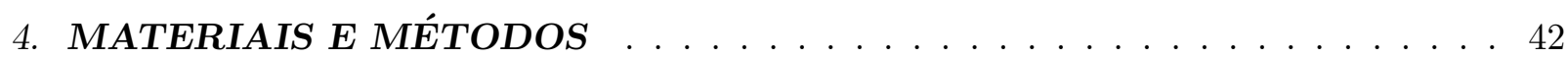

4.1 Equipamentos de Irradiação . . . . . . . . . . . . . . . . . . . 42

4.1 .1 Acelerador Linear . . . . . . . . . . . . . . . . . 42

4.1 .2 Raios-X . . . . . . . . . . . . . . . . 45

4.1 .3 Aplicador de ${ }^{90} \mathbf{S r}+{ }^{90} \mathbf{Y}($ Betaterapia $) \ldots \ldots \ldots \ldots \ldots$

4.2 Sistema de Medições de Radiação . . . . . . . . . . . . . . . . . . . 46

4.2 .1 Câmara de Ionização . . . . . . . . . . . . . . . . . . . . 46

4.2 .2 Eletrômetros . . . . . . . . . . . . . . . . 47

4.2 .3 Dosímetros Termoluminescentes (TLD LiF-100) . . . . . . . . . 48

4.2 .4 Objetos Simuladores . . . . . . . . . . . . . . . 49

4.3 Simulação Computacional . . . . . . . . . . . . . . . . . 50

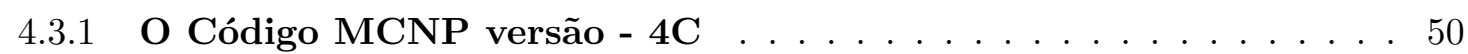

4.3.2 Estrutura dos Dados de Entrada no Código MCNP. . . . . . . . . . 51

4.3.3 Visualização e Análise das Saídas do MCNP. . . . . . . . . . . . 52

4.4 Descrições dos Experimentos e das Simulações com o Código MCNP4C. 53

4.4.1 Caracterização dos Feixes de Elétrons de $4 \mathrm{MeV}$ e $9 \mathrm{MeV}$ do Acelerador Linear Clinac 2100C. . . . . . . . . . . . . . . 53

4.4.2 Medidas Experimentais dos Perfis de Dose dos Feixes de Elétrons de $4 \mathrm{MeV}$ e $9 \mathrm{MeV}$ em Função das Espesssuras de Atenuadores . 59

4.4.3 Medidas Experimentais do Perfil de Dose do Feixe de Elétrons de $4 \mathrm{MeV}$ com TLD em Função das Espessuras dos Atenuadores. 61

4.4.4 Medidas Experimentais das Planuras dos Feixes de Elétrons em Várias Profundidades . . . . . . . . . . . . . . . . 63

4.4.5 Medidas Experimentais do Perfil de Dose do Feixe de Raios-X de 90 kVp em Função das Espessuras de Atenuadores. 
4.4 .6 Casos Clínicos . . . . . . . . . . . . . . . . . 66

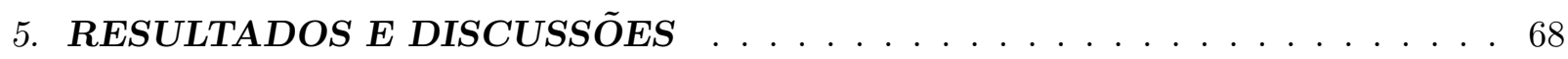

5.1 Reconstruções dos Espectros Energéticos e Espaciais com o MCNP4C para os Feixes de Elétrons de $4 \mathrm{MeV}$ e $9 \mathrm{MeV} \ldots \ldots$. . . . . . . . . . . 68

5.1.1 Reconstrução do Espectro: Parte Axial . . . . . . . . . . . . . . . 69

5.1 .2 Reconstrução do Espectro: Parte Radial . . . . . . . . . . . . . . . . 72

5.2 Resultados dos Experimentos e Cálculos com o MCNP4C do Perfil Axial de Dose dos Feixes de Elétrons em Função de Atenuadores . . . . . . . . . 75 5.2.1 Resultados para Feixe de Elétrons 4 MeV. . . . . . . . . . . . . . . 75

5.2.2 Resultados para o Feixe de Elétrons de $9 \mathrm{MeV}$. . . . . . . . . . . 77

5.3 Resultados dos Experimentos e Cálculos com o MCNP4C do Perfil Radial de Dose (planura) dos Feixes de Elétrons em Função de Atenuadores 78 5.3.1 Resultados das Planuras do Feixe de Elétrons de 4 MeV. . . . . . . 79

5.3.2 Resultados das Planuras do Feixe de Elétrons de 9 MeV. . . . . . . 81

5.4 Resultados dos Experimentos e Cálculos com o MCNP4C do Perfil de Dose do Feixe de Raios-X de 90 kVp . . . . . . . . . . . . . . . 85

5.5 Comparação Dosimétrica entre os Feixe de Elétrons de $4 \mathrm{MeV}$, Elétrons de $9 \mathrm{MeV}$, Raios-X de $90 \mathrm{kVp}$ e Fonte de ${ }^{90} \mathrm{Sr}+{ }^{90} \mathrm{Y} \ldots \ldots \ldots$. . . . . . 86

5.6 Resultados das Simulações dos Casos Clínicos . . . . . . . . . . . . 88

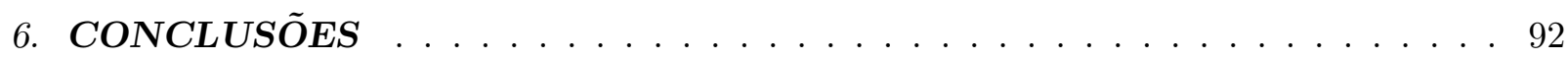

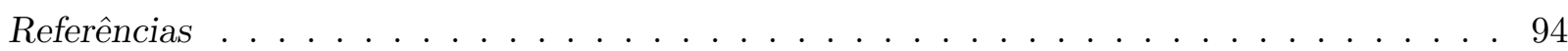




\section{Capítulo 1}

\section{INTRODUÇÃO}

As lesões dermatológicas submetidas à terapia com fontes de radiação podem apresentar diferentes padrões de malignidade. Os tumores de pele mais comumente encontrados nos serviços de radioterapia são os carcinomas. Estes por sua vez são denominados basocelulares ou epidermóides. Os carcinomas basocelulares (CBC) correspondem a cerca de $70 \%$ dos cânceres de pele diagnosticados, e são originários da epiderme e dos apêndices cutâneos acima da camada basal, como os pêlos. Os carcinomas epidermóides (CEC), aparecem em cerca de $25 \%$ dos tumores de pele tratados e têm origem no queratinócio da epiderme, podendo também aparecer no epitélio escamoso das mucosas. Conforme dados do Instituto Nacional de Câncer ${ }^{1}$, os números de mortes em 2007 foram de 1.296 sendo 753 homens e 543 mulheres, a estimativa de novos casos para 2010 são de 113.850, sendo 53.410 homens e 60.440 mulheres.

No Brasil os carcinomas de pele CBC e CEC continuam sendo os de maior incidência em ambos os sexos. Embora apresente baixo índice de mortalidade (letalidade), em alguns casos onde há demora no diagnóstico e na terapia, esses cânceres podem levar a ulcerações e deformidades físicas graves, comprometendo severamente a qualidade de vida dos doentes. A maioria destes cânceres é devida à exposição excessiva aos raios solares.

Os raios ultra-violetas (R.U.V.) possuem comprimento de onda na faixa de 200 a 400 nanômetros, e são classificados em raios UV-A, UV-B e UV-C. Face à destruição da camada de ozônio, têm-se verificado um aumento progressivo na incidência dos raios UV-B e UV-C os quais estão diretamente relacionados ao surgimento de câncer de pele. Os raios UVA independem da camada de ozônio, podendo causar câncer de pele em pessoas que se

\footnotetext{
${ }^{1}$ http://www.inca.gov.br
} 
expõem por tempo prolongado e durante muitos anos em horários de maior incidência.

Outro tipo de câncer diagnosticado, mas de baixa incidência e não responsivo à radioterapia, é o melanoma o qual apresenta letalidade mais elevada que os CBC e CEC.

Algumas lesões benignas (não cancerígenas) de pele que também podem ser submetidas à radioterapia com fontes de betaterapia são os pterígios e os quelóides. Quelóides são cicatrizes hipertróficas da pele que surgem em algumas pessoas como resposta incomum do organismo a algum trauma cutâneo. O pterígio é uma neoformação fibrovascular da conjuntiva do bulbo ocular (SALVAJOLI et al., 1999).

A radioterapia nas lesões dermatológicas é realizada com feixes de radiação de baixa penetração como os raios-X de ortovoltagem, feixes de elétrons (radiação corpuscular) e fontes radioativas $\left({ }^{192} \mathrm{Ir},{ }^{198} \mathrm{Au}\right.$ e $\left.{ }^{90} \mathrm{Sr}+{ }^{90} \mathrm{Y}\right)$ arranjadas em moldes superficiais ou aplicadores metálicos (FERNANDES, 2000).

A dosimetria destes feixes é realizada com detectores específicos para cada tipo de radiação e adequados para a respectiva energia. No caso de feixes de raios-X, utiliza-se câmaras de ionização calibradas para baixas energias de raios-X, para feixes de elétrons utilizam-se câmaras de ionização de placas paralelas. No entanto, para os moldes superficiais com fontes radioativas, a determinação do perfil da dose com câmaras de ionização é prejudicada devido à pequena dimensão das fontes e do tamanho do campo. Nestes casos o uso de filmes radiográficos de resposta lenta e dosímetros termoluminescentes podem resultar em medidas mais apropriadas.

Face à grande demanda de pacientes, a rotina clínica dos serviços de radioterapia no Brasil, principalmente naqueles que atendem ao Sistema Único de Saúde (S.U.S.), dificulta ao serviço de física médica, a determinação da dose de radiação bem como do perfil de distribuição de dose de forma adequada no volume tumoral. Além disso, por questão de restrição de tempo, ou de ausência de instrumentos de medidas adequados ou mesmo recursos computacionais, a análise dosimétrica é obtida com base em tabelas fornecidas na literatura. Estas, porém nem sempre estão atualizadas e às vezes não são adequadas ao radioisótopo ou tipo de fonte utilizada. Portanto, faz-se necessário o desenvolvimento de metodologias mais simples, eficientes, confiáveis, e de fácil aquisição, e que garanta a qualidade dos procedimentos clínicos, permitindo, desta forma, proceder de forma mais eficaz a análise dosimétrica dos procedimentos. 
Sistemas computacionais, que utilizam algorítmos matemáticos aplicados ao Método de Monte Carlo, vêm ganhando espaço por se mostrarem eficientes nos trabalhos de física aplicada à medicina com importantes resultados na determinação da distribuição de dose de radiação oriunda de vários tipos de radionuclídeos interagindo com o tecido biológico.

O desenvolvimento de rotinas computacionais adaptadas com dados sobre feixes de radiação de uso terapêutico vem apresentando resultados satisfatórios e tem colaborado para procedimentos de dosimetria numérica, onde se pode obter o perfil de distribuição de dose sobre determinada fonte interagindo com diferentes materiais. Neste contexto, a técnica de Monte Carlo aplicada à física da radioterapia vem alcançando confiabilidade, face à sua versatilidade na configuração geométrica de feixes de radiação e variabilidade de interfaces de diferentes densidades.

A literatura ainda é escassa no que se refere ao uso das técnicas computacionais de análises dosimétricas de fontes utilizadas para terapia de lesões dermatológicas. O estado atual do conhecimento solicita que sejam realizados experimentos que possam validar os cálculos gerados pelas simulações. Com a validação, as simulações fornecem informações prévias que trarão maior conhecimento sobre os procedimentos terapêuticos destas lesões.

A credibilidade na análise dosimétrica numérica ainda proporcionará uma redução significativa da exposição à radiação da equipe de profissionais envolvidos nos procedimentos terapêuticos quando da necessidade da realização do controle de qualidade destas fontes.

\subsection{Objetivo}

Pretende-se neste trabalho analisar o perfil de distribuição de dose terapêutica de radiação produzida por fontes de radiação utilizadas em procedimentos radioterápicos em lesões superficiais da pele. Para isso serão realizadas medidas experimentais de distribuição de dose em objetos simuladores, sendo que, os resultados serão comparados com cálculos obtidos através das simulações destes experimentos, através da utilização do código de Monte Carlo MCNP4C. Com base nos resultados e comparações do presente trabalho, pretende-se fornecer subsídios para auxilio no planejamento de tratamento de lesões dermatológicas na rotina clínica. 


\section{Capítulo 2 \\ FUNDAMENTOS TEÓRICOS EM RADIOTERAPIA}

Neste capítulo pretende-se dissertar brevemente sobre a evolução da radioterapia e também descrever os principais conceitos e definições de alguns formalismos utilizados em dosimetria na radioterapia para compreensão da teoria e da prática deste trabalho.

\subsection{Evolução da Radioterapia}

\subsubsection{Descobertas e as Primeiras Aplicações}

A radioterapia é a área da medicina que utiliza radiações ionizantes para destruição de

células malignas. É um método de tratamento local do câncer, que utiliza equipamentos e técnicas variadas para irradiar áreas do organismo humano.

O objetivo da radioterapia é liberar máxima dose no tecido tumoral e preservar o máximo de tecido normal.

A radioterapia divide-se em duas modalidades de tratamento:

- Teleterapia - forma de tratamento externa onde a fonte de radiação encontra-se a uma certa distância da área a ser tratada, em geral de $40 \mathrm{~cm}$ a $100 \mathrm{~cm}$.

- Braquiterapia - forma de tratamento em que a fonte radioativa fica em contato ou dentro de uma cavidade, tumor, ou órgão a ser tratado.

Três acontecimentos científicos permitiram o uso das radiações para fins científicos e médicos: 
- A descoberta do raios-X em 1895, por Wilhelm Conrad Roengten, engenheiro mecânico;

- A descoberta da radioatividade em 1896, pelo físico Antonie Henry Becquerel;

- A descoberta do Radio em 1898, pelo casal Marie e Pierre Curie.

Essas descobertas foram muito importantes para o progresso e aperfeiçoamento da radioterapia, pois após esses acontecimentos a medicina fez uso de suas propriedades para fins diagnósticos e terapêuticos, o que possibilitou um grande avanço científico e tecnológico, principalmente para a área da saúde.

Em 1896, foi descrito o emprego da radioterapia para tratamento de tuberculose. Em seguida foi aplicada a combinação de raios-X e de rádio no tratamento de diversas lesões de cabeça, pescoço, tumores de rinofaringe, carcinomas de estômagos, tumores de pele em diversos processos inflamatórios (SALVAJOLI et al.,1999).

Em janeiro de 1896, a primeira paciente portadora de um volumoso câncer de mama foi tratada com finalidade terapêutica. Em julho de 1896 foi descrito na França, o tratamento de um câncer gástrico. Oito tratamentos foram dados, duas vezes ao dia, com grande melhora de dor e diminuição de massa tumoral.

Já nos primórdios da Braquiterapia houve uma evolução mais lenta em comparação a teleterapia, devido à falta de fontes radioativas adequadas. Somente em 1900 aconteceu o primeiro uso terapêutico do rádio para braquiterapia de pele pelo Dr. Danlos do Hospital Saint-Louis - Paris (SALOMON, 2006).

\subsubsection{Desenvolvimento da Dosimetria em Radioterapia}

Em 1902 já existia a preocupação de se realizar a dosimetria que é o monitoramento da dose quando há exposição de pacientes à radiação nos diagnósticos em medicina e durante terapias. Nos primórdios da radioterapia, administrava-se tanta dose de radiação quanto se julgava capaz de tolerar, sendo, geralmente, o limite de dose estabelecido pela tolerância da pele. As tentativas de sistematizar o emprego da radiação datam de 1906, quando tentavam padronizar o tratamento, relacionando o tempo de exposição com a miliamperagem, construindo uma tabela mostrando a intensidade de dose e as doses de segurança em função de diferentes distâncias. Tentavam-se medir a energia calórica emitida 
pelos aparelhos: a medida de dose pela mudança de cor que a irradiação provocava em certas substâncias químicas (SALVAJOLI et al.,1999).

A fim de definir grandezas físicas para radiação foi criada em 1925 a Comissão Internacional de Unidades e Medidas da Radiação, The International Commission on Radiation Units and Measurements, ICRU, e logo em seguida em 1928 preocupada com a proteção radiológica nasce o ICRP, The International Commission on Radiological Protection (SALOMON, 2006). Em 1929, definiu-se pela primeira vez, durante o II Congresso Internacional de Radiologia, realizado em Estocolmo, uma unidade padrão de dose de exposição, o roentgen $(\mathrm{R})$, que uniformizou os critérios da dosimetria. A unidade roentgen (R) posteriormente foi substituída pelo rad que também foi substituído pelo centiGray (cGy)(SALVAJOLI et al., 1999).

A dosimetria em radioterapia pode ser dividida em dosimetria absoluta e dosimetria relativa. Na dosimetria absoluta a dose é determinada no ponto de referência em condições padronizadas, já a dosimetria relativa é uma medida relativa, num determinado ponto de interesse, e que posteriormente é relacionada à medida absoluta.

Todo procedimento de caracterização e dosimetria é baseado em protocolos, ou seja, um conjunto de normas que asseguram que os serviços determinarão parâmetros dosimétricos da mesma maneira.

Em 1970 a Agência Internacional de Energia Atômica (AIEA) publicou o primeiro protocolo de dosimetria o Technical Reports Series (TRS), o TRS-110 "Manual de dosimetria em Radioterapia", posteriormente outros protocolos foram publicados (ARAÚJO et al, 2005):

- TRS-277 - "Determinação da dose absorvida em feixes de fótons e elétrons- Um código de Prática Internacional”, em 1987.

- TRS - 381 - "Uso de Câmaras de ionização de Placas Paralelas em Feixes de Fótons e Elétrons de Alta energia - Um código de Prática Internacional para Dosimetria", em 1997.

- TRS 398 - "Determinação da Dose Absorvida em Radioterapia de Feixes Externos" - Um código de Prática Internacional para Dosimetria Baseada em Padrões de Dose Absorvida da Água, em 2000. 
A dosimetria das radiações ionizantes é importante para que procedimentos possam ser tomados com o objetivo de maximizar os efeitos benéficos que ela pode oferecer à sociedade e minimizar os danos dela decorrente.

No estado atual do conhecimento da dosimetria muito tem se falado sobre dosimetria numérica. A dosimetria numérica utiliza simulações computacionais baseadas em técnicas de Monte Carlo para o cálculos de dose absorvida, e outras grandezas de interesse, relacionados ao tratamento do câncer. Uma das vantagens da dosimetria numérica é a redução significativa da exposição à radiação da equipe de profissionais envolvidos nos procedimentos terapêuticos.

A medida que ocorre o avanço tecnológico na área computacional, a técnica de Monte Carlo para uso em transporte de radiação , especificamente, para a área de Física Médica, tende a aumentar. Com isso, códigos mais sofisticados e precisos surgirão para aplicação em dosimetria e sistemas de planejamento em modalidades que usam a radiação para tratamento de câncer (YORIYAZ, 2009).

Simulações computacionais baseado em técnicas de Monte Carlo para análises dosimétricas vem ganhando espaço e confiabilidade, e com isso vem surgindo vários códigos computacionais tais como: EGS4, MCNP4C, GEANT4, PENELOPE.

O MCNP atualmente é um dos códigos mais utilizados na área de transporte de radiação e tem se tornado uma ferramenta valiosa na área de física médica no cálculo de dose.

A figura 2.1 mostra um desenho ilustrativo de uma simulação computacional de transporte de radiação.

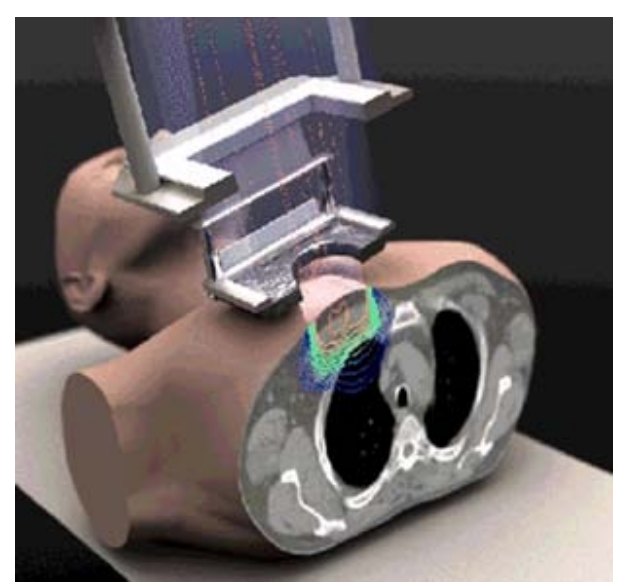

Figura 2.1: Desenho ilustrativo de uma simulação computacional utilizando transporte de radiação ionizante para tratamento de paciente. 


\subsubsection{Desenvolvimento dos Equipamentos de Radioterapia}

Em relação aos aparelhos de radioterapia, pode-se dizer que houve um grande avanço no desenvolvimento tecnológico em 1917, devido o advento de transformadores mais eficientes.

Por volta de 1915 conseguia-se produzir energia na ordem de $100 \mathrm{kVp}$, a fim de produzir radiações mais penetrantes. Pesquisadores procuravam desenvolver equipamentos de raios$\mathrm{X}$ de alta energia, até que por volta de 1950 dispunham-se de equipamentos de raios-X de até $750 \mathrm{kVp}$.

As primeiras fontes na ordem de megavoltagem foram os aparelhos que utilizavam-se o rádio como material radioativo, porém no inicio da década de 1950 a teleterapia com rádio atingiu seu último grau de desenvolvimento, devidas as grandes dificuldades do seu alto custo e de sua obtenção.

Após a Segunda Guerra Mundial, já era possível produzir isótopos radioativos em reator nuclear. Em 1946 já se cogitava a idéia do cobalto-60 ser o substituto do rádio. As fontes de megavoltagem na ordem de $1 \mathrm{MeV}$ só se popularizaram com os aparelhos de telecobaltoterapia. Os aparelhos de cobalto permitiam o uso da energia ordem 1,2 MeV e com isso houve uma grande expansão das técnicas de radioterapia.

Os aparelhos de cobaltoterapia consistem em uma pastilha de material radioativo (cobalto-60) de forma cilíndrica inserida em uma cápsula. Quando o aparelho é ligado para tratamento a fonte muda de posição e a cápsula se abre expondo a fonte e emitindo radiação.

Em 1951 foi fabricado o primeiro protótipo de unidade de cobalto-60 disponível do mercado, o El Dorado. Em 1961 cerca de 1500 unidades já estava em operação. Após as unidades de cobalto surgiu a necessidade de produzir feixes com energias maiores, para isso passou a ser necessário buscar técnicas diferentes para promover aceleração dos elétrons sem o uso de altas diferenças de potencial entre os eletrodos, surgiram assim os aceleradores lineares. Em 1952 o primeiro acelerador linear clínico de $8 \mathrm{MeV}$ foi instalado no Hammersmith Hospital em Londres.(NOBREGA, 2008).

Com relação aos equipamentos de braquiterapia, o início clínico da braquiterapia foi 1901, quando após a queimadura acidental de Becquerel, Pierre Currie espalhou rádio impuro no seu braço por 10 horas. A pele demorou 52 dias para se reconstruir, deixando uma cicatriz. Logo em seguida Pierre emprestou uma pequena quantidade de rádio a um 
amigo médico que usou o rádio para preparar aplicadores de superfícies no tratamento de lesões de pele. Em 1935 ocorreram desenvolvimentos de novos métodos com ${ }^{192} \mathrm{Ir}$ e ${ }^{137} \mathrm{Cs}$. A figura (2.2) mostra equipamentos que fizeram parte da evolução da radioterapia.
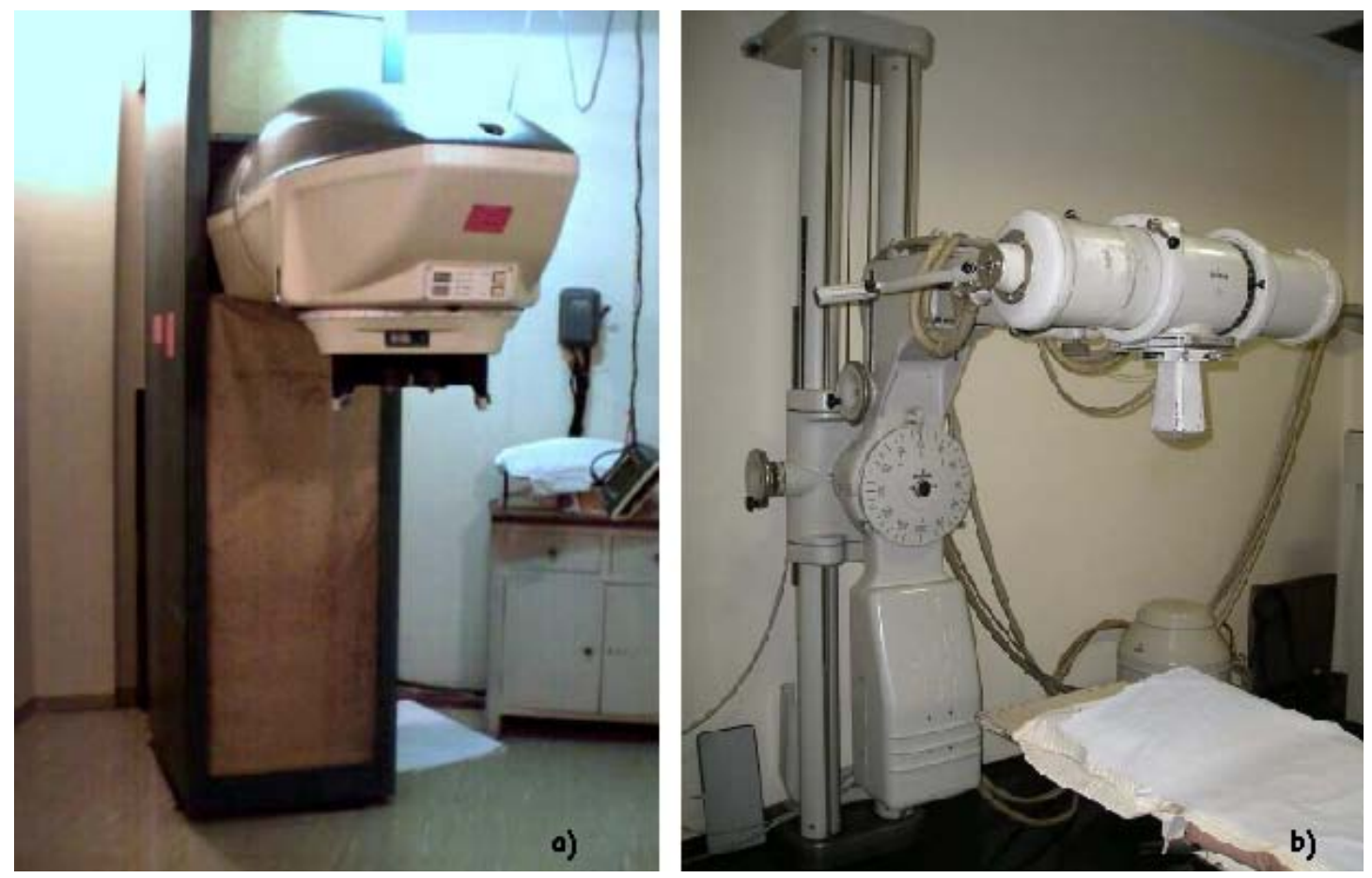

Figura 2.2: Equipamentos dos Primórdios da Radioterapia a) Equipamento de Cobalto -60, El Dorado, b) Equipamento ortovoltagem - Stabilipan.

\subsection{Formalismo da Dosimetria Clínica e Física}

\subsubsection{Dose Absorvida}

A dose absorvida $\mathrm{D}$, de qualquer radiação ionizante, é a quantidade de energia $d E$ liberada à matéria pela radiação ionizantes, por unidade de massa $d m$ :

$$
D=\frac{d E}{d m}
$$

A dose absorvida é a principal grandeza física usada em radioterapia e é expressa em joules por quilograma $(\mathrm{J} / \mathrm{kg})$, também denominada gray $(\mathrm{Gy}): 1 \mathrm{~Gy}=1 \mathrm{~J} / \mathrm{kg}$.

\subsubsection{Porcentagem de Dose Profunda - PDP}

A porcentagem de dose profunda (PDP) nada mais é do que uma relação percentual da dose em uma determinada profundidade $(\mathrm{Dd})$, no eixo central do feixe, em relação à 
profundidade máxima (Dm).

$$
P D P=100 \frac{D d}{D m}
$$

A PDP decresce com o aumento da profundidade devido à lei do inverso do quadrado da distância e a maior atenuação sofrida, exceto para a região de build-up, onde a dose aumenta até atingir um valor máximo. Essa região de Build-up aumenta conforme aumenta a área do campo, pois com o aumento do volume irradiado há o aumento da radiação espalhada. Da mesma forma quando se compara a PDP para dois valores de distância fonte-superfície, verifica-se o aumento desta região conforme aumenta a distância; A PDP também se torna maior com o aumento da energia da radiação, pois esta será mais penetrante, logo será menos atenuada.

\subsubsection{Build-up e Equilíbrio Eletrônico}

Os fótons interagem com a matéria, produzindo elétrons por ionização. A intensidade de ionizações diminui com a profundidade. A fluência de elétrons e a dose absorvida pela matéria aumentam com a profundidade até um certo ponto, diminuindo à medida que os fótons são absorvidos. Em consequência disto a dose absorvida inicialmente aumenta com a profundidade, atingindo um máximo a partir do qual passa a decrescer. A região entre a superfície irradiada e a profundidade onde a dose atingiu o valor máximo é chamada de região de build-up (acúmulo). A espessura da região de build-up é denominada espessura de equilíbrio eletrônico. Além deste ponto a dose decresce pela atenuação e inversamente ao quadrado da distância.

\subsubsection{Distância Fonte-Superfície (DFS) e Distância Fonte-Isocentro (DFI)}

Um dos formalismos mais usados em radioterapia é um termo que chama-se setup. Existem dois tipos de setup que definem os parâmetros de tratamento de acordo com o posicionamento do paciente. A primeira técnica é a distância fonte-superfície (DFS), que mantém constante a distância da fonte de radiação à superfície do paciente ou do simulador de tecido. A outra técnica é a distância da fonte - isocentro (DFI), que mantém fixa a distância da fonte de radiação ao ponto de isocentro do paciente. A técnica DFI é frequentemente utilizada em tratamentos que incluem vários campos ao redor do alvo, 
enquanto a DFS é geralmente utilizada para tratamentos de lesões superficiais (POLI, 2007). A figura 2.3 mostra os dois tipos de setup citado.

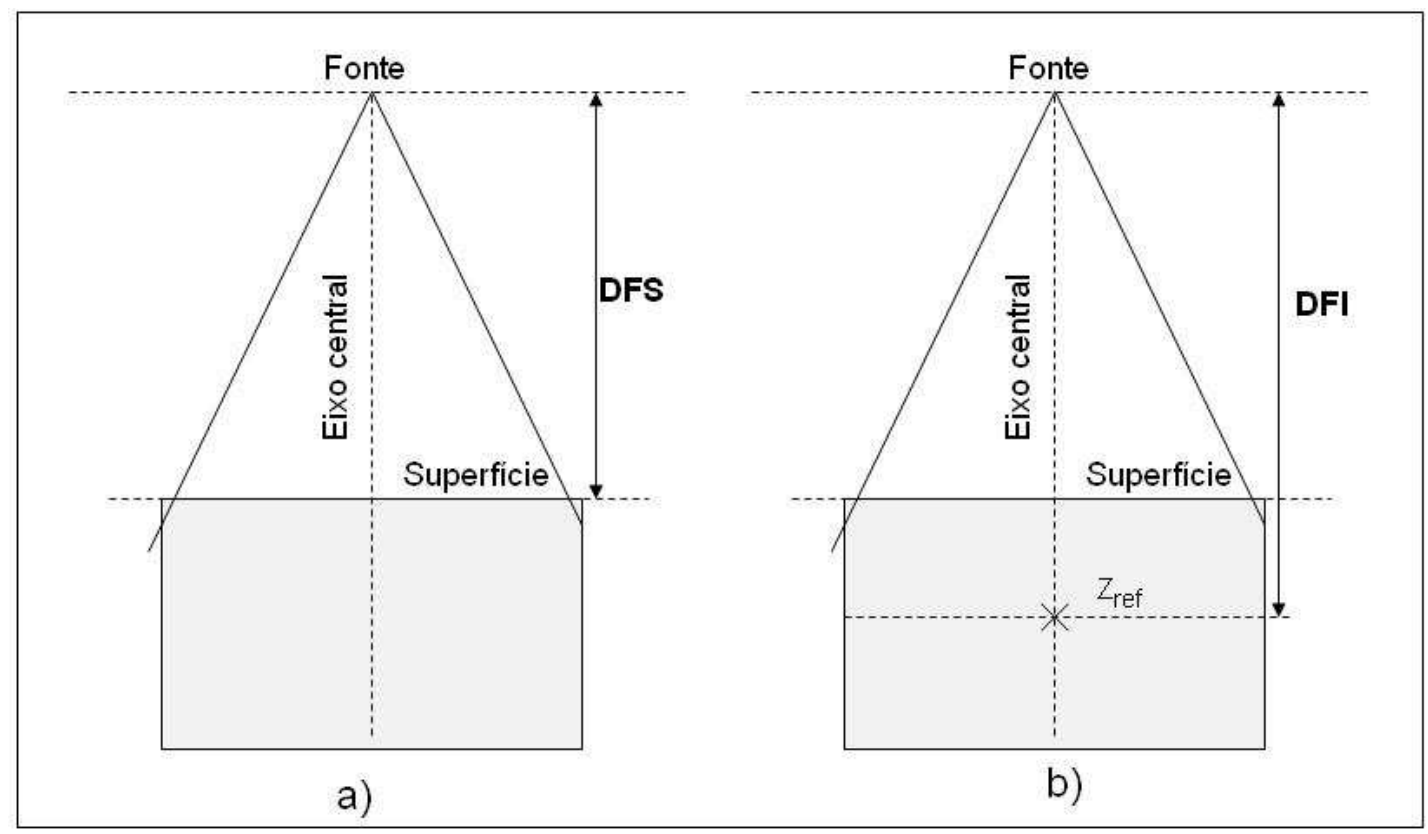

Figura 2.3: Configurações: a) Distância Fonte-superfície (DFS), b) Distância Fonte-isocentro (DFI).

\subsubsection{Tamanho de Campo do Feixe de Radiação}

O tamanho de campo de irradiação é determinado pela área da superfície do paciente que se pretende irradiar. A escolha do tamanho de campo depende do tamanho do tumor e do volume a ser irradiado. Em um caso clínico o tamanho do campo de irradiação é definido através de imagens de diagnóstico (tomografia e ressonância). Os feixes usados em radioterapia possuem diversas formas. Quatro grupos de forma geral são utilizados na radioterapia: quadrado, retangular, circular e irregular. Campos quadrados e retangulares são geralmente produzidos com colimadores instalados no cabeçote da unidade, os campos circulares com colimadores especiais conectados à máquina e campos de tratamento irregulares com blindagem de blocos ou colimadores multileaf ligados ao aceleradores de tratamento. (PODGORSAK, 2005). 


\subsubsection{Perfil do Feixe (Simetria e Planura)}

O Perfil do feixe é uma das características mais importantes de um feixe clínico. Para determinação do perfil do feixe, é necessário avaliar a uniformidade e a penumbra do feixe. A uniformidade é definida pela simetria e planura do feixe. O tamanho e a localização da região de planura é expressa como $80 \%$ da largura do feixe, quando o valor normalizado da dose no eixo central do feixe for $50 \%$ do seu valor máximo. A planura dentro dessa região está limitada a $\_3 \%$ da dose normalizada máxima.

A simetria do feixe para ser avaliada requer a comparação de dois pontos eqüidistantes e simétricos ao eixo central do feixe dentro dessa região de $80 \%$. A penumbra é definida como a distância lateral entre as linhas de isodose de $20 \%$ e $80 \%$, para um campo de dimensão $10 \mathrm{~cm}$ X $10 \mathrm{~cm}$ medido na profundidade de $10 \mathrm{~cm}$ com distância foco-pele de 100 cm ao longo dos eixos principais (SANTOS, 2002). A figura 2.4 representa uma ilustração dos conceitos de planura e simetria, e penumbra respectivamente.

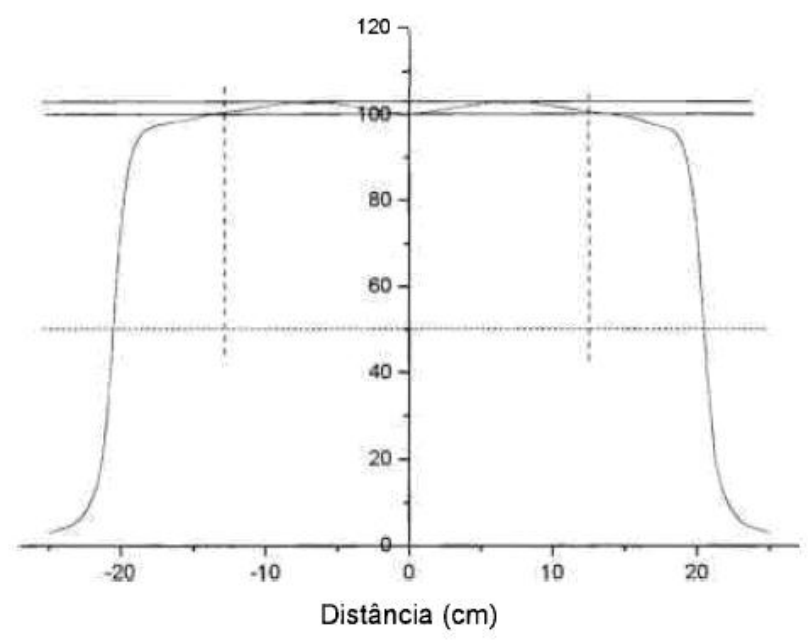

a)

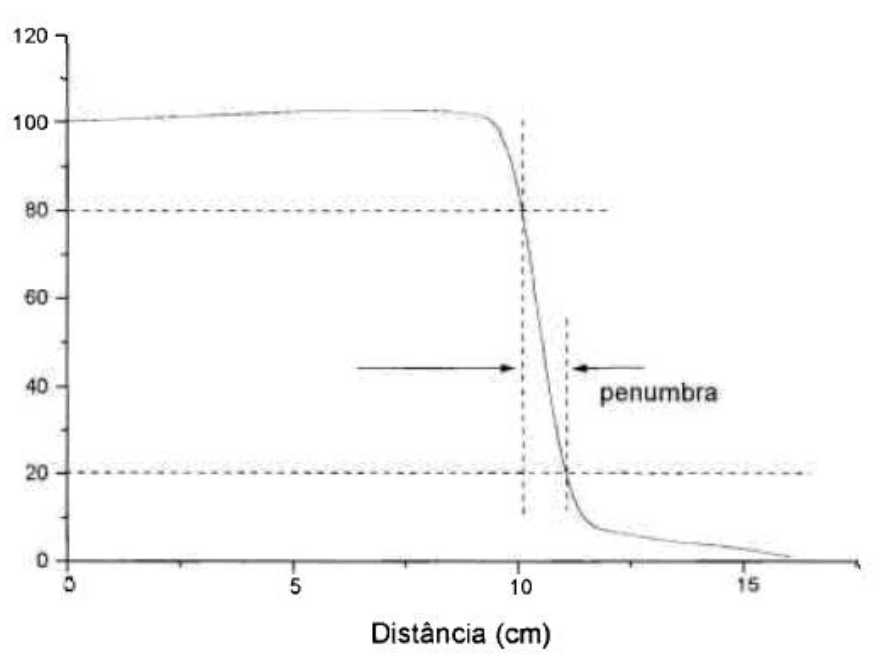

b)

Figura 2.4: Conceitos a) Definição de planura e simetria de feixes clínicos, b) Definição de penumbra de feixes clínicos.

\subsubsection{Profundidade para $100 \%$ da Dose $\boldsymbol{R}_{100}$}

A profundidade de dose máxima $\left(\mathrm{R}_{100}\right)$ é um parâmetro onde a curva de dose normalizada atinge o valor máximo. Este parâmetro depende da energia, da forma de distribuição 
de energia e da distância fonte-superfície e do tipo de radiação.

\subsubsection{Alcance à meia Profundidade $\boldsymbol{R}_{50}$}

O $R_{50}$ é a profundidade na qual a dose absorvida atinge $50 \%$ do seu valor máximo. Como a meia profundidade está localizada na região atingida por aproximadamente metade dos elétrons primários, é razoável supor que essa profundidade esteja mais relacionada com a energia do que com a energia mais provável dos elétrons incidentes.

\subsubsection{Profundidade de Referência $Z_{r e f}$}

A profundidade de referência, $\mathrm{Z}_{r e f}$, especifica uma profundidade de referência para o posicionamento da câmara de ionização. No antigo protocolo TRS 277 a profundidade de referência $Z_{r e f}$ era definida pela profundidade onde se localizava o $R_{100}$, já os protocolos recentes de dosimetria baseado no AIEA TRS 398, definem que a profundidade de referência para os feixes de elétrons pode ser expressa em termo do $R_{50}$ pela equação: $Z_{r e f}=0,6 R_{50}-$ $0,1 \mathrm{~g} / \mathrm{cm}^{3}$.

A profundidade de referência $\left(Z_{r e f}\right)$ na água é próximo da profundidade de dose máxima $\left(\mathrm{Z}_{\max }\right)$.

\subsubsection{Alcance Terapêutico $\boldsymbol{R}_{85}$}

O alcance terapêutico é definido como o intervalo de profundidade no qual a dose absorvida excede $85 \%$ de seu valor máximo. $\mathrm{O} \mathrm{R}_{85}$ é o intervalo de profundidade da distribuição de dose em profundidade que deve coincidir com o volume alvo do tumor. É importante obter uma variação bem pequena do volume alvo, pois, sabe-se que uma diferença menor do que 10\% no valor da dose pode causar uma mudança considerável na razão entre a fração de pacientes curados e aqueles que sofrerão complicações (ARAÚJO et. al., 2005).

\subsubsection{Alcance Prático $\boldsymbol{R}_{p}$}

O alcance prático é definido como sendo a profundidade de intersecção da tangente através do ponto de maior inclinação, tanto em uma curva de dose quanto de ionização em profundidade, com a radiação de fundo de fótons. Este valor é obtido fazendo-se um 
ajuste linear dos dados na região descendente da curva de dose em profundidade entre $70 \%$ e 20\%. A radiação de fundo de fótons, que é definida como sendo uma extrapolação da extremidade da distribuição de dose em profundidade até o alcance prático, é também obtida fazendo-se um ajuste linear nos valores obtidos até o último ponto da curva de distribuição de dose (ARAÚJO et al., 2005).

A figura (2.5) mostra os principais parâmetros clínicos citados até aqui. .

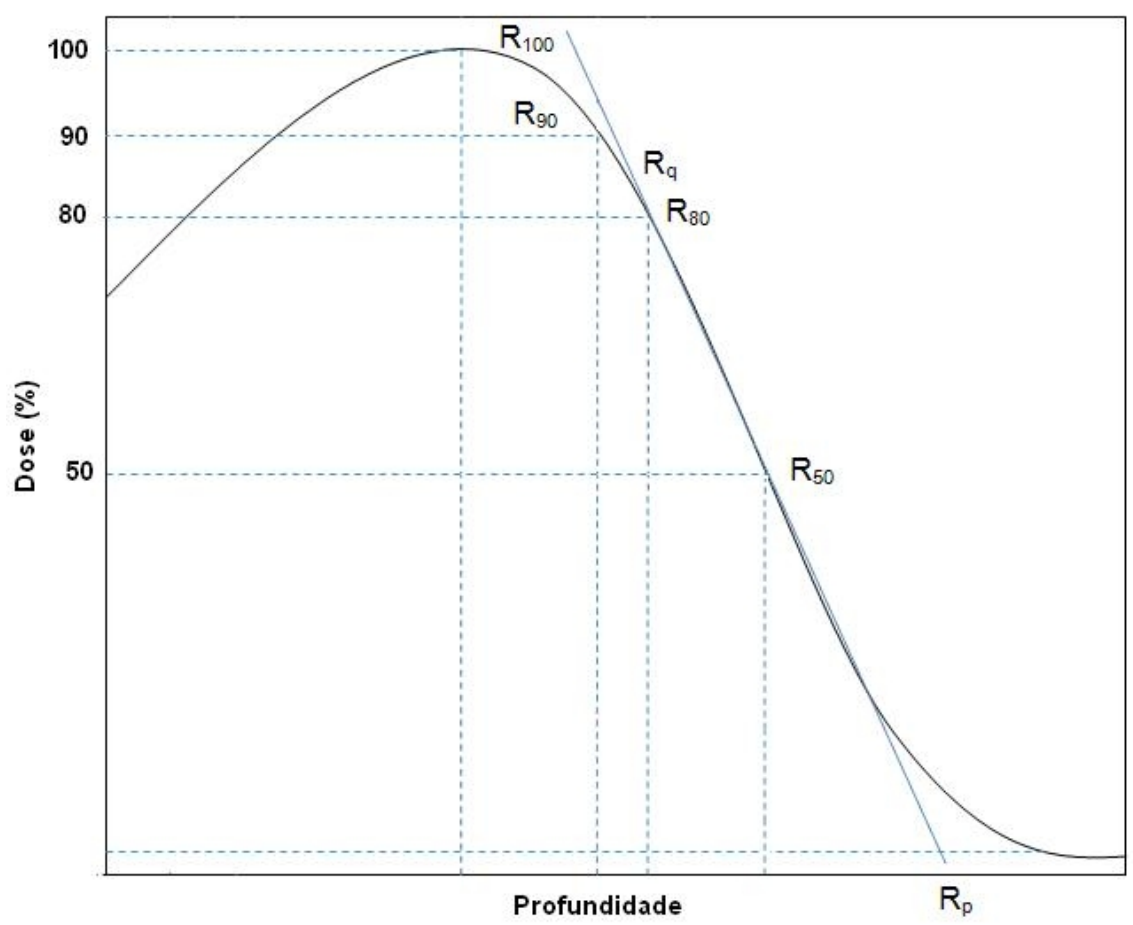

Figura 2.5: Distribuição terapêutica de dose em profundidade com as definições de parâmetros $\mathrm{R}_{100}, \mathrm{R}_{85}, \mathrm{R}_{50}$ e $\mathrm{R}_{p}$. 


\section{Capítulo 3}

\section{REVISÃO BIBLIOGRÁFICA}

São apresentadas neste capítulo as lesões de pele mais comumente encontradas nos serviços de radioterapia e suas características geométricas. Também apresenta-se as modalidades terapêuticas para o tratamento de tumores de pele submetidos a radioterapia.

\subsection{Pele - Anatomia}

A pele é o maior órgão do corpo humano, corresponde a $15 \%$ do peso corpóreo, e é responsável pelo revestimento e proteção, isolando o corpo de agressões. A pele é o principal tecido atingido pela radiação ultravioleta (RUV) e a parte mais acessível à observação. Este órgão apresenta variações regionais de estrutura (dimensões, composições e geometrias) e diferenças relacionadas com o sexo e idade.

A palavra pele derivada do latim pellis, também chamada cútis (lat. cútis), intergumentum commune, ou ainda couro na linguagem popular (MICHALANY et.al, 2002).

A pele é constituída de duas camadas: a epiderme e a derme. Algumas literaturas consideram a hipoderme como a terceira camada da pele. A epiderme é a camada mais externa e está em constante regeneração, variando de espessura conforme a região.

A estrutura da epiderme organiza-se em 5 camadas e são denominadas por: 1 - Camada Basal, 2 - Camada Espinhosa, 3- Camada Granulosa, 4- Camada Lúcida e 5 - Camada Córnea, sendo que a camada basal é a camada mais profunda da epiderme e que divide a derme da epiderme. A epiderme é composta por células epiteliais (queratinócitos), melanócitos (pigmentos que definem a cor da pele) e células de Langerhans (células de defesa imunológicas) (MICHALANYet al, 2002). 
A derme é a camada da pele mais espessa do que a epiderme, geralmente é mais fina nas mulheres. A derme se divide em duas camadas: papilar (mais externas) e reticular (mais interna). Esta camada da pele é formada por fibras colágenas, elásticas e reticulares que são responsáveis pela resistência da pele. Abaixo da pele e acima dos músculos encontra-se a tela subcutânea, mais conhecida por hipoderme, e é constituída basicamente por tecido adiposo. A figura (3.1) mostra a anatomia da pele.

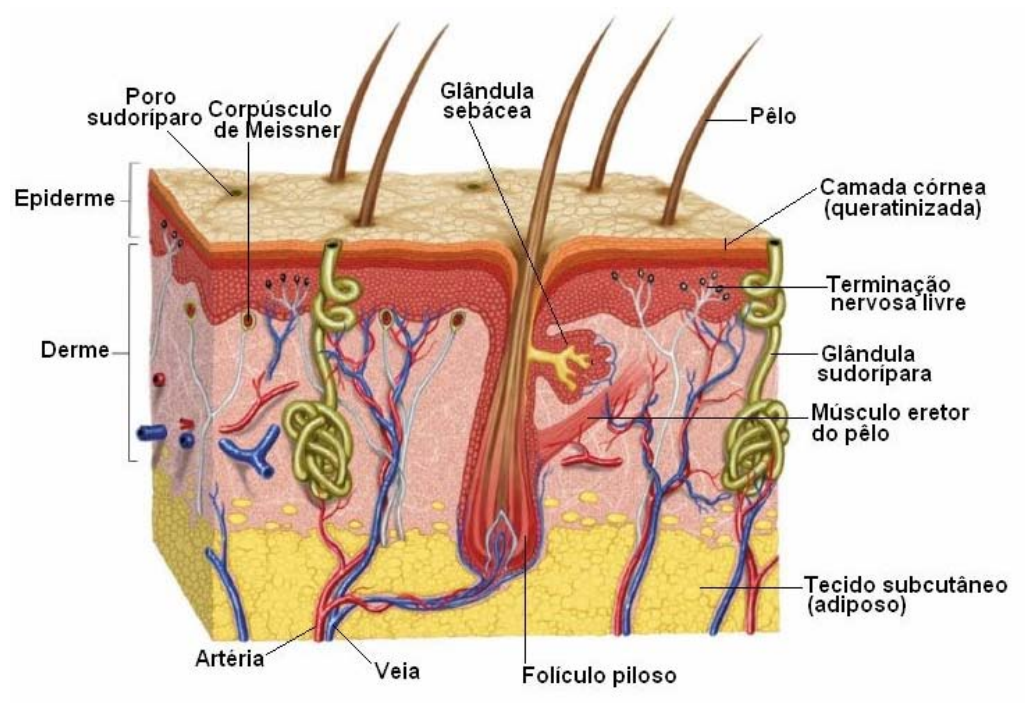

Figura 3.1: Anatomia da Pele.

A espessura da pele depende tanto da epiderme como da derme, sendo maior nas superfícies palmar, plantar, dorsal e extensora do que nas ventrais e flexoras. A Tabela 3.1 apresenta espessuras da epiderme e da derme em diferentes regiões anatômicas onde os carcinomas são mais comuns (ICRP 89).

Tabela 3.1 - Regiões anatômicas onde os carcinomas são mais comuns e suas respectivas espessuras de pele.

\begin{tabular}{ccccc}
\hline \hline $\begin{array}{c}\text { Locais de maiores } \\
\text { incidências dos } \\
\text { carcinomas basocelulares }\end{array}$ & \multicolumn{2}{c}{ Homens } & \multicolumn{2}{c}{ Mulheres } \\
\hline & Espessura da epiderme & Espessura da derme & Espessura da epiderme & Espessura da dermne \\
\hline Face & $52 \mu m$ & $2300 \mu m$ & - & - \\
Tronco & $49-92 \mu m$ & $2200-2500 \mu m$ & $45-61 \mu m$ & $1500-1900 \mu m$ \\
Pescoço & $52 \mu m$ & $2300 \mu m$ & - & - \\
\hline
\end{tabular}


A hipoderme não tem espessura definida, sua espessura depende da quantidade de células adiposas de cada individuo, podendo variar de 0 a $3 \mathrm{~cm}$.

\subsection{Lesões de Pele}

Câncer de pele é um tumor formado por células da pele que sofreram uma transformação e multiplicam-se de maneira desordenada e anormal dando origem a um novo tecido (neoplasia).

O câncer de pele é o de maior incidência dentre todos os tipos de câncer, correspondendo a cerca de $25 \%$ de todos os tumores malignos registrados no Brasil e no mundo. Quando detectado precocemente este tipo de câncer apresenta altos percentuais de cura. As principais formas de câncer de pele são os melanomas e os não-melanomas.

Os melanomas são originários dos melanócitos, tem baixa incidência e não são responsivos à radioterapia, apresentam letalidade mais elevada que os não melanomas (SALVAJOLI et al, 1999). Os não-melanomas tem maior incidência e baixa mortalidade, os tumores de pele não-melanomas mais freqüentes são os carcinomas basocelulares (CBC), correspondente a cerca de $70 \%$ dos cânceres de pele diagnosticados, e os carcinomas espinocelulares (CEC), que correspondem a cerca de $25 \%$ dos tumores de pele.tratados. ${ }^{1}$.

Algumas lesões benignas (não cancerígenas) de pele que também podem ser submetidas à radioterapia são os pterígios e as quelóides. Quelóides são cicatrizes hipertróficas da pele que surgem em algumas pessoas como resposta incomum do organismo a algum trauma cutâneo. O pterígio é uma neoformação fibrovascular da conjuntiva do bulbo ocular.

\subsubsection{Carcinomas Basocelulares}

O Carcinoma Basocelular (CBC) é a neoplasia cutânea mais comum entre os seres humanos no mundo. Tem crescimento lento e atinge as áreas expostas ao sol, raramente metastatiza e pode se tornar localmente invasivo ao redor dos olhos, nariz e orelhas (SALVAJOLI et al, 1999).

Existe uma grande variabilidade com relação as formas das lesões do CBC, sendo que, as formas mais comuns clinicamente são: nódulo-ulcerativo, pigmentado, superficial, e fibroepitelial (KOPKE et al, 2002).

\footnotetext{
${ }^{1}$ http://www.inca.gov.br
} 
Estudos mostram que os CBC aparecem principalmente em pacientes com faixa etária entre 30 a 88 anos, tendo uma maior ocorrência nos pacientes do sexo masculino (CASTRO et al, 1996).

A região do corpo onde o carcinoma basocelular tem maior incidência é a face. O CBC deriva de células basais da epiderme e a taxa de mortalidade é baixa devido à precocidade do diagnóstico do CBC nas áreas expostas e ao crescimento lento das lesões. O CBC é predominante em pacientes com a pele clara, raramente aparecem em orientais e negros. A figura 3.2a ilustra um CBC de forma nódulo ulcerativa e a figura $3.2 \mathrm{~b}$ apresenta um CBC de forma superficial.
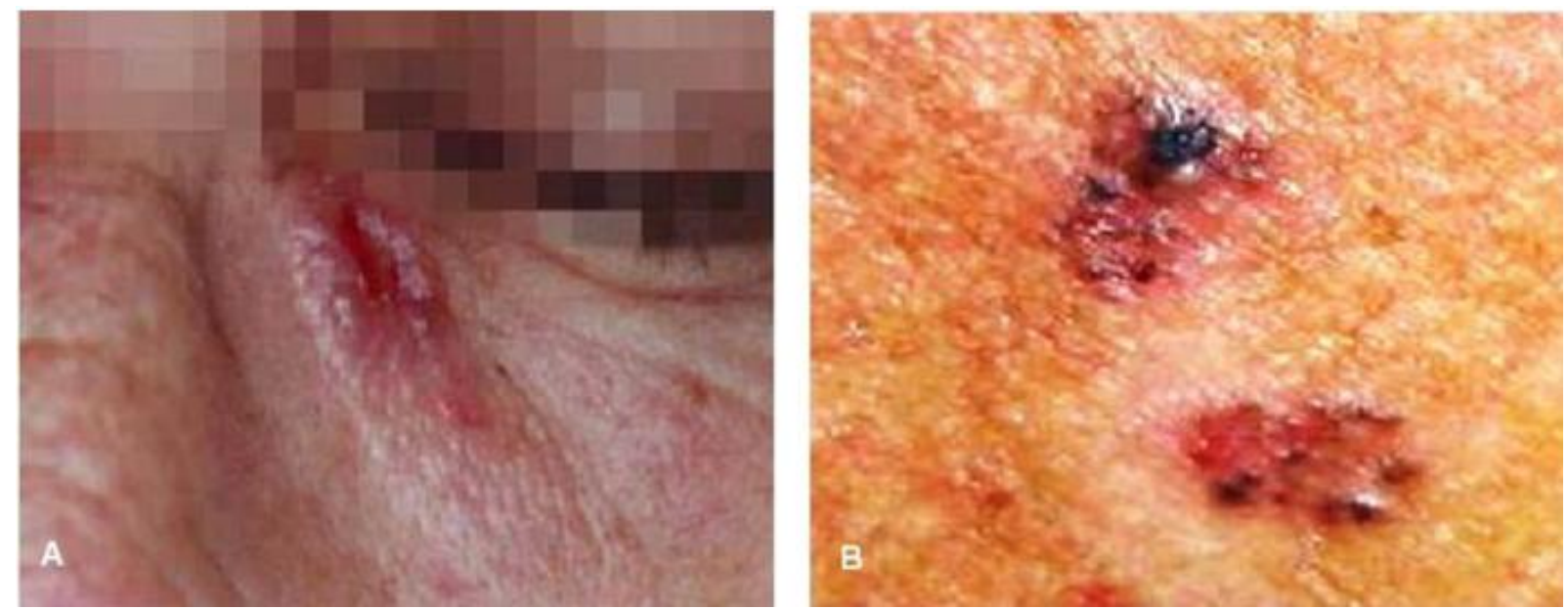

Figura 3.2: Carcinomas Basocelulares: a) CBC nódulo ulcerativo; b) CBC forma superficial.

\subsubsection{Carcinomas Espinocelulares}

O Carcinoma Espinocelular (CEC) é menos freqüente que os carcinomas basocelulares. É o segundo tipo mais comum de câncer de pele,e tem comportamento mais agressivo do que o CBC. Os carcinomas espinocelulares geralmente aparecem nas regiões mais expostas ao sol e também na mucosa labial (SALVAJOLI et al., 1999).

A maior ocorrência do CEC prevalece no sexo masculino e pessoas de pele branca. As figuras $3.3 \mathrm{a}$ e a figura 3.3b apresentam tipos de CEC. 

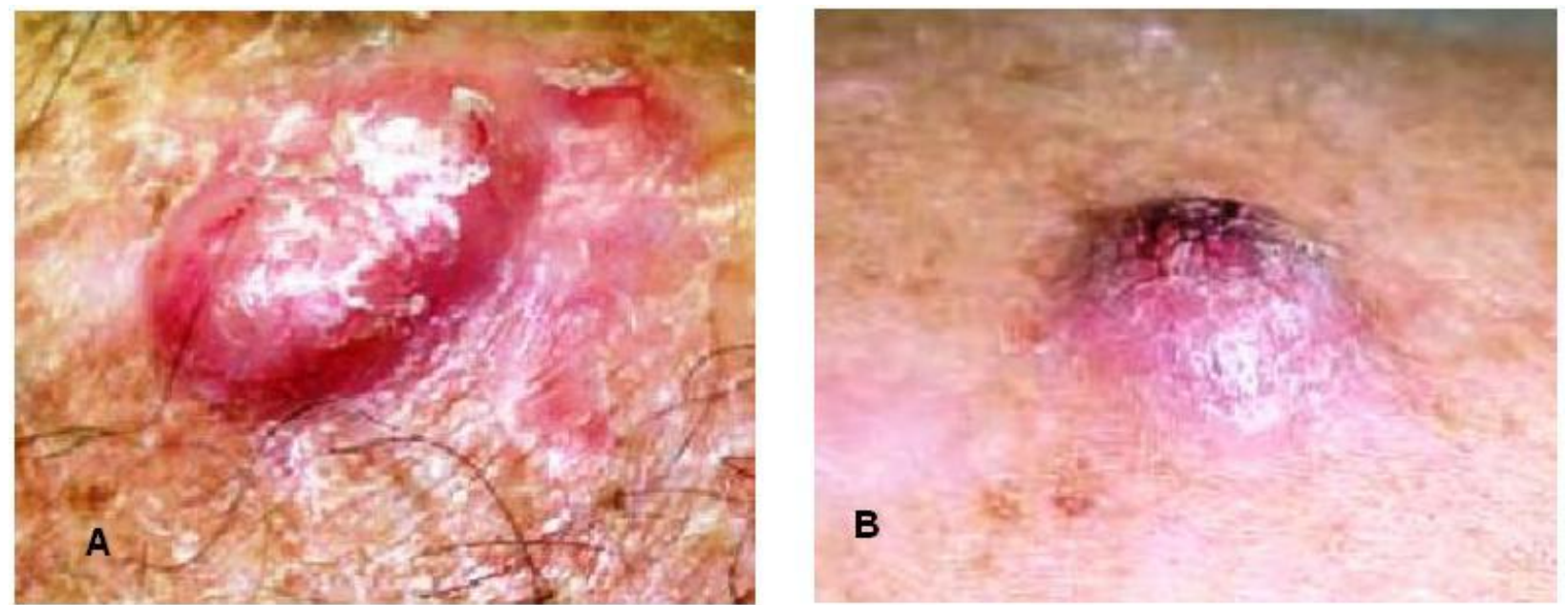

Figura 3.3: Carcinomas Espinocelulares: a) CEC nodular , b) CEC ulcerado.

\subsubsection{Etiologia dos Tumores de Pele}

Quanto à etiologia dos tumores de pele, as pesquisas mostram que há forte correlação entre o câncer de pele e a exposição à radiação ultravioleta (RUV). O fator de risco mais importante associado com a etiologia desses tumores é a exposição solar, quando a RUV atinge a pele, parte é refletida de volta ao meio e a parte transmitida é absorvida pelas camadas da pele até que a energia absorvida seja totalmente dissipada. A espessura da pele e seu teor de melanina interferem na absorção e difusão da radiação (OKUNO et al, 2005).

\subsubsection{Características dos CBC e CEC (Formas Geométricas, Tamanho e Profundidade)}

As características dos Carcinomas Basocelulares e Espinocelulares são muito variáveis e individualizados. É muito difícil estabelecer um padrão quanto as formas geométricas, mas em geral, eles são arredondados ou discóides sendo que os CEC tendem a ser mais planos que os CBC. Com relação aos tamanhos dos tumores de pele estima-se um diâmetro de 1 a 1,5 cm na maioria das vezes, dependendo da localização, até um pouco menos de 0,5 cm, que é quando as pessoas notam e procuram o médico. Tumores muito maiores são bem menos freqüentes. Com relação às profundidades dos tumores, em geral, não passam de $5 \mathrm{~mm}$ a partir da superfície da pele conforme mostra figura 3.4.

Entretanto, deve-se pensar em ter a isodose de 80 ou $90 \%$ a até pelo menos $1 \mathrm{~cm}$ de 
profundidade (Informação Verbal) ${ }^{2}$.

A forma mais comum é arredondada ou circular, e os volumes são lesões pápulo ou nódulo, ou nódulo-ulceradas. Quanto às dimensões, variam bastante de $\mathrm{mm}$ a $\mathrm{cm}$ e seu crescimento assemelha-se a um balão dentro da superfície cutânea, ou seja, crescimento centrífugo. A característica clínica do CEC já é outra com crescimento mais irregular. Quanto à composição desses tumores, existe uma grande variedade histopatológica encontrada na literatura (Informação Verbal). ${ }^{3}$.

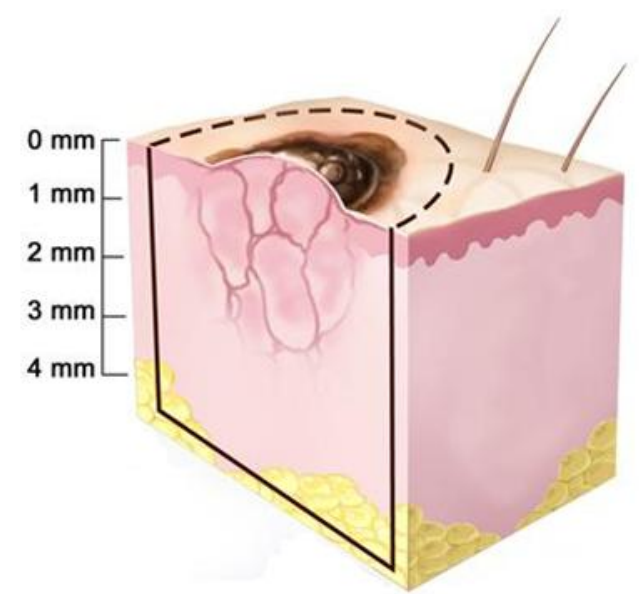

Figura 3.4: Desenho ilustrativo da profundidade dos tumores de pele.

\subsection{Procedimentos Terapêuticos}

Existem várias modalidades terapêuticas para o tratamento de tumores cutâneos: Excisão Cirúrgica; Quimioterapia; Terapia Fotodinâmica; Radioterapia entre outras. Não existem regras claras que determinem a melhor alternativa terapêutica para os carcinomas de pele. A modalidade terapêutica adequada para as lesões de pele depende da característica do paciente e do tumor a ser tratado. Deve-se escolher a modalidade que oferece chance de controle da doença com melhores resultados estéticos e funcionais. A terapêutica mais freqüente é a excisão cirúrgica e a segunda forma terapêutica mais usada é a radioterapia (SALVAJOLI et al, 1999).

\footnotetext{
${ }^{2}$ Informação fornecida pela Dra. Heloisa médica radioterapeuta do Hospital das Clínicas de São Paulo em correspondência via correio eletrônico.

${ }^{3}$ Informação cedida pelo Dr. Hamilton Stolf médico dermatologista do Hospital das Clínicas de Botucatu em correspondência via correio eletrônico.
} 
Para o tratamento de lesões superficiais pode-se utilizar feixe de elétrons, raios-X de ortovoltagem e fontes radioativas.

\subsubsection{Tratamento com Feixe de Elétrons}

A radioterapia inicia-se pelo exame clínico, pois é necessário conhecer as características e dimensões (largura, altura e profundidade) do volume a ser irradiado. Existem feixes de elétrons com espectros energéticos variáveis, que podem adequar-se as diferentes dimensões das lesões de pele. Os feixes de elétrons, principalmente os de menor energia, têm absorção rápida pelos tecidos, com queda em profundidade. Para obter feixes apropriados, os acelerados lineares produzem feixe com energias de $4 \mathrm{MeV}$ a $35 \mathrm{MeV}$. A Tabela 3.2 mostra a relação entre a energia dos elétrons, faixa clínica (PDP 80\%) e alcance prático dos feixes (ARAÚJO et al, 2005).

Tabela 3.2 - Relação entre a energia dos elétrons, faixa clínica (PDP 85\%) e alcance prático dos feixes.

\begin{tabular}{ccc}
\hline \hline Energia $(\mathrm{MeV})$ & Faixa Clínica-80\% $(\mathrm{cm})$ & Alcance Prático $(\mathrm{cm})$ \\
\hline 4 & 0,1 a 1,0 & 1,5 \\
6 & 0,3 a 1,5 & 2,7 \\
9 & 0,2 a 2,8 & 4,2 \\
10 & 0,2 a 3,5 & 4,8 \\
12 & 0,0 a 4,0 & 5,6 \\
16 & 0,0 a 5,2 & 7,7 \\
20 & 0,0 a 6,4 & 10,0 \\
30 & 0,0 a 9,0 & 16,0 \\
35 & 0,0 a 11,0 & 18,0 \\
\hline
\end{tabular}

Para lesões de pele superficiais os feixes mais utilizados são aqueles com energias mais baixas, $4 \mathrm{MeV}$ a $9 \mathrm{MeV}$, pois são energias que oferecem boa cobertura na superfície, assegurando a dose até o final da lesão e preservando tecidos normais. A figura (3.5) apresenta exemplos de curvas de porcentagem de dose em profundidade (PDP) de um acelerador linear de elétrons em função da profundidade na água (LEMOS, 2006). 
Com relação ao tamanho de campo de radiação mais utilizado, não existe um padrão ou uma estatística. A distância entre a fonte e o tumor irradiado em geral é de $100 \mathrm{~cm}$ (DFS), com ou sem bólus. ${ }^{4}$

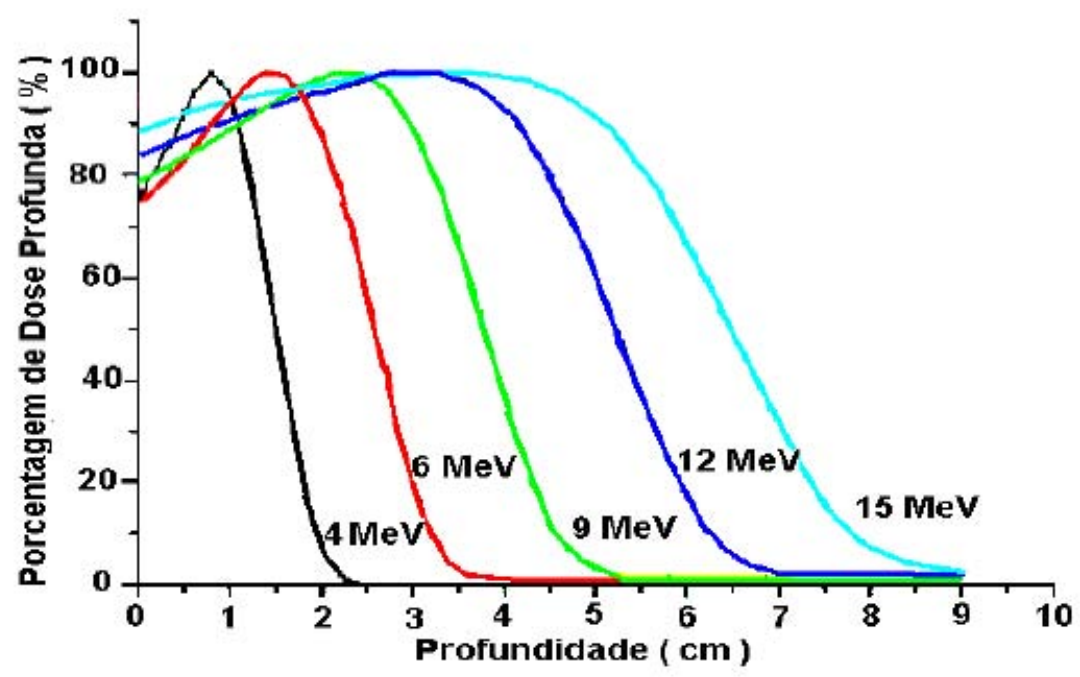

Figura 3.5: Exemplos de curvas de porcentagem de dose para feixe de elétrons de megavoltagem.

\subsubsection{Tratamento com Raios-X de Ortovoltagem}

A radioterapia de ortovoltagem durante muito tempo foi considerada como radioterapia convencional e consistia na modalidade preferencial antes do advento dos aceleradores lineares. Atualmente, são poucos os locais que dispõem de equipamentos de ortovoltagem para tratamento. Geralmente as lesões de pele que são tratadas com raios-X de ortovoltagem, utilizam energias que variam de $50 \mathrm{kVp}$ a $100 \mathrm{kVp}$ e a distância fonte detector varia entre $40 \mathrm{~cm}$ a $100 \mathrm{~cm}$, a DFS depende da qualidade da radiação. Especialistas em radioterapia comentam que se tivesse que escolher uma só energia para simulação numérica seria 80 $\mathrm{kVp}$ e DFS de $40 \mathrm{~cm}$ (Informação Verbal). ${ }^{5}$ A figura 3.6 mostra exemplos de curvas típicas de PDPs na água para raios-X de quilovoltagem e megavoltagem. (LEMOS, 2006).

\footnotetext{
${ }^{4}$ Bólus são moldes utilizados para superficializar a dose.

${ }^{5}$ Informação fornecida pela Dra. Heloisa médica radioterapeuta do Hospital das Clínicas de São Paulo em correspondência via correio eletrônico.
} 


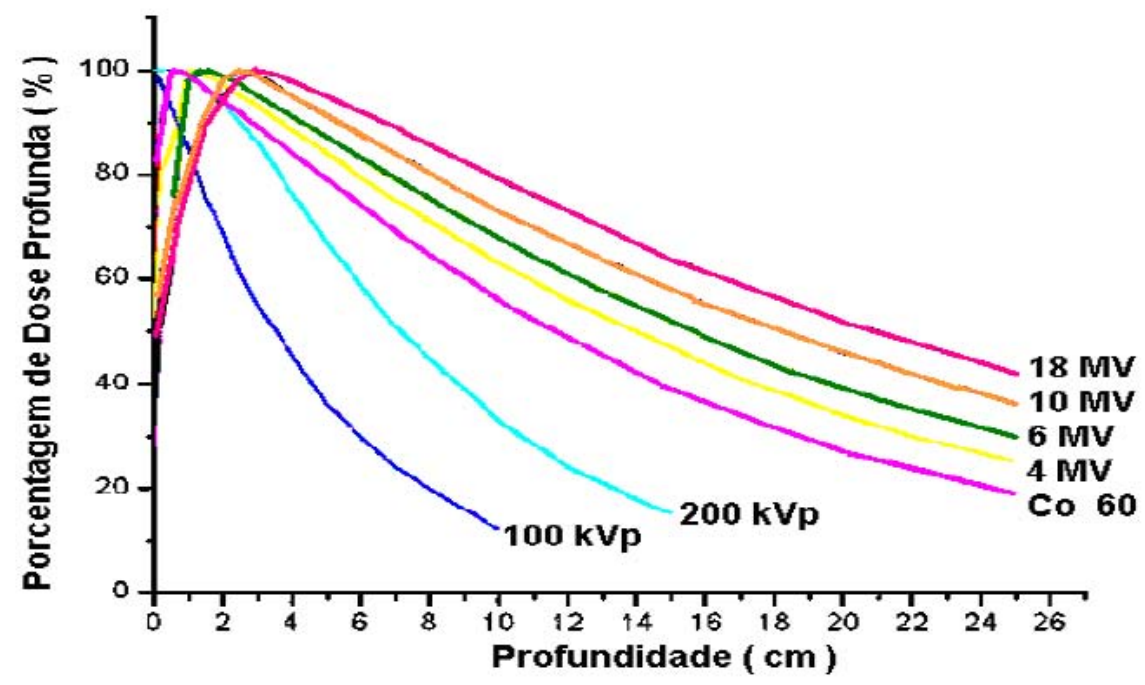

Figura 3.6: Exemplos de curvas de porcentagem de dose para feixe de fótons de quilovoltagem e megavoltagem.

\subsubsection{Procedimento com Betaterapia e Braquiterapia}

A Betaterapia é uma modalidade de radioterapia que utiliza fontes emissoras de radiação do tipo beta (B). Em dermatologia é utilizada na prevenção de quelóides e tratamento de lesões bastante superficiais da pele, e doenças oftalmológicas como pterígio. Estas partículas têm grande poder de ionização e pequeno alcance no tecido, provocando altos níveis de doses em volumes pequenos. $\mathrm{O}{ }^{90} \mathrm{Sr}$ é o elemento radioativo mais utilizado em betaterapia no Brasil e possui meia-vida de 28,5 anos emitindo partículas $\beta$ com energia máxima de 0,546 MeV do seu decaimento radioativo obtem-se o ${ }^{90} \mathrm{Y}$ com 64,1 horas de meia-vida e energia máxima de 2,279 MeV. A dose máxima de radiação se dá na superfície do tecido, caindo a $40 \%$ a $2,0 \mathrm{~mm}$ de profundidade.

A Braquiterapia é a modalidade da radioterapia em que a fonte de radiação fica a curta distância ou em contato com o tecido tumoral. Os isótopos radioativos podem ser inseridos em uma cavidade corporal (braquiterapia intracavitária), dispostos sobre uma superfície tumoral (molde superficial), ou inseridos dentro do tumor (FERNANDES, 2000 ).

A Braquiterapia é uma alternativa de tratamento em lesões de pele onde a radioterapia externa fracionada-não é bem-tolerada. O ${ }^{192} \mathrm{Ir}$ ou ${ }^{137} \mathrm{Cs}$ são os isótopos mais utilizados. 


\section{Capítulo 4}

\section{MATERIAIS E MÉTODOS}

Neste capítulo estão descritos os funcionamentos e as especificações dos equipamentos de irradiação e medição utilizados nos experimentos. Apresenta-se ainda a metodologia da dosimetria numérica através do software MCNP4C.

As descrições dos experimentos e das simulações com o código MCNP estão basicamente dividida em quatro etapas:

1 - Caracterização dos feixes de elétrons de $4 \mathrm{MeV}$ e $9 \mathrm{MeV}$ parte radial e axial.

2 - Medidas experimentais em função de atenuadores para os feixes de elétrons de 4 MeV e 9 MeV utilizando câmara de ionização e dosímetros termoluminescentes.

3 - Medidas experimentais com feixe de raios-X de $90 \mathrm{kVp}$ utilizando câmara de ionização para baixas energias de raios-X.

4 - Validação dos Cálculos no código MCNP4C e modelagem dos casos clínicos.

\subsection{Equipamentos de Irradiação}

\subsubsection{Acelerador Linear}

No processo de caracterização dos feixes de elétrons e das medidas experimentais de $4 \mathrm{MeV}$ e $9 \mathrm{MeV}$, utilizou-se um acelerador linear, marca Varian, modelo Clinac 2100C, instalado no Serviço de Radioterapia do Hospital das Clínicas da Faculdade de Medicina da UNESP de Botucatu. As energias para uso clínico são de $4 \mathrm{MeV}, 6 \mathrm{MeV}, 9 \mathrm{MeV}, 12$ MeV e $15 \mathrm{MeV}$. A figura 4.1 mostra o acelerador acima citado.

O acelerador linear do HC da UNESP de Botucatu é capaz de produzir tanto feixe de fótons quanto feixe de elétrons. 


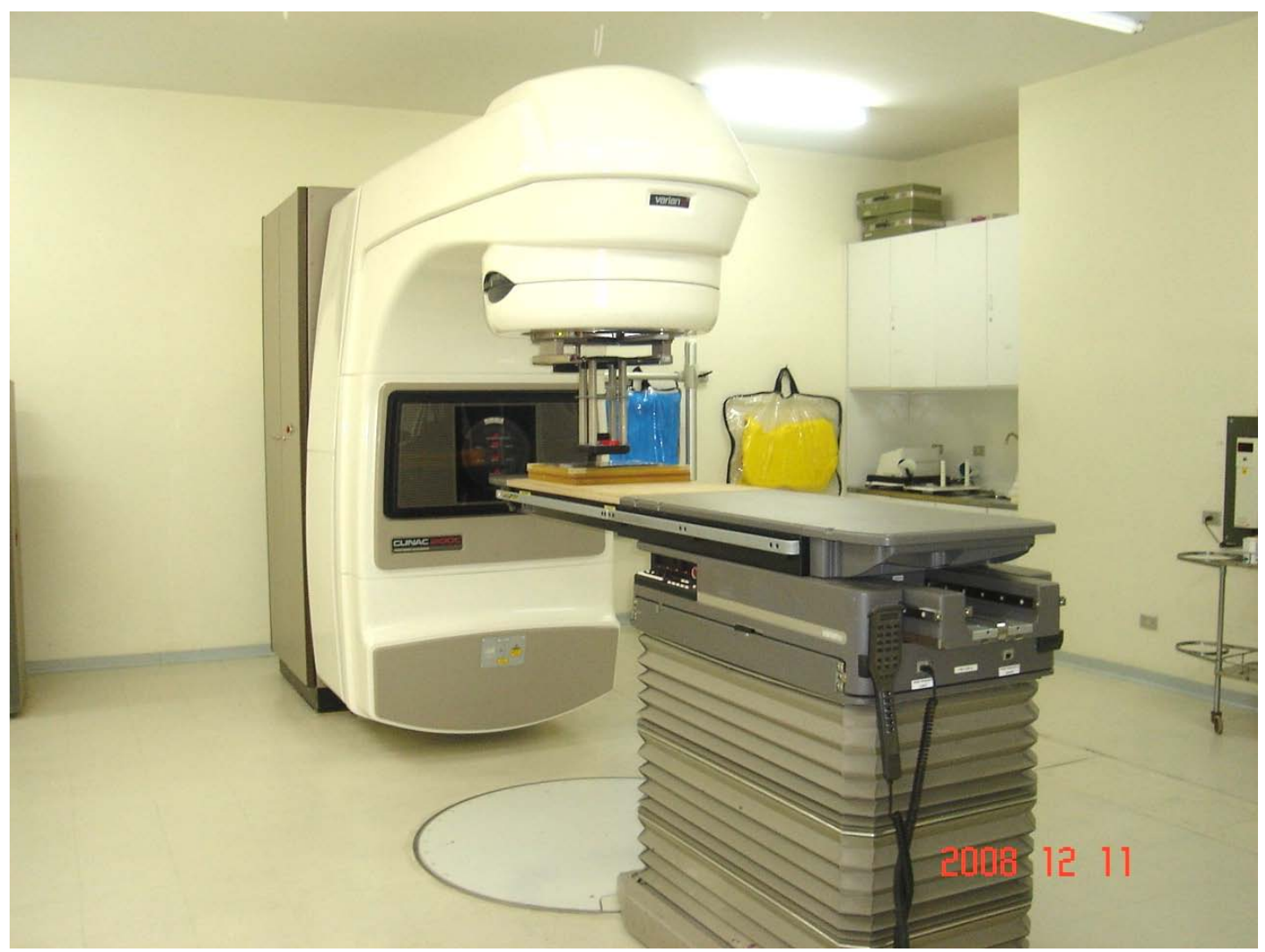

Figura 4.1: Acelerador linear Varian, modelo Clinac 2100C.

Com os aceleradores lineares de uso clínico (Clinac) foi possível utilizar os feixes de elétrons para radioterapia superficial. Os aceleradores lineares constituem uma tecnologia de alto custo e complexidade pelas possibilidades que oferecem na realização de tratamentos de tumores superficiais e profundos com precisão do alvo, da dose entregue ao tumor, envolvendo sistemas de segurança mecânicos, elétricos e de proteção radiológica (VIERA, 2008).

Existem dois tipos de aceleradores: aqueles que somente produzem fótons e aqueles que produzem fótons e elétrons. Nestes tipos de aceleradores o alvo de tungstênio é removido e os elétrons colidem em lâminas bem finas de cobre ou chumbo obtendo-se um feixe de elétrons (NOBREGA, 2008)

No processo de Bremsstrahlung um feixe fino de elétrons de alta energia choca-se com um alvo massivo de alto número atômico $(\mathrm{Z})$ para produzir feixe de fótons. O mecanismo de formação da radiação é semelhante aos aparelhos de raios-X, pois em ambos equipamentos a radiação só é formada quando o aparelho é ligado a uma fonte de alimentação. 
O princípio básico de funcionamento dos aceleradores consiste em acelerar os elétrons com energia correspondente a milhares de elétrons-volt antes de colidir com o alvo. Para isso utilizam-se etapas intermediárias de aceleração entre a produção dos elétrons e sua colisão com o alvo. Os elétrons são submetidos a um campo elétrico enquanto viajam através de uma estrutura constituída por anéis metálicos (eletrodos) ligados a uma fonte de RF (radiofrequência). As dimensões dos eletrodos, a distância entre eles e o valor da frequência de RF são calculados de forma que as partículas sofram uma aceleração enquanto estiverem entre os eletrodos. Quando o campo elétrico estiver invertido, as partículas estarão passando no interior dos eletrodos em que o campo elétrico é nulo.

Os principais componentes de um acelerador linear são: canhão de elétrons (responsável pela geração dos elétrons que serão acelerados); tubo acelerador (estrutura que acelera os elétrons até a velocidade (energia) desejada; chave de energia (controla a sintonia do tubo para que possa ser usado em energias diferentes da que foi projetado); target (alvo para a colisão de elétrons e geração de fótons); Bend Magnet (direciona os elétrons em uma curva de 270 graus em direção ao Target); carrossel (posiciona os diferentes filtros ou espalhadores de elétrons na direção do feixe); Câmara de Ionização (mede os parâmetros do feixe que sai do acelerador; Colimadores (colimam o feixe para que atinja somente a área desejada (SALEMME, 2005).

Os aceleradores lineares utilizam ondas de radiofrequência da ordem de $3000 \mathrm{MHz}$. Se o campo elétrico aplicar uma força sobre a partícula carregada, essa partícula será levada pela onda. Nos aceleradores lineares a onda de radiofrequência é gerada por válvulas especiais chamadas de Magnetron (para energias até $10 \mathrm{MeV}$ ) e Klystron (para energias acima de $10 \mathrm{MeV}$ ). Os elétrons são ejetados do tubo pelo lado em que a velocidade é mínima e são carregados pela onda, aumentando a velocidade na mesma proporção que ela. Os elétrons, ao deixarem o tubo acelerador, formam feixes paralelos, sendo encaminhados para um alvo metálico (tungstênio), no qual são produzidos os raios-X.

Os aceleradores lineares se diferem das unidades de cobaltoterapia, pois a radiação é emitida continuamente pela fonte independe de fonte de alimentação para gerar radiação. 


\subsubsection{Raios-X}

Para as medidas experimentais com o feixe de fótons (raios-X) utilizou-se um equipamento de raios-X, marca Pantak/Seifert, modelo ISOVOLT 160-HS, pertencente ao Laboratório de Calibração de Instrumentos do IPEN. A figura 4.2a mostra o tubo de raios-X e a figura $4.2 \mathrm{~b}$ a sala de controle do tubo de raios- $\mathrm{X}$.
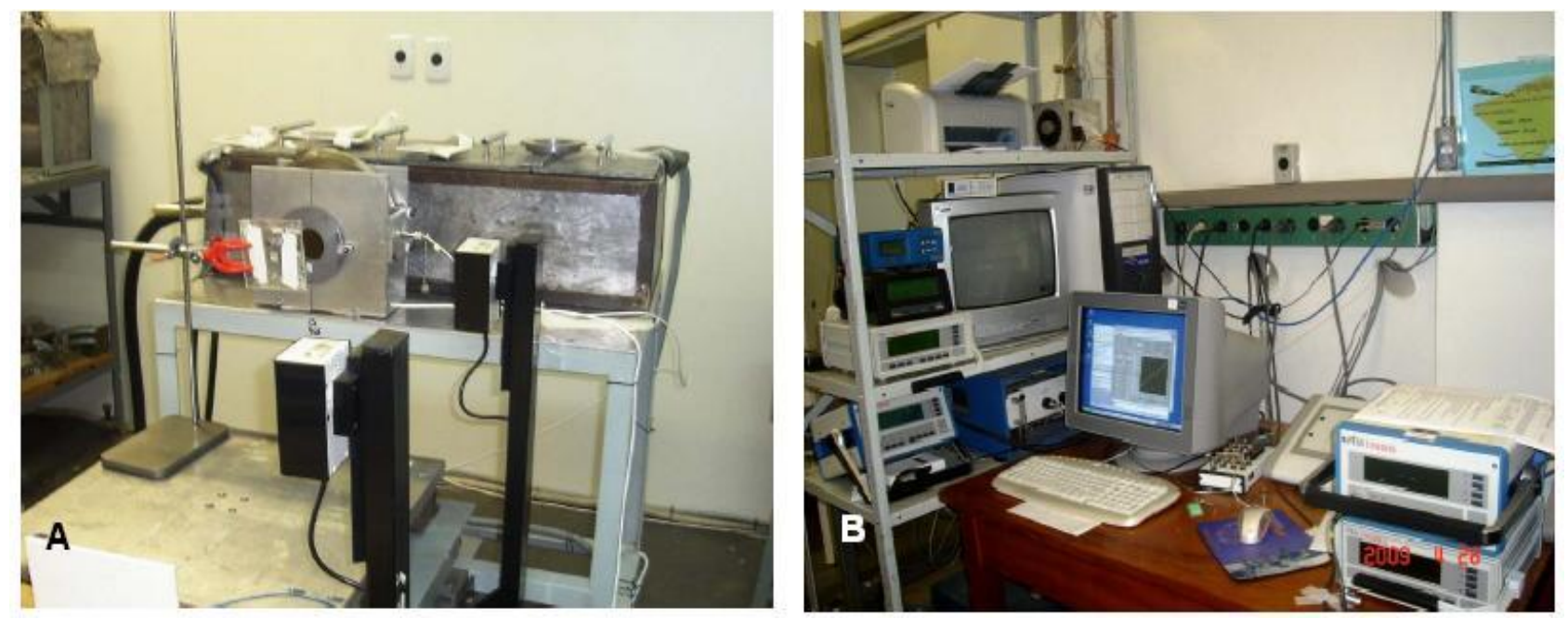

Figura 4.2: a) Tubo de raios-X IPEN, b) Sala de controle do tubo de raios-X

Nestes aparelhos os raios-X são produzidos através de uma alta diferença de potencial. A voltagem aplicada é da ordem de quilovolts $(\mathrm{kV})$ e a corrente no tubo é na ordem de miliampére $(\mathrm{mA})$. Os tubos de raios-X consistem em um cátodo e um ânodo, colocados dentro de uma ampola de vidro onde é feito vácuo. O cátodo consiste em um filamento helicoidal de tungstênio (W), que tem alto ponto de fusão. Quando o filamento é aquecido, elétrons são liberados termoionicamente e acelerados em direção ao ânodo através de uma diferença de potencial entre o filamento (-) e o ânodo (+), constituindo uma corrente eletrônica. Esses elétrons acelerados, ao colidirem com o ânodo, que também é conhecido por alvo, têm parte da sua energia convertida em raios-X. Em volta da ampola há uma carapaça metálica que filtra parte da radiação emitida do alvo. A radiação resultante que será utilizada nos procedimentos radioterápicos é o feixe útil.

\subsubsection{Aplicador de ${ }^{90} \mathbf{S r}+{ }^{90} \mathbf{Y}($ Betaterapia)}

Os aplicadores de Betaterapia foram utilizados em um trabalho em paralelo com mesmo objetivo de análise dosimétrica em lesões dermatológicas, para fins comparativos (SALLES 
et al, 2009).

O aplicador apresentado na figura 4.3 pertence a clínica Nucleata. ${ }^{1}$ Os aplicadores $\beta$ são muito utilizados no tratamento de lesões superficiais, pois as partículas $\beta$ têm grande poder de ionização e pequeno alcance no tecido.

O nuclídeo utilizado no aplicador, que possui uma meia-vida de 28,5 anos e emite partículas $\beta$ de energia máxima de $0,546 \mathrm{MeV}$. O aplicador possui uma barreira primária de acrílico de espessura aproximadamente 10,0 mm. Os aplicadores dermatológicos podem ser planos, retangulares ou esféricos normalmente com dimensões de $10 \mathrm{~mm}$ a $22 \mathrm{~mm}$ de diâmetro.
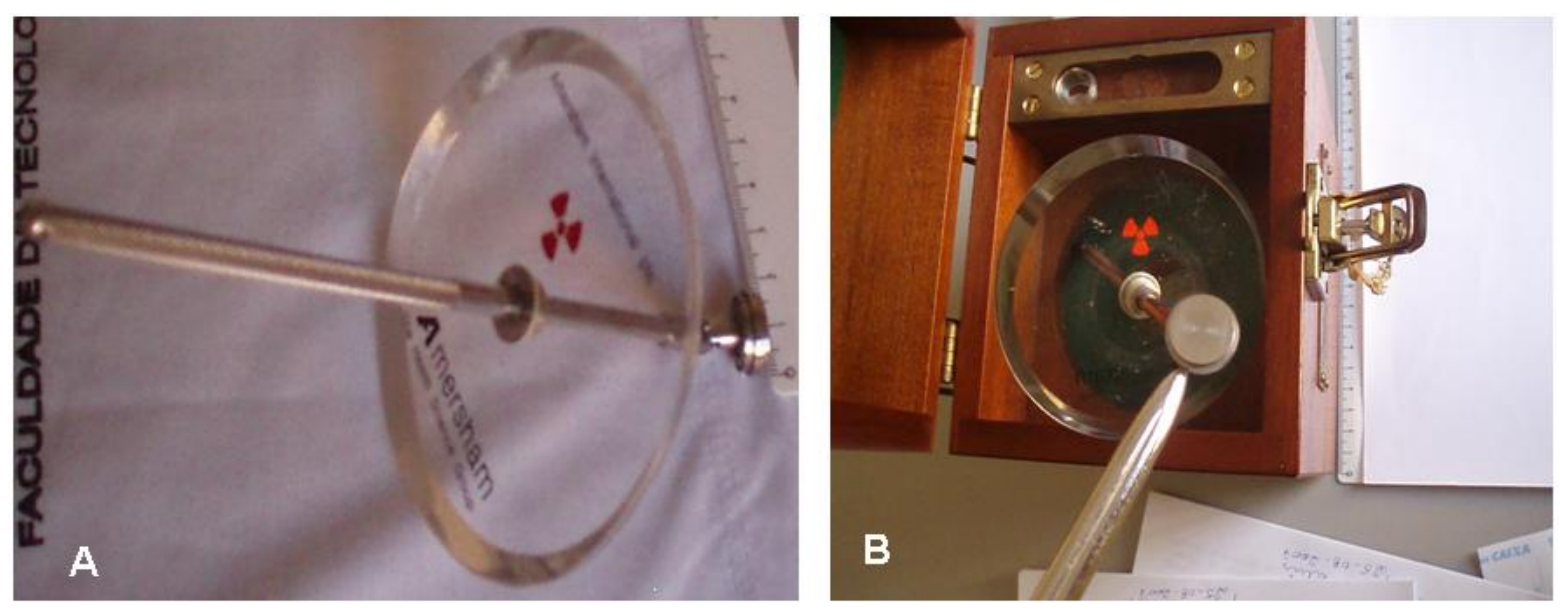

Figura 4.3: a) Aplicador dermatológico de ${ }^{90} \mathrm{Sr}+{ }^{90} \mathrm{Y}$, b) Proteção do Aplicador dermatológico ${ }^{90} \mathrm{Sr}+{ }^{90} \mathrm{Y}$.

\subsection{Sistema de Medições de Radiação}

\subsubsection{Câmara de Ionização}

O detetor utilizado para dosimetria dos feixes de elétrons foi uma câmara de ionização de placas paralelas à prova d'água, marca Exradin, modelo P11, acoplada ao eletrômetro (Standard Imaging CDX-2000B-JO10553). Para dosimetria dos feixes de raios-X foi utilizada uma câmara de ionização padrão da marca PTW, modelo 77334, número de série 2052 do Laboratório de Calibração do IPEN. As figuras 4.4a e 4.4b mostram as câmaras de ionização descritas.

\footnotetext{
${ }^{1}$ Aplicador cedido pelo Físico Prof. Dr. Marco Antonio Rodrigues Fernandes.
} 

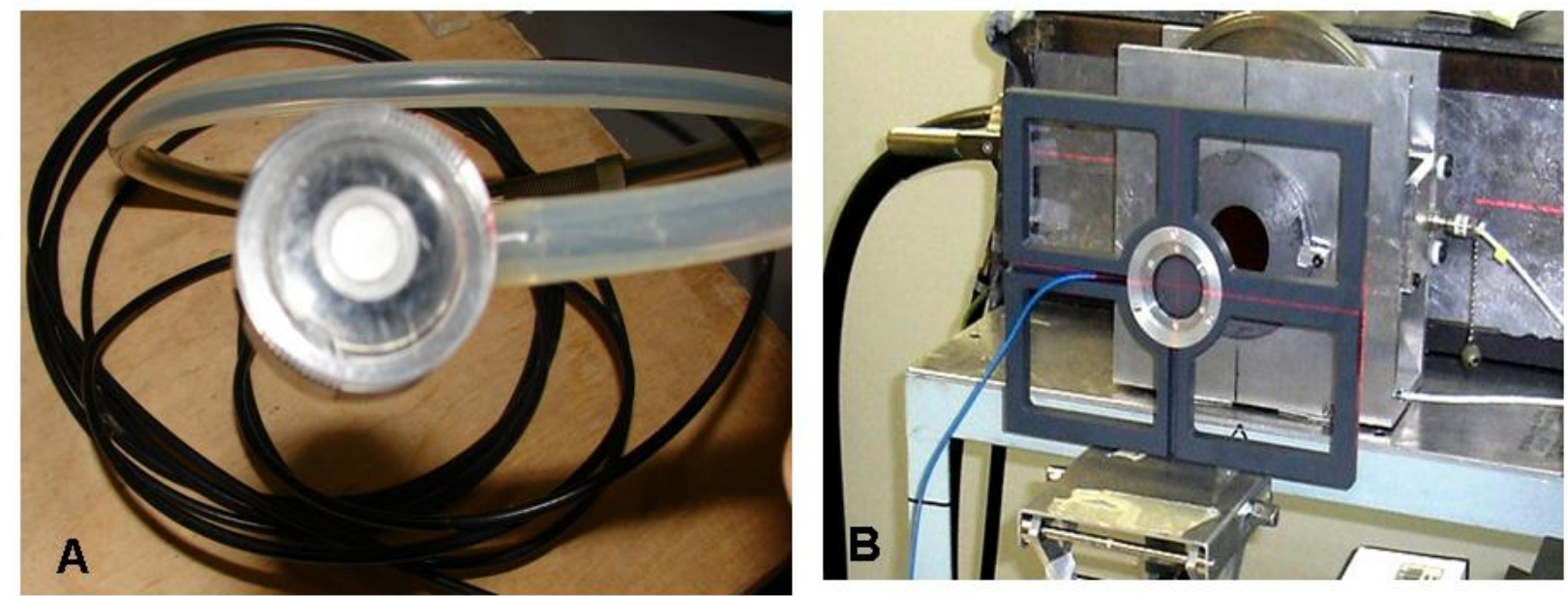

Figura 4.4: Camâras de Ionização a) CI de Placas Paralelas, b) Câmara de Ionização .

A câmara de ionização de placas paralelas é constituída por três eletrodos, sendo dois eletrodos de carga (um positivo e um negativo) e um anel de guarda. Aplicando-se uma tensão entre os eletrodos, os íons formados são coletados fornecendo o sinal registrado. A leitura da corrente formada pelo eletrodo coletor é feita através do eletrômetro. A câmara de placa paralelas é o dosímetro mais prático e o mais utilizado para as medidas precisas em feixe de radiação radioterapêuticas.

\subsubsection{Eletrômetros}

O eletrômetro utilizado nas medidas experimentais com feixe de elétrons foi o Standard Imaging CDX-2000B-JO10553, que possui um mostrador digital e uma resolução de três dígitos. Para as medidas experimentais com feixe de raios-X utilizou um eletrômetro da marca PTW, modelo 77334, pertencente ao laboratório de calibração do IPEN. A figura 4.5a e a figura $4.5 \mathrm{~b}$ mostram os eletrômetros descritos.

As conexões dos eletrômetros com as respectivas câmaras de ionização foram feitas por meio de cabos, permitindo que os eletrômetros ficassem fora das salas onde se realizavam as irradiações. Os eletrômetros são instrumentos capazes de medir cargas provenientes de câmaras de ionização, um único eletrômetro pode ser acoplado a várias câmaras de ionização. 

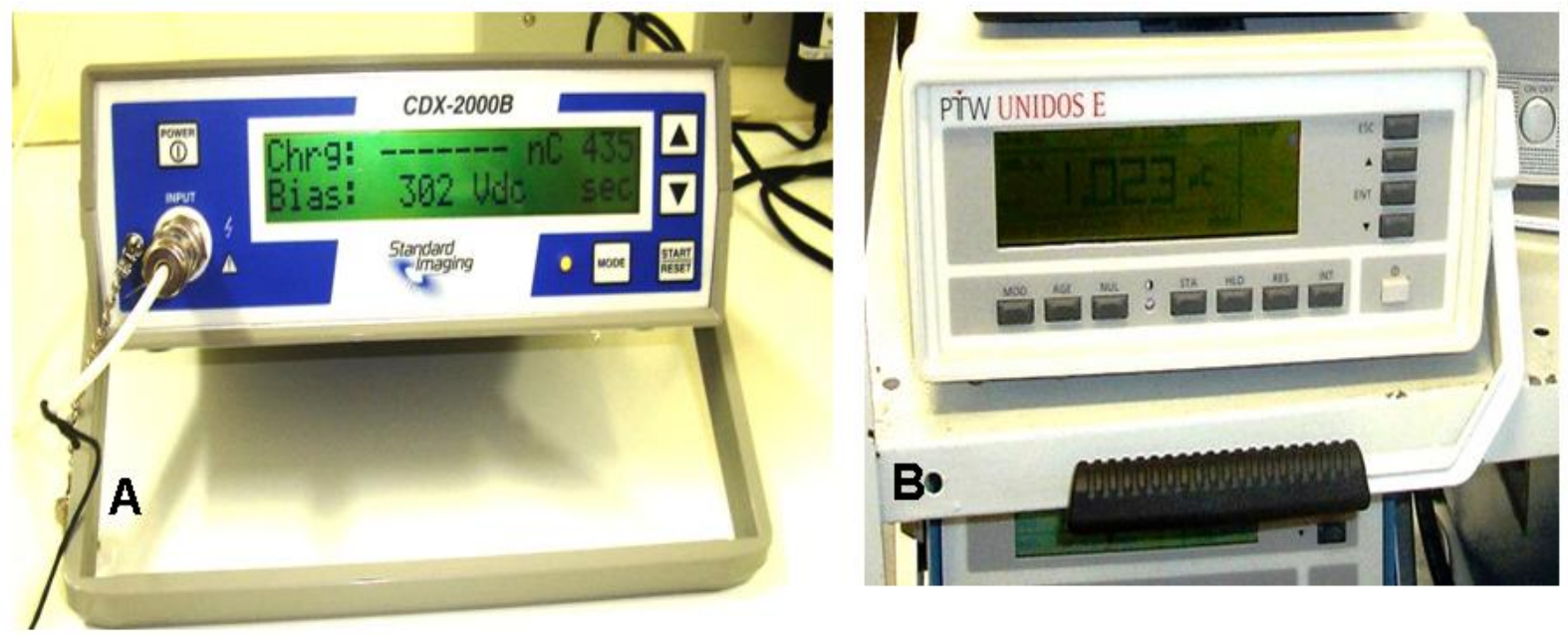

Figura 4.5: Eletrômetros a) Eletrômetro CDX -2000B, b) Eletrômetro PTW Unidos.

\subsubsection{Dosímetros Termoluminescentes (TLD LiF-100)}

Para as medidas experimentais com feixes de elétrons também foram utilizados outro tipo de detector, os dosímetros termoluminescentes TLD-LiF-100, apresentados na figura 4.6a.

Os dosímetros termoluminescentes são compostos de Fluoreto de Lítio (LiF) do tipo TLD-100 fabricados pela Harshaw. Os TLD-100 é resultante de uma fusão homogênea do fluoreto de lítio, fluoreto de magnésio e titânio, muito usado em aplicações médicas. O Fluoreto de Lítio é um halogeneto alcalino de densidade $2,6 \mathrm{~g} / \mathrm{cm}^{3}$, com número atômico efetivo bem perto do valor quanto do tecido humano e não solúvel em água (MARIN, 2003).

A primeira etapa para o uso dos TLDs é o processo de seleção do lote dos TLDs através do levantamento da curva de calibração. Nesta etapa do trabalho foram utilizados os TLDs pré-selecionados por alunos de iniciação científica do Centro de Engenharia Nuclear/IPEN (FONSECA et al., 2007).

A cada experimento foi necessário submeter as pastilhas a um tratamento térmico. No processo de tratamento térmico os TLDs foram submetidos a uma temperatura de $400{ }^{\circ} \mathrm{C}$ no decorrer de quatro horas. Após esta etapa as pastilhas foram irradiadas. Para obtenção dos resultados fez-se o uso de uma leitora da marca Harshaw, modelo 3500,apresentada na figura 4.6b, com o auxílio de uma digitalizadora e utilizando o programa WinREMS PL26732.8.1.0.0 pertecente ao Hospital das Clínicas do InRAD. A partir do processo ocorrido 
na leitora, foram alcançados dados para análises da avaliação de dose.
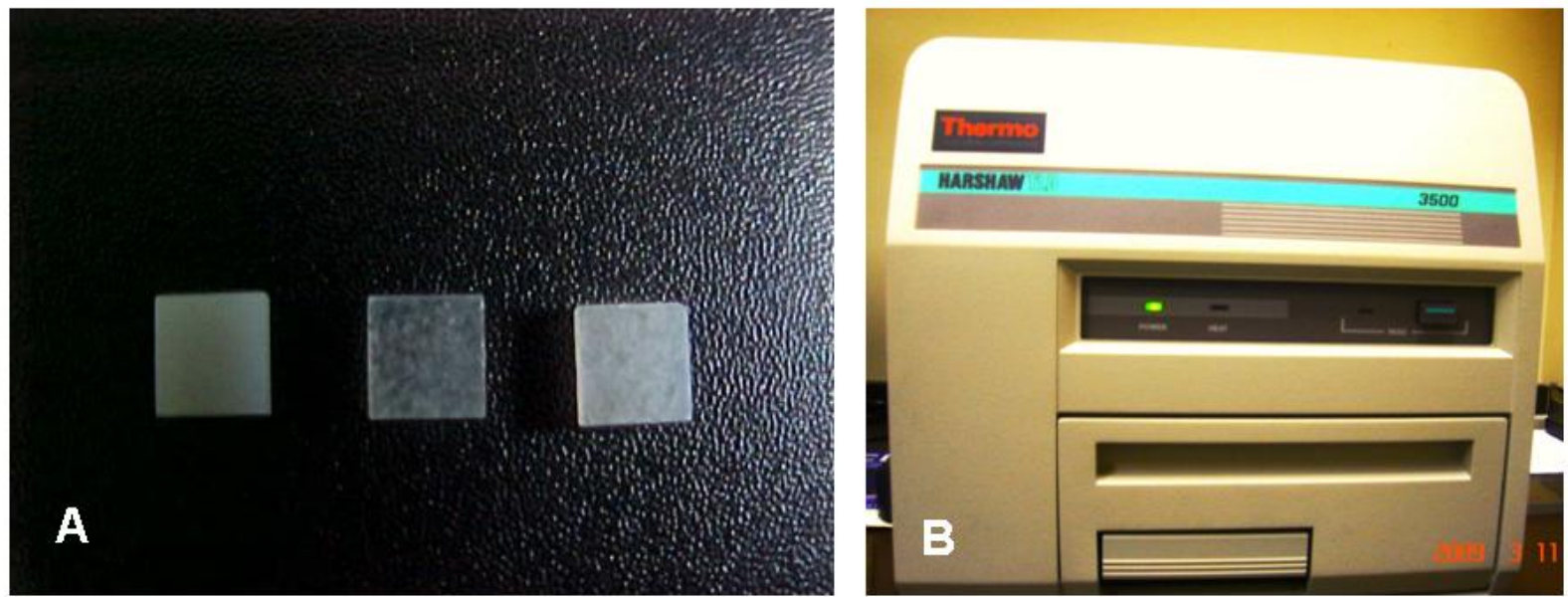

Figura 4.6: a) Dosímetros termoluminescente TDL LiF-100; b) Leitora dos TLDs Harshaw, modelo 3500 pertecente ao HC/USP.

\subsubsection{Objetos Simuladores}

Para algumas medidas experimentais utilizou-se neste trabalho um objeto simulador de água, com dimensões de $38 \mathrm{~cm} \mathrm{x} 38 \mathrm{~cm}$ x $38 \mathrm{~cm}$ da marca Oxford, com paredes de acrílico (figura 4.7a). Outro objeto simulador utilizado e equivalente ao objeto simulador de água são as placas de água sólida. A figura 4.7b mostra exemplos de placas de água sólida utilizadas.
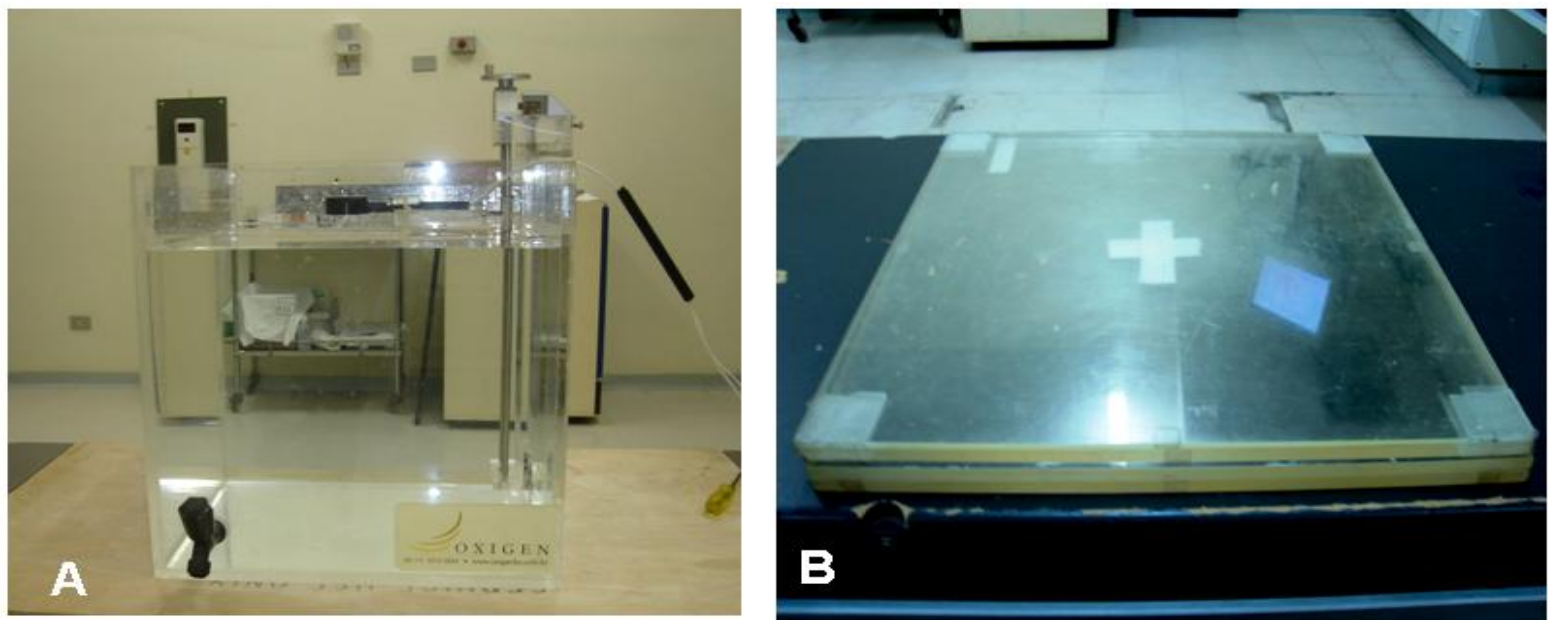

Figura 4.7: a) Objeto simulador de água, b) Placas de água sólida 
Medidas experimentais, geralmente são realizadas utilizando-se objetos simuladores cujos materiais simulam o corpo humano, absorvendo e espalhando as radiações de uma maneira bem semelhante, esses materiais possuem densidades bem próximas a da água, a qual é a maior constituinte do corpo humano.

$\mathrm{Na}$ tabela 4.1 estão listados alguns materiais constituintes de objetos simuladores e suas principais propriedades (SCAFF, 1997).

Tabela 4.1 - Propriedades de alguns materiais constituintes de objetos simuladores

\begin{tabular}{ccc}
\hline \hline Material & Composição Química & Densidade $\mathrm{g} / \mathrm{cm}^{3}$ \\
\hline Água & $\mathrm{H}_{2} \mathrm{O}$ & 1,00 \\
Poliestireno & $\left(\mathrm{C}_{8} \mathrm{H}_{8}\right) \mathrm{n}$ & 1,04 \\
Acrílico & $\left(\mathrm{C}_{5} \mathrm{O}_{2} \mathrm{H}_{8}\right) \mathrm{n}$ & 1,18 \\
Água sólida & $\left(\mathrm{C}_{8} \mathrm{H}_{8}\right)+2,1 \% \mathrm{TiO} 2$ & 1,04 \\
Polietileno & $\left(\mathrm{CH}_{2}\right) \mathrm{n}$ & 0,92 \\
\hline
\end{tabular}

\subsection{Simulação Computacional}

\subsubsection{O Código MCNP versão - 4C}

O método de Monte Carlo pode ser usado para representar teoricamente um processo estatístico, tal como a interação da radiação com a matéria. Esse processo de amostragem estatística é baseado na utilização de números aleatórios. No transporte dos fótons da radiação, a técnica de Monte Carlo consiste em seguir o fóton desde a fonte até o fim de sua trajetória (TEIXEIRA, 2009).

Neste trabalho, foi usado o código de Monte Carlo MCNP versão 4C. Este software simula o transporte de radiação e interação de partículas (neutrons, fótons e elétrons), baseado em princípios físicos e estatísticos. O código MCNP foi originalmente desenvolvido no Los Alamos National Laboratory (LANL), situado nos Estados Unidos, durante o projeto Manhattan, nos anos 40. As áreas específicas de aplicação incluem a proteção contra as radiações, dosimetria, blindagem de radiação, radiologia, física médica, de segurança e criticalidade nuclear. 
O método apresenta uma vasta área de aplicação inclusive em sistemas de planejamento de tratamento de pacientes nos hospitais. ${ }^{2}$

\subsubsection{Estrutura dos Dados de Entrada no Código MCNP.}

O arquivo de dados de entrada do MCNP permite ao usuário especificar o tipo de fonte, espectro de energia, configuração experimental através de geometrias, composições do meio que a radiação irá interagir, e definição geométrica do detector desejado.

A estrutura do arquivo de entrada do MCNP é dividida basicamente em três blocos:

\section{Bloco de Células - CELL Cards}

Nesse bloco encontra -se os dados de entrada onde é definida a geometria do problema. As configurações dos arranjos experimentais são modeladas através de geometrias compostas por planos, esferas, cilindros, elipsóides, descritas no item subquente Bloco Superfície).

As combinações das regiões são realizadas através de operadores booleanos, união, intersecção etc. Neste bloco define-se também as densidades em $\mathrm{g} / \mathrm{cm}^{3}$ e os materiais descritos nos itens subseqüentes no terceiro bloco. O código MCNP tem a capacidade de simular sistemas com geometrias que vão de superfícies pré-determinadas como esferas, planos, cilindros, elipsóides, até superfícies bem elaboradas utilizando conjunto de pontos no espaço.

A importância das células também pode ser definida nesse bloco, através dos mnemônicos: $I M P$ cards. Estes mnemônicos, IMP: N, P ou E determinam a importância da célula, separando assim regiões com diferentes importâncias de acordo com o problema a ser resolvido.

\section{Bloco de Superfícies - Surface Card}

Define-se as superfícies a serem utilizadas na simulação, através de caracteres mnemônicos indicando o tipo de superfície e os coeficientes da equação da superfície selecionada. Neste trabalho as geometrias mais utilizadas foram os planos, cilindros e elipsóides.

\footnotetext{
${ }^{2}$ http://mcnp-green.lanl.gov.
} 


\section{Bloco de Dados - DATA Cards}

Neste bloco são definidos os parâmetros físicos para a simulação e que são:

- O tipo de transporte das partículas na simulação - MODE Card transporte de elétrons (E); transporte de fótons $(\mathrm{P})$; transporte de nêutrons $(\mathrm{N})$; transporte de fótons e elétrons $(\mathrm{P}, \mathrm{E})$ e transporte de nêutrons e fótons (N P);

- Parâmetros físicos da fonte SOURCE Card através das variáveis da fonte; posição (POS); energia (ERG); tipo de partícula (PAR).

- O tipo de resposta que se deseja na saída dos resultados - TALLY Card através do uso de mnemônicos há várias opções de grandezas para os resultados tais como: *F8: (calcula a energia depositada, MeV); F6 (energia média depositada - Kerma por unidade de massa); F5: (Fluência media em detetor pontual, partícula/ $\mathrm{cm}^{2}$ ); F1: ( corrente integrada sobre uma superfície) entre outras.

- Composições dos materiais utilizados nos experimentos - Mn, os materiais podem serem expressos em fração atômica ou fração de massa.

- Tamanho da simulação - NPS, o número de partículas (histórias) da ordem de $10^{6}$, ou mais dependendo da precisão que é desejada no resultado do problema.

A figura 4.8 ilustra a janela de um bloco de notas, onde se estrutura a entrada de dados no MCNP4C.

\subsubsection{Visualização e Análise das Saídas do MCNP.}

A visualização das estruturas geométricas definidas no arquivo de entrada é feita diretamente com o uso do programa compilado, com a inclusão do comando "ip"para abrir a interface gráfica em 2D, que permite a verificação da descrição feita. A resposta da simulação de Monte Carlo é dada em termos $\bar{x}_{-}^{+} \mathrm{R}$. Onde $\bar{x}$ é valor médio acompanhado pelo erro relativo $\mathrm{R}$, que é razão do desvio padrão $S\left(\bar{x}_{j}\right)$ pelo valor médio, tal que $\mathrm{R}=S\left(\bar{x}_{j}\right)$ $/ \bar{x}$ 


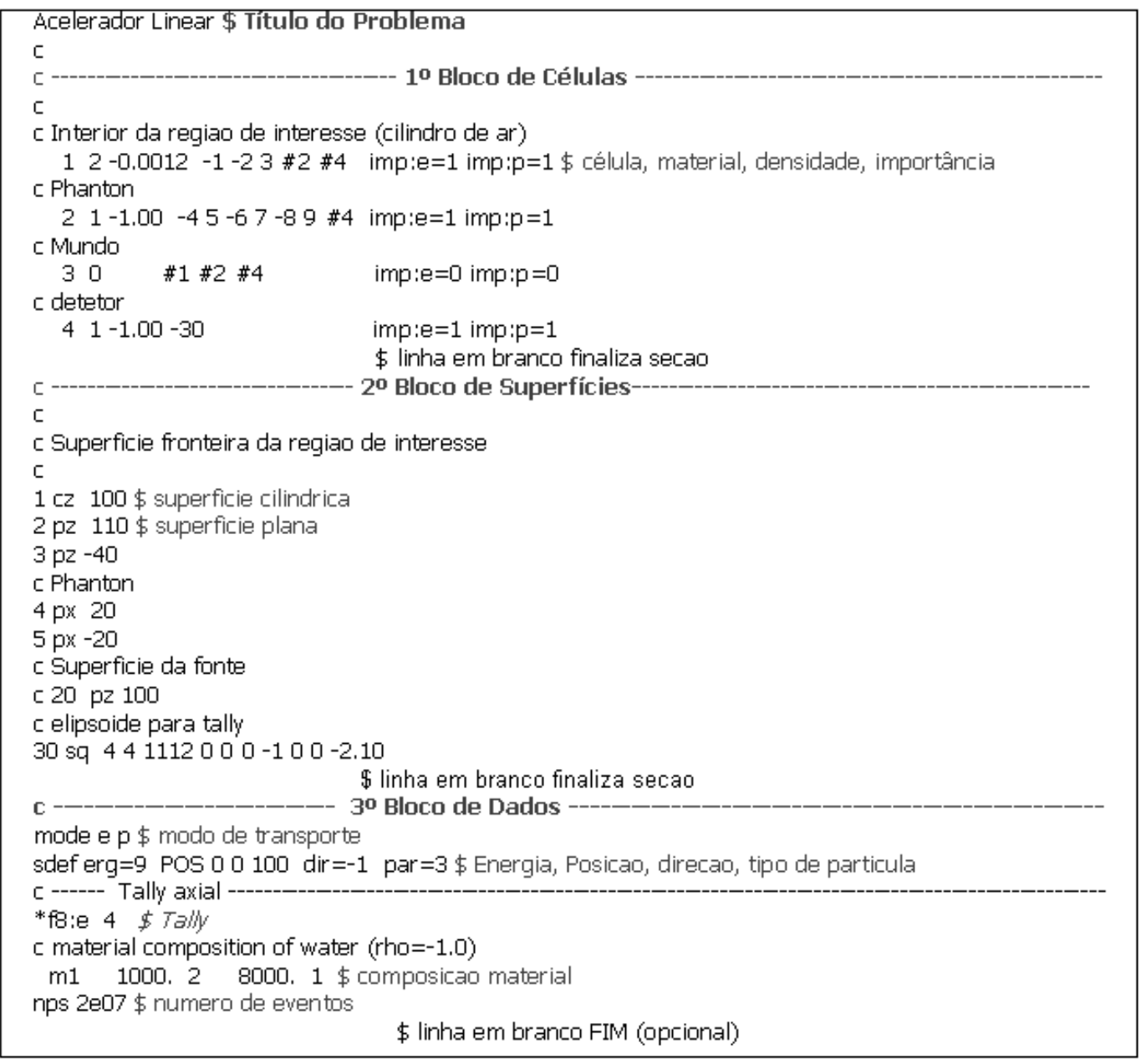

Figura 4.8: Exemplo de arquivo de entrada contendo as variáveis iniciais e seus valores designados para simulação com o código MCNP4C. Estrutura do arquivo de entrada do MCNP4C basicamente dividida em três blocos.

\subsection{Descrições dos Experimentos e das Simulações com o Código MCNP4C.}

\subsubsection{Caracterização dos Feixes de Elétrons de $4 \mathrm{MeV}$ e $9 \mathrm{MeV}$ do Acelerador Linear Clinac 2100C.}

As energias escolhidas para os experimentos foram as energias de $4 \mathrm{MeV}$ e $9 \mathrm{MeV}$, pois são as faixas de energias mais utilizadas para o tratamento de lesões superficiais.

A caracterização dos feixes de um acelerador é separada em duas partes, sendo a primeira a caracterização energética do feixe, realizada com base em medidas de dose em profundidade, e a segunda a caracterização da distribuição espacial do feixe, determinada 
com base nas medidas de perfis radiais. A fonte de radiação que sai do acelerador é caracterizada completamente quando se tem a parte axial e radial.

\section{Parte Axial}

Para a primeira parte da caracterização dos feixes, iniciou-se o levantamento das curvas de ionizações seguindo as recomendações do protocolo IAEA/ TRS-398. Posicionou-se a câmara de ionização (CI) no interior do objeto simulador de água alinhando-se adequadamente no eixo central do feixe, e procedeu-se a varredura em várias profundidades, de baixo para cima de modo a evitar o efeito da tensão superficial da água. Variou-se a profundidade da CI no interior do objeto simulador de $2,0 \mathrm{~cm}$ a $0,3 \mathrm{~cm}$ para $4 \mathrm{MeV}$ e de $5,0 \mathrm{~cm}$ a $0,1 \mathrm{~cm}$ para $9 \mathrm{MeV}$, determinando as profundidades correspondentes às doses de radiação máximas na água e assim também obteve-se as PDPs experimentais.

O tamanho de campo utilizado para ambas energias foram de $10 \mathrm{~cm} \mathrm{x} 10 \mathrm{~cm}$ e distância fonte superfície de $100 \mathrm{~cm}$. A figura 4.9 mostra os arranjos experimentais dos equipamentos utilizados para caracterização energética dos feixes de elétrons.
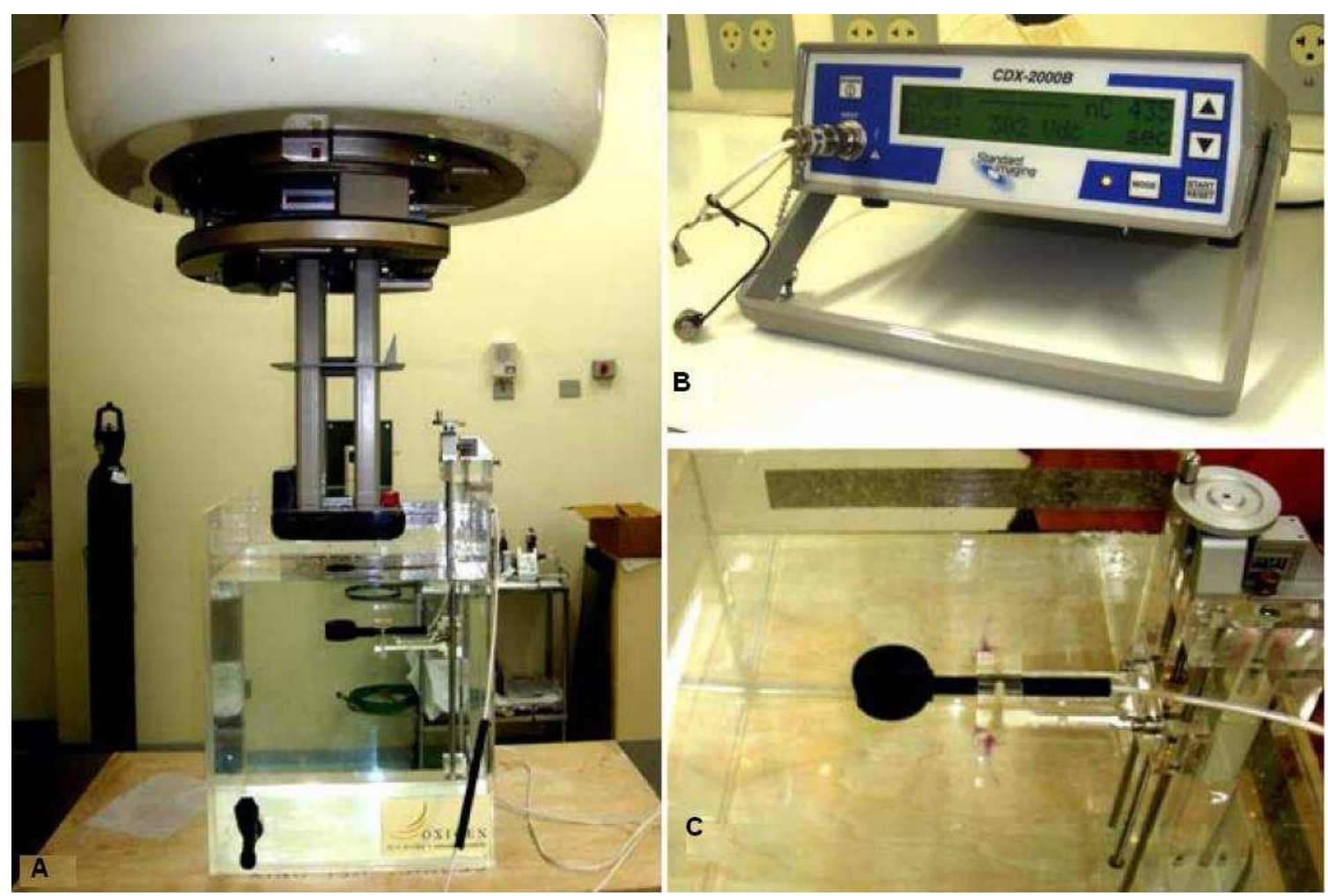

Figura 4.9: Arranjo experimental da caracterização dos feixes - Parte Axial a) Acelerador Linear e objeto simulador, b) Eletrômetro, c) Posicionamento e alinhamento da CI. 
Para as simulações com o MCNP4C modelou - se as geometrias equivalentes ao arranjo experimental realizado, para ambas energias. O objeto simulador de água foi representado por um cubo constituído de planos (px, py e pz) e a região de interesse para cálculo da dose representado por elipsóides $\left[\mathrm{A}(\mathrm{x}-\mathrm{a})^{2}+\mathrm{B}(\mathrm{y}-\mathrm{b})^{2}+\mathrm{C}(\mathrm{z}-\mathrm{c})^{2}+2 \mathrm{D}(\mathrm{x}-\mathrm{a})+2 \mathrm{E}(\mathrm{y}-\mathrm{b})+\right.$ $2 \mathrm{~F}(\mathrm{z}-\mathrm{c})+\mathrm{G}=0]$, conforme mostra figura 4.10 .

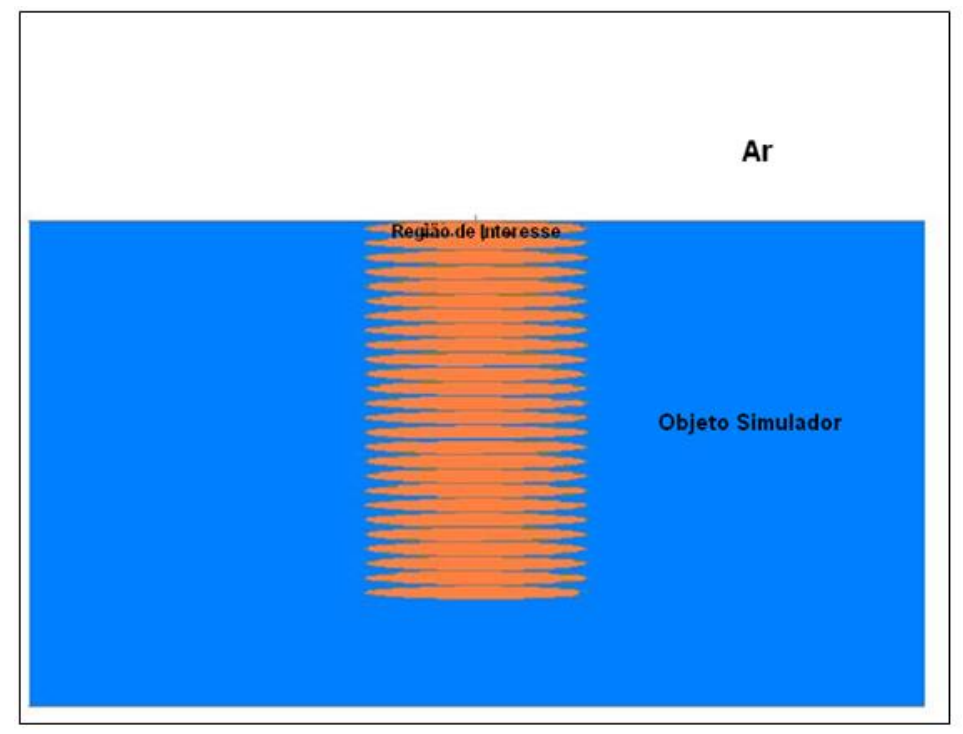

Figura 4.10: Geometria utilizada para caracterização do feixe de elétrons $4 \mathrm{MeV}$ e $9 \mathrm{MeV}$.

Para simular o espectro da fonte, foi necessário aplicar a técnica de reconstrução do espectro do feixe energético do feixe. A reconstrução do espectro é de fundamental importância, pois possibilita simulações de quaisquer experimentos que se deseja realizar com um acelerador em particular e também simular situações de tratamento para análise de distribuição de dose no auxílio em sistemas de planejamento (YORIYAZ et al, 2007).

As reconstruções dos espectros energéticos dos feixes de elétrons foram feitas a partir das PDPs obtida experimentalmente com câmara de ionização. O processo de reconstrução possui uma vantagem de não precisar do conhecimento da composição e geometria do acelerador.

A figura 4.11 ilustra a complexidade da geometria dos principais componentes de um acelerador linear. Os principais componentes do cabeçote do acelerador e que influenciam o feixe de radiação são um feixe de elétrons, um colimador primário, um filtro, uma câmara de ionização monitora, um espelho para a luz de campo, os colimadores secundários (mandíbulas) X e Y, responsáveis pela colimação dos campos de tratamento, e eventuais 
outros acessórios, como um colimadores multi-lâminas (MLC) ou os filtros físicos (VIEIRA, 2008).

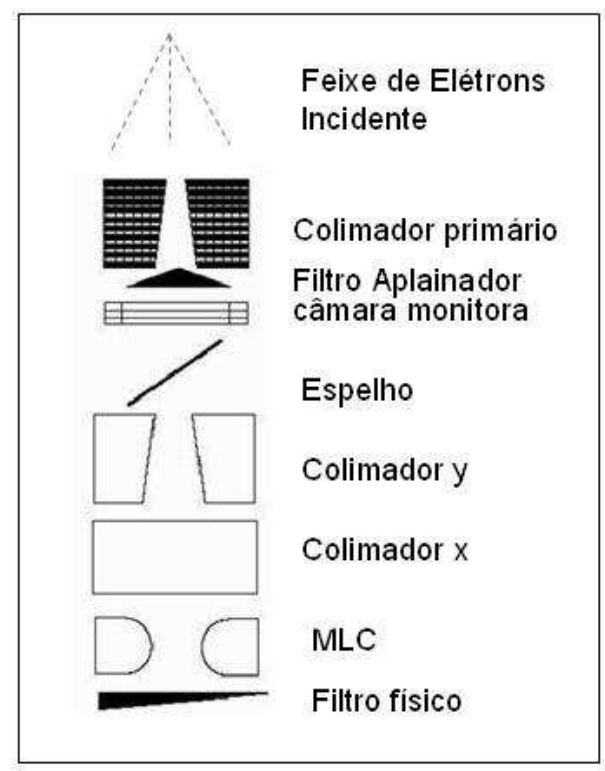

Figura 4.11: Ilustração da Geometria típica dos componentes do modelo de um CLINAC utilizados em simulação pelo método de Monte Carlo.

No arquivo de entrada do MCNP4C, inicialmente considerou-se o feixe monoenergético, adotando um valor explícito através da variável erg=4. Através dos cartões de informações (SIn) e dos cartões de probabilidades (SPn), foi possível definir uma distribuição energética.

Na figura 4.12, observa-se uma janela ilustrativa da distribuição energética da fonte de elétrons no código MCNP4C. Os valores definidos na linha 2 através do cartão informação da fonte (SI3) representam uma grade de energia representada por limites de histogramas, e na linha 3 através do cartão de probabilidades encontram-se números discretos de pesos espectrais que representam as intensidades daquelas energias. A distribuição energética do feixe é definida quando se encontra a melhor aproximação da PDP simulada com a PDP experimental. Os valores desses pesos são obtidos empiricamente na base de tentativa e erro. No código MCNP é preciso especificar o que se pretende obter nos cálculos do MCNP, para isso são utilizados os cartões tallies. Neste caso o tally utilizado para o cálculo da dose foi o ${ }^{*} \mathrm{~F} 8$, que calcula a energia depositada para elétrons, fornecendo uma resposta em $\mathrm{MeV}$. 


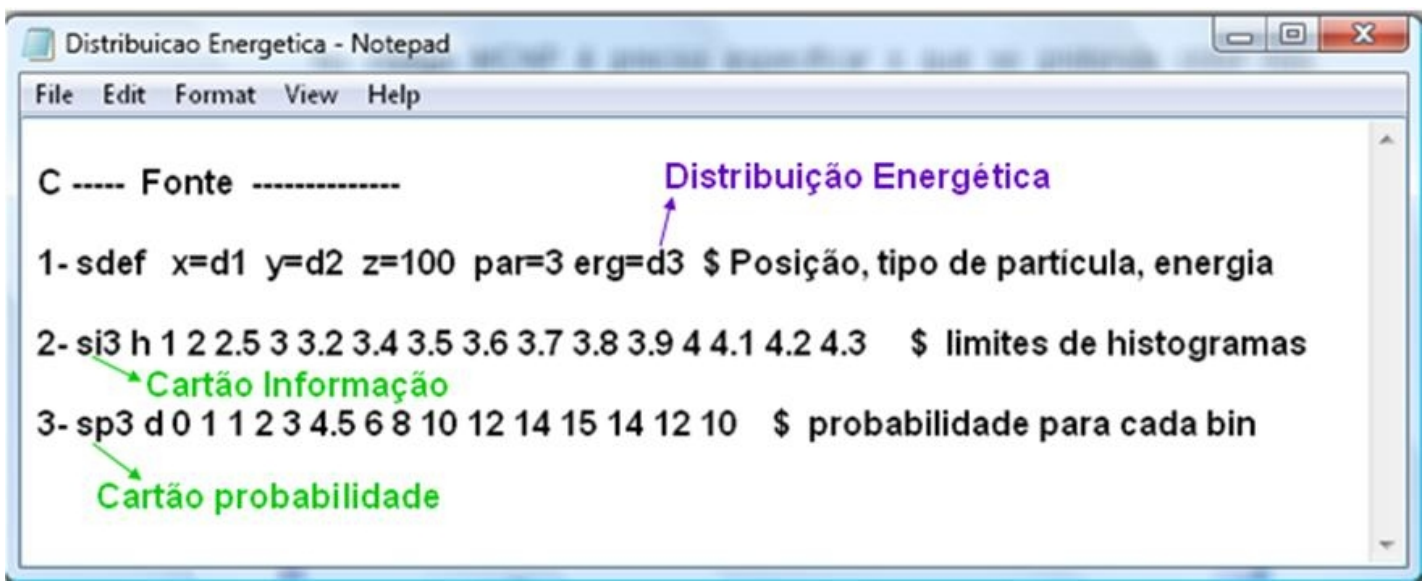

Figura 4.12: Janela ilustrativa da distribuição energética da fonte de elétrons no código MCNP4C.

\section{Parte Radial}

Para a segunda parte da caracterização dos feixes, foi realizado medidas experimentais dos perfis radiais. O levantamento dos perfis radiais dos feixes de elétrons de $4 \mathrm{MeV}$ e 9 $\mathrm{MeV}$ foi realizado com o mesmo sistema de irradiação e o mesmo sistema de medida.

A CI foi envolvida por placas de água sólida e placas de acrílico conforme mostra a figura 4.13a. A CI ficou fixa na posição de dose máxima deslocando horizontalmente apenas a mesa do acelerador linear. Com auxílio de uma régua e de um feixe de laser, conforme mostra figura $4.13 \mathrm{~b}$, o deslocamento variou-se de $-5 \mathrm{~cm}$ a $5 \mathrm{~cm}$, com varredura de $2 \mathrm{~cm}$ nos primeiros pontos e o último ponto $1 \mathrm{~cm}$.
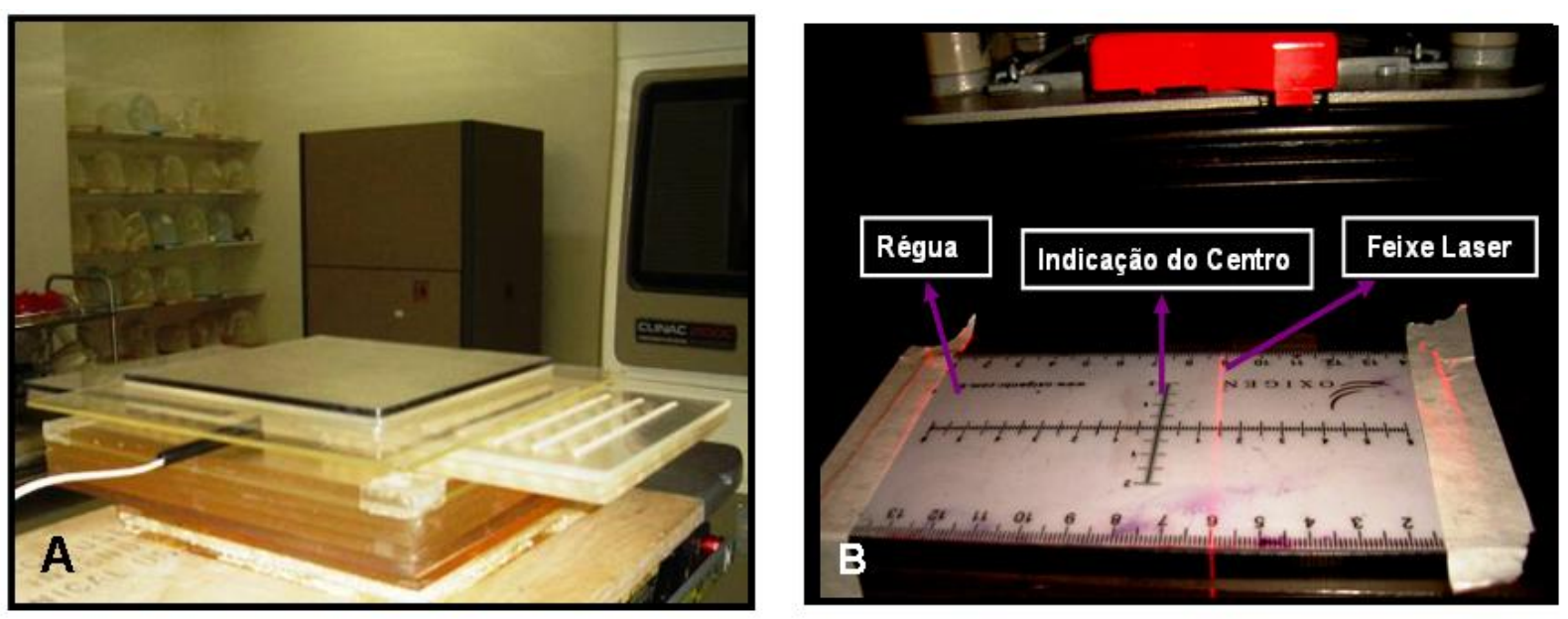

Figura 4.13: a) Arranjo experimental para medidas de perfis radiais dos feixes de elétrons,

b) Sistema de Medição de deslocamento da Planura. 
A geometria da simulação da parte radial do feixe foi representada por planos e elipsóides, sendo que cada elipsóide foi modelada na posição do descolamento do feixe conforme mostra figura 4.14.

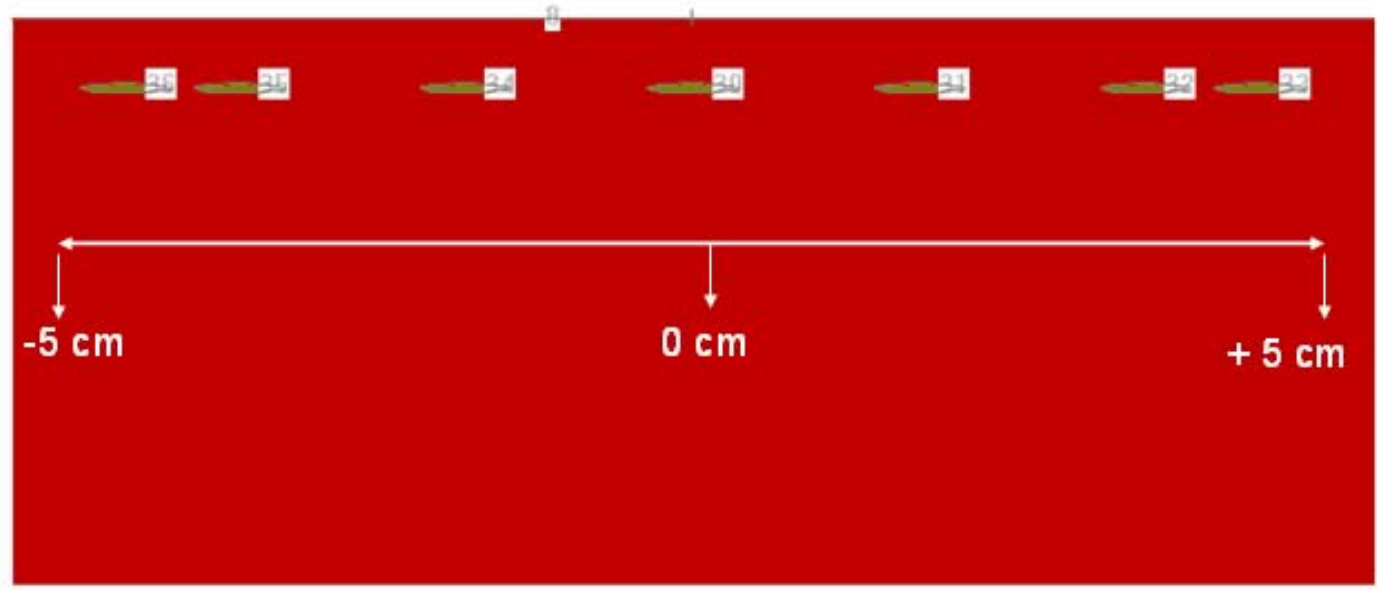

Figura 4.14: Geometria utilizada para a reconstrução da distribuição espacial dos feixes de elétrons de $4 \mathrm{MeV}$ e $9 \mathrm{MeV}$ do Acelerador Linear de Botucatu.

A simulação com o MCNP4C inicialmente utilizou uma distribuição espacial homogênea em todas as regiões, ou seja, considerou que o feixe era uniforme em todo campo 10 cm X 10 cm nos eixos x e y. Considerando que nenhuma ponderação foi feita, ou seja, que as intensidade da fonte é igual em toda área do campo de radiação temos diferenças significativas entre os perfis experimentais e simulados.

No arquivo de entrada no MCNP4C, através dos cartões de informações da fonte e cartões de probabilidades, definiu-se a distribuição espacial do feixe criando subdivisões e alterando as intensidades, até que se obtivesse um resultado simulado próximo ao experimental. Os valores desses pesos também são obtidos empiricamente na base de tentativa e erro.

A figura 4.15 mostra uma janela ilustrativa dos dados de entrada para reconstrução da distribuição espacial da fonte. 


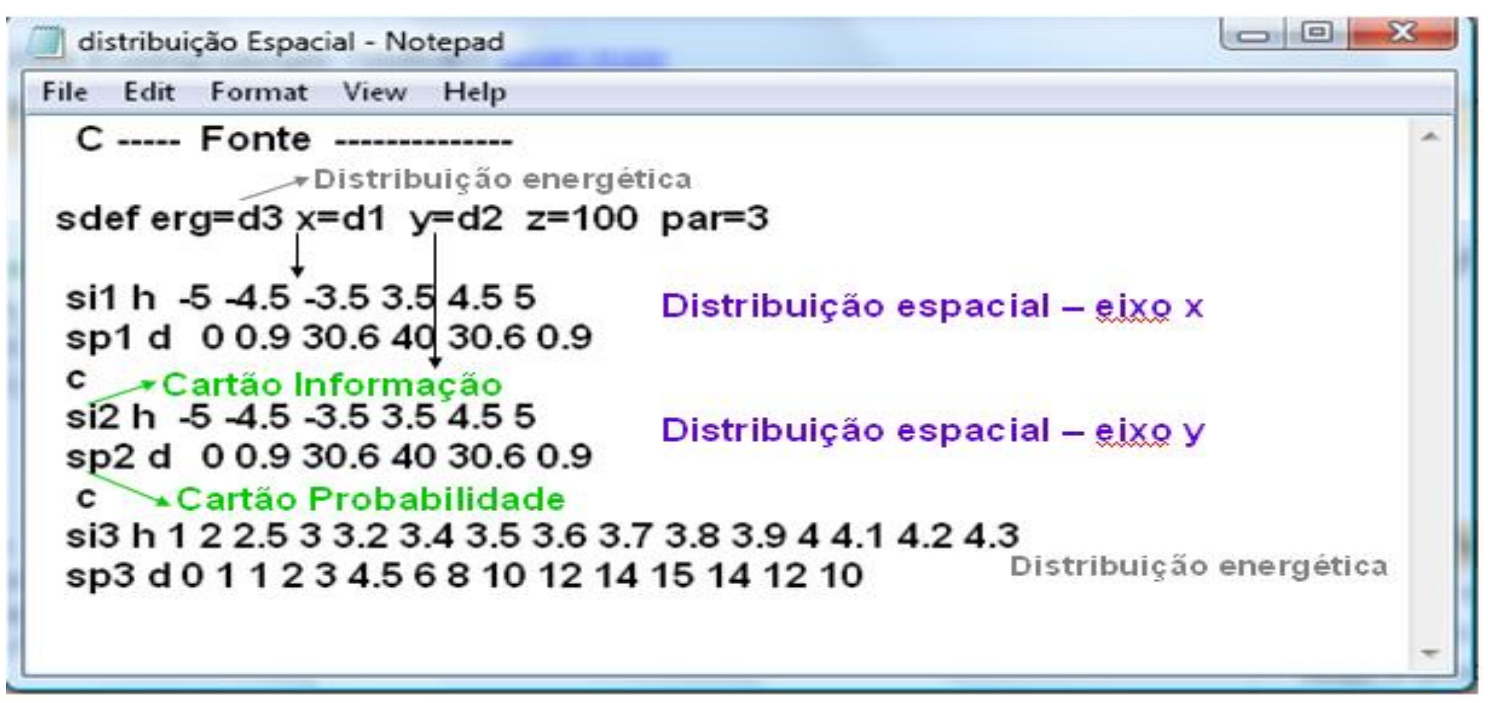

Figura 4.15: Janela ilustrativa com a especificações da distribuição espacial da fonte de elétrons no código MCNP4C.

\subsubsection{Medidas Experimentais dos Perfis de Dose dos Feixes de Elétrons de $4 \mathrm{MeV}$ e $9 \mathrm{MeV}$ em Função das Espesssuras de Atenuadores}

Para finalizar o processo de caracterização energética do feixe de um acelerador é preciso validar a fonte em outra condição além da utilizada para ajustar o espectro. Isto é feito para garantir que o espectro simulado produz resultados próximos aos reais. Para validação do espectro energético realizaram-se medidas experimentais em função de placas atenuadoras.

Para análise dos perfis de doses dos feixes de elétrons de $4 \mathrm{MeV}$ e $9 \mathrm{MeV}$ em função de placas atenuadoras utilizaram-se o mesmo sistema de irradiação e medição usado na caracterização do feixe. Antes de iniciar as medidas, analisaram-se as curvas de PDPs levantadas experimentalmente para verificar as posições de doses máximas que foi o ponto de fixação do detector. Desta forma, o detector foi posicionado a $0,75 \mathrm{~cm}$ da superfície para energia de $4 \mathrm{MeV}$ e 2,10 $\mathrm{cm}$ para energia de $9 \mathrm{MeV}$.

A distância adotada entre a CI e a superfície é aquela necessária para se ter a dose máxima exatamente na superfície da câmara de ionização. A água acima do detector faz a função da placa de build-up. Para simular as camadas da pele utilizou-se 10 placas de polietileno de espessura de $0,6 \mathrm{~mm}$ para o feixe de $4 \mathrm{MeV}$ e 20 placas para o feixe de $9 \mathrm{MeV}$. As placas atenuadoras foram posicionadas no aplicador do acelerador linear, conforme mostra a figura 4.16b.

A cada irradiação acrescentou-se uma placa, sendo que a primeira irradiação foi sem 
placa. É importante ressaltar que o detector ficou fixo na posição de dose máxima variando somente as profundidade com o acréscimo de placas de polietileno.
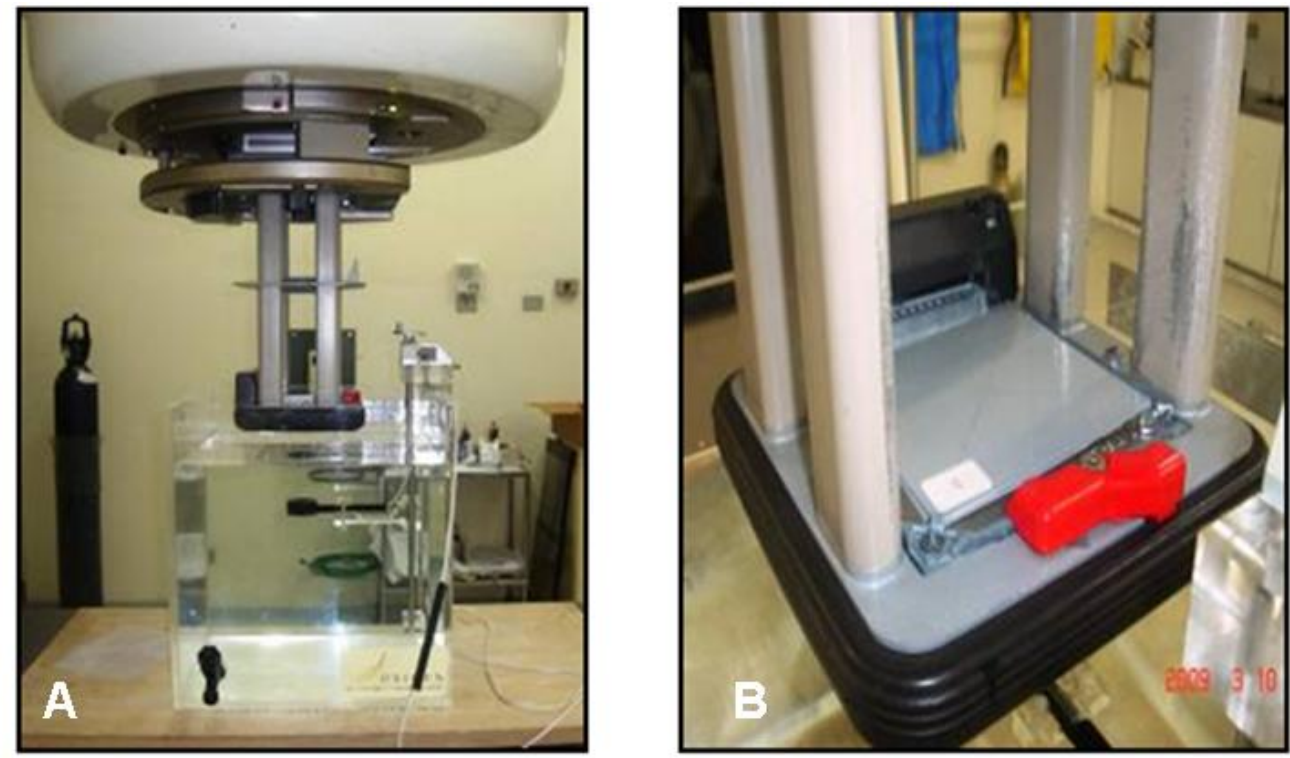

Figura 4.16: Arranjo experimental da atenuação dos feixes de elétrons em função das espessuras de atenuadores a) Posicionamento da CI no objeto simulador, b) posicionamento das placas atenuadoras no aplicador.

A tabela 4.2 mostra as características físicas dos equipamentos utilizados e as condições utilizadas nos experimentos.

Tabela 4.2 - Configurações utilizadas no experimento com feixes de elétrons.

\begin{tabular}{ll} 
Parâmetro & Caracteristicas ou valores de Referêcias \\
\hline Sistema de Irradiação & Acelerador Linear Varian 2100C - HC Botucatu \\
Feixe de Elétrons & Energia $4 \mathrm{MeV}$ e $9 \mathrm{MeV}$ \\
Sistema de Medida & \\
Objeto Simulador de Água & Acrílico $(38 \mathrm{~cm} \mathrm{X} 38 \mathrm{~cm} \mathrm{X} 38 \mathrm{~cm})$ \\
Câmara de ionização de Placas Paralelas & Exradin P11 \\
Eletrômetro & Standard Imaging CD-X 2000000B-J0 10553 \\
Posicionamento do ponto de Dose Máxima da C.I & Zmáx=0,75 cm $(4 \mathrm{MeV})$ e Zmáx=2,10 $(9 \mathrm{MeV})$ \\
Tamanho de Campo & $10 \mathrm{~cm} \mathrm{X} 10 \mathrm{~cm}$ \\
Distância Fonte-superfície & $100 \mathrm{~cm}$ \\
número de placas atenuadoras & $10(4 \mathrm{MeV})$ e $20(9 \mathrm{MeV})$. \\
\hline
\end{tabular}


Para as simulações dos experimentos com o MCNP4C foram realizadas 20 modelagens referentes as 20 irradiações para $9 \mathrm{MeV}$ e 10 modelagens para $4 \mathrm{MeV}$ referentes as 10 irradiações e o Tally utilizado foi *F8:e.

Na figura 4.17 pode-se observar duas geometrias utilizadas no arquivo de entrada do MCNP4C para simulações dos experimentos em função das espessuras das placas atenuadoras para os feixes de elétrons.

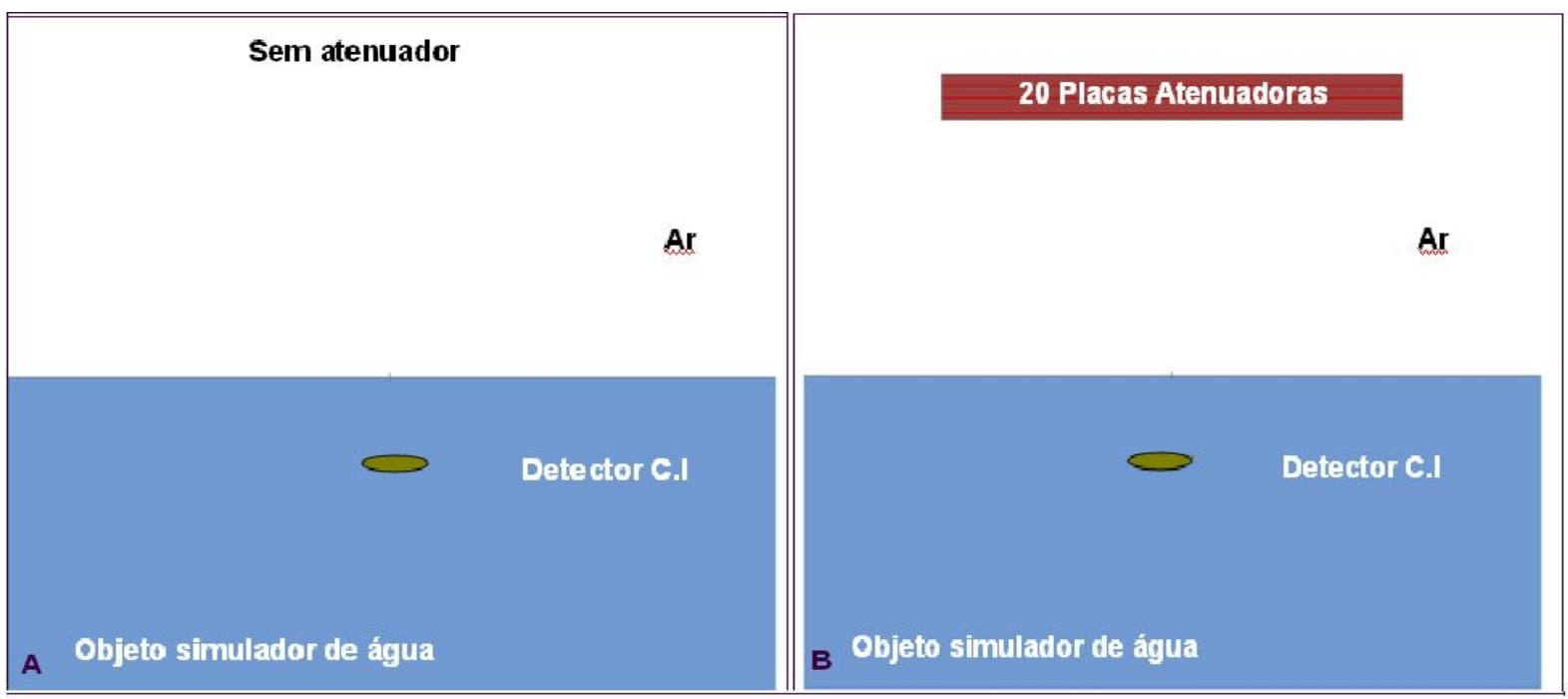

Figura 4.17: Exemplo de duas geometrias utilizadas no MCNP para análise do perfil de atenuação de dose dos feixes de elétrons em função de placas atenuadoras a) arquivo de entrada sem placa, b) arquivo de entrada com 20 placas.

\subsubsection{Medidas Experimentais do Perfil de Dose do Feixe de Elétrons de 4 MeV com TLD em Função das Espessuras dos Atenuadores.}

A mesma medida experimental se repetiu com o feixe de elétrons de $4 \mathrm{MeV}$ descrita no item 4.4.2, mantendo as mesma configurações do feixe (tamanho de campo e DFS) entretanto, variando-se o tipo de detector e o arranjo experimental. As medidas foram realizadas com dosímetros termoluminescentes, TLD LiF-100. A cada irradiação utilizouse 9 TLDs, que foram posicionados em um suporte de acrílico. Abaixo do suporte dos TLDs colocou-se 5 placas de água sólida para garantir o equilíbrio eletrônico, e acima do suporte do TLDs colocou-se uma placa de build-up de $7 \mathrm{~mm}$ para obter a dose máxima exatamente na superfície do detector, conforme mostra figura 4.18. 


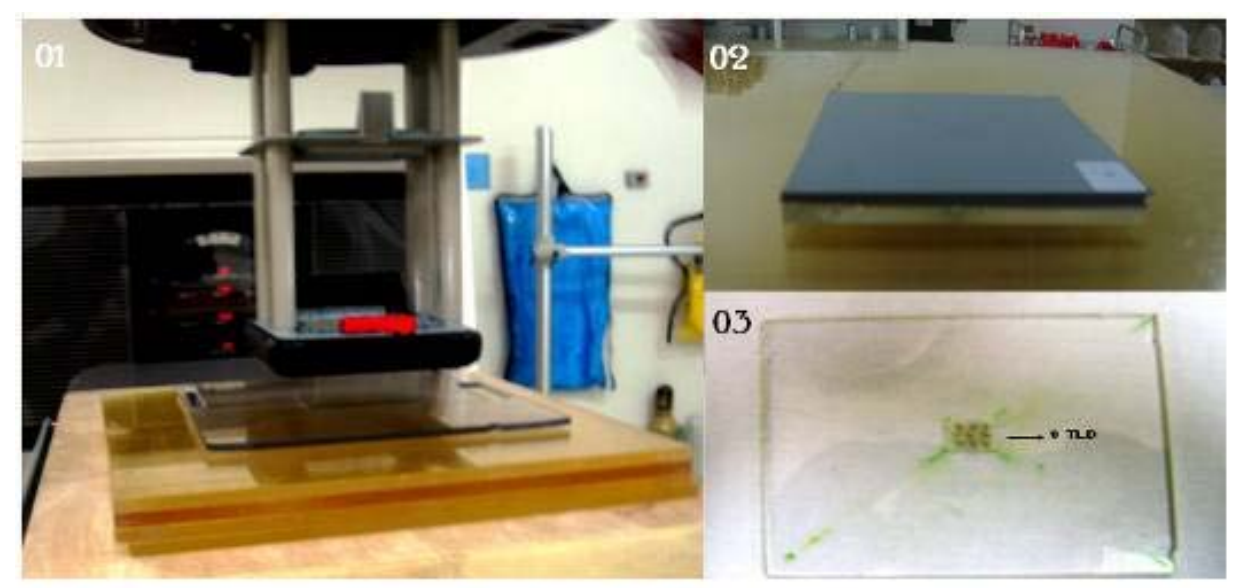

Figura 4.18: Arranjo experimental da atenuação dos feixes de elétrons de $4 \mathrm{MeV}$ em função das espessuras de atenuadores utilizando TLD: 01) Configuração experimental, 02) Placas de Polietileno e suporte de acrílico e 03) TLDs no suporte.

Para representar as camadas da pele utilizaram-se 10 placas de polietileno, cada uma com espessura de 0,6 mm. A cada irradiação acrescentou-se uma placa de polietileno, sendo que a primeira irradiação foi sem placa. As placas de polietileno foram sempre posicionadas abaixo da placa de build-up. O mesmo experimento foi realizado duas vezes mantendo-se os mesmos parâmetros do experimento com a câmara de ionização, ou seja, energia de $4 \mathrm{MeV}$; tamanho de campo $10 \mathrm{~cm} \mathrm{X} 10 \mathrm{~cm}$, porém as medidas foram realizadas para dois diferentes posicionamento do detector, considerando distância fonte detector DFI $=100 \mathrm{~cm}$ e fonte-superfície DFS $=100 \mathrm{~cm}$, conforme mostra a figura 4.19 .

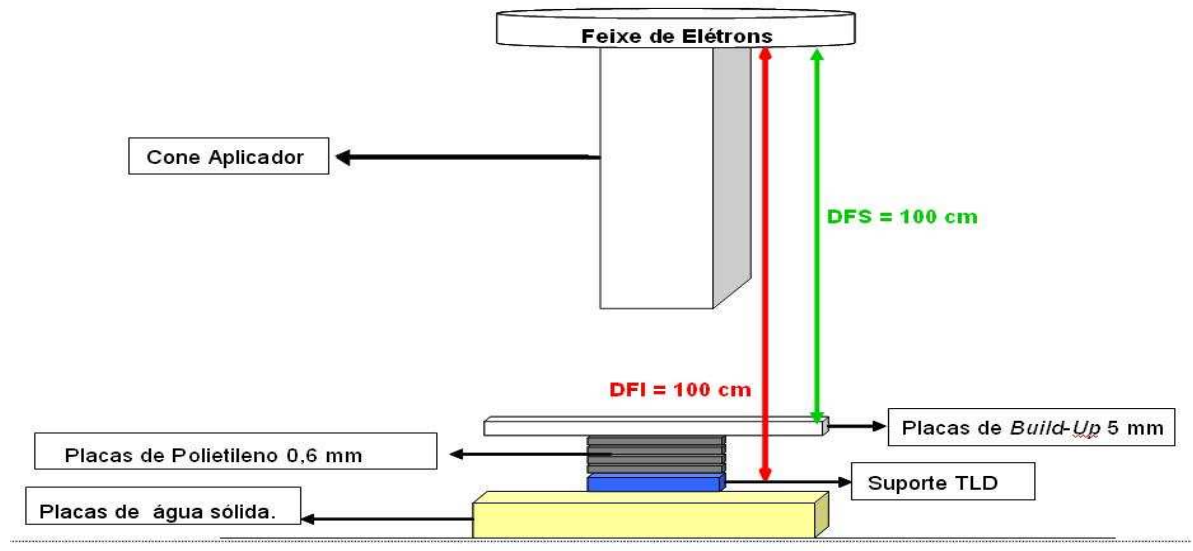

Figura 4.19: Configuração experimental utilizado nas medidas do feixe de elétrons de $4 \mathrm{MeV}$ com TLD, Setup DFI $=100 \mathrm{~cm}$, Setup DFS $=100 \mathrm{~cm}$. 


\subsubsection{Medidas Experimentais das Planuras dos Feixes de Elétrons em Várias Profundidades}

Para validação da reconstrução da distribuição espacial realizaram-se medidas experimentais da parte radial dos feixes em várias profundidades, utilizando placas atenuadoras.

O arranjo experimental utilizado foi o mesmo citado para caracterização da parte radial dos feixes. As planuras foram realizadas em 4 profundidades diferentes para cada energia. Para $4 \mathrm{MeV}$ realizaram-se medidas nas profundidades de $0 \mathrm{~mm}, 1,2 \mathrm{~mm}, 3 \mathrm{~mm}$ e $6 \mathrm{~mm}$ e para $9 \mathrm{MeV}$ realizou-se medidas para profundidades de $0 \mathrm{~mm}, 3 \mathrm{~mm}, 6 \mathrm{~mm}$ e $9 \mathrm{~mm}$.

As profundidades das planuras foram definidas por quantidades de placas de polietileno e o deslocamento variou de $-5 \mathrm{~cm}$ a $5 \mathrm{~cm}$, com varredura de $2 \mathrm{~cm}$ nos primeiros pontos centrais e o último ponto $1 \mathrm{~cm}$.

Para simulação da geometria dos experimentos das planuras no MCNP4C, modelaramse elipsóides representando a região de interesse para cálculo da dose, para isso posicionouse cada elipsóide na posição de deslocamento e nas respectivas profundidades. A figura 4.20a apresenta a configuração experimental e a figura 4.20b mostra a geometria utilizada para simulação no MCNP4C.
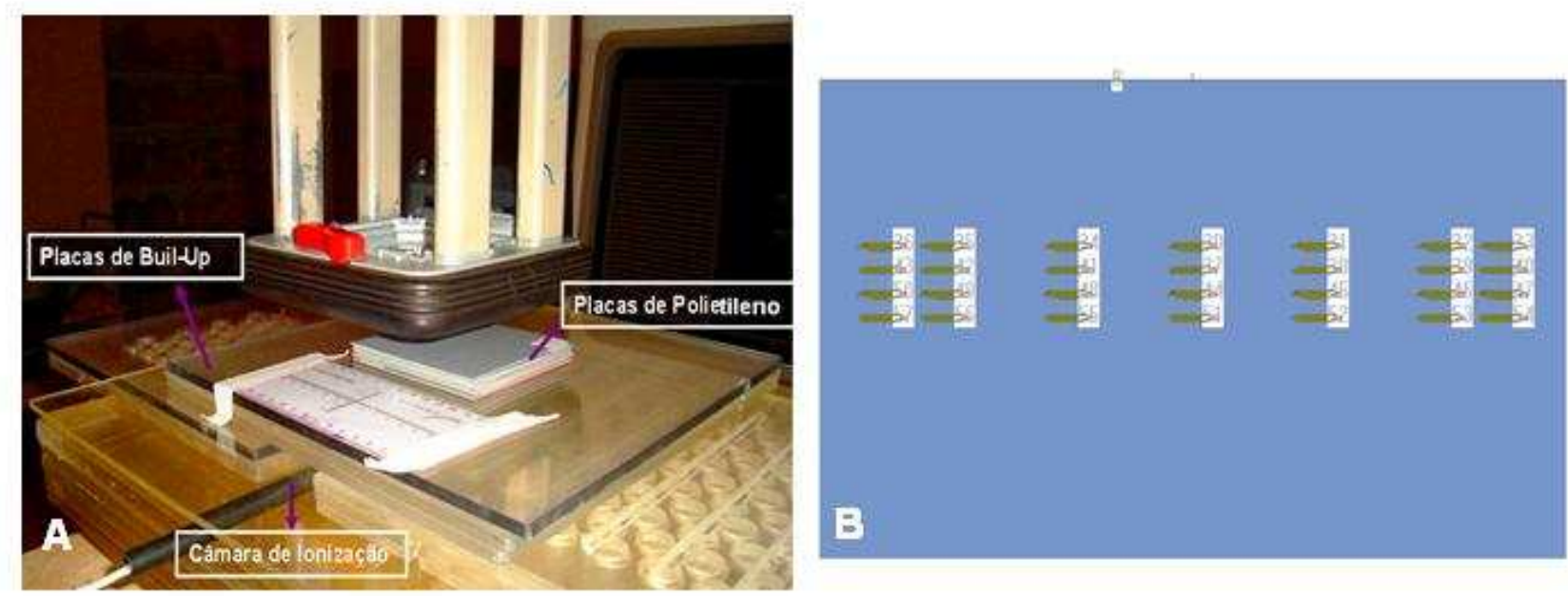

Figura 4.20: a) Arranjo das medidas experimentais das Planuras; b) Geometria utilizada para planura do feixe de elétrons $4 \mathrm{MeV}$ e $9 \mathrm{MeV}$. 


\subsubsection{Medidas Experimentais do Perfil de Dose do Feixe de Raios-X de 90 $k V p$ em Função das Espessuras de Atenuadores.}

Para analisar a atenuação do feixe de raios-X em função das placas atenuadoras utilizouse a tensão para irradiação de $90 \mathrm{kVp}$, com o diâmetro de $6,8 \mathrm{~cm}$ de abertura do colimador. Utilizou-se um filtro de alumínio de $2,5 \mathrm{~mm}$, e a qualidade do feixe RQR7. A distância fonte detector foi de $50 \mathrm{~cm}$ e a energia efetiva de $33 \mathrm{keV}$. Cada irradiação durou cerca de 1 minuto e 25 segundos. Foram realizadas 10 irradiações, sendo que a primeira irradiação foi feita sem a presença da placa de polietileno, a segunda irradiação inseriu-se uma placa de polietileno e assim sucessivamente. A figura 4.21 mostra os equipamentos e configurações utilizadas no experimento.

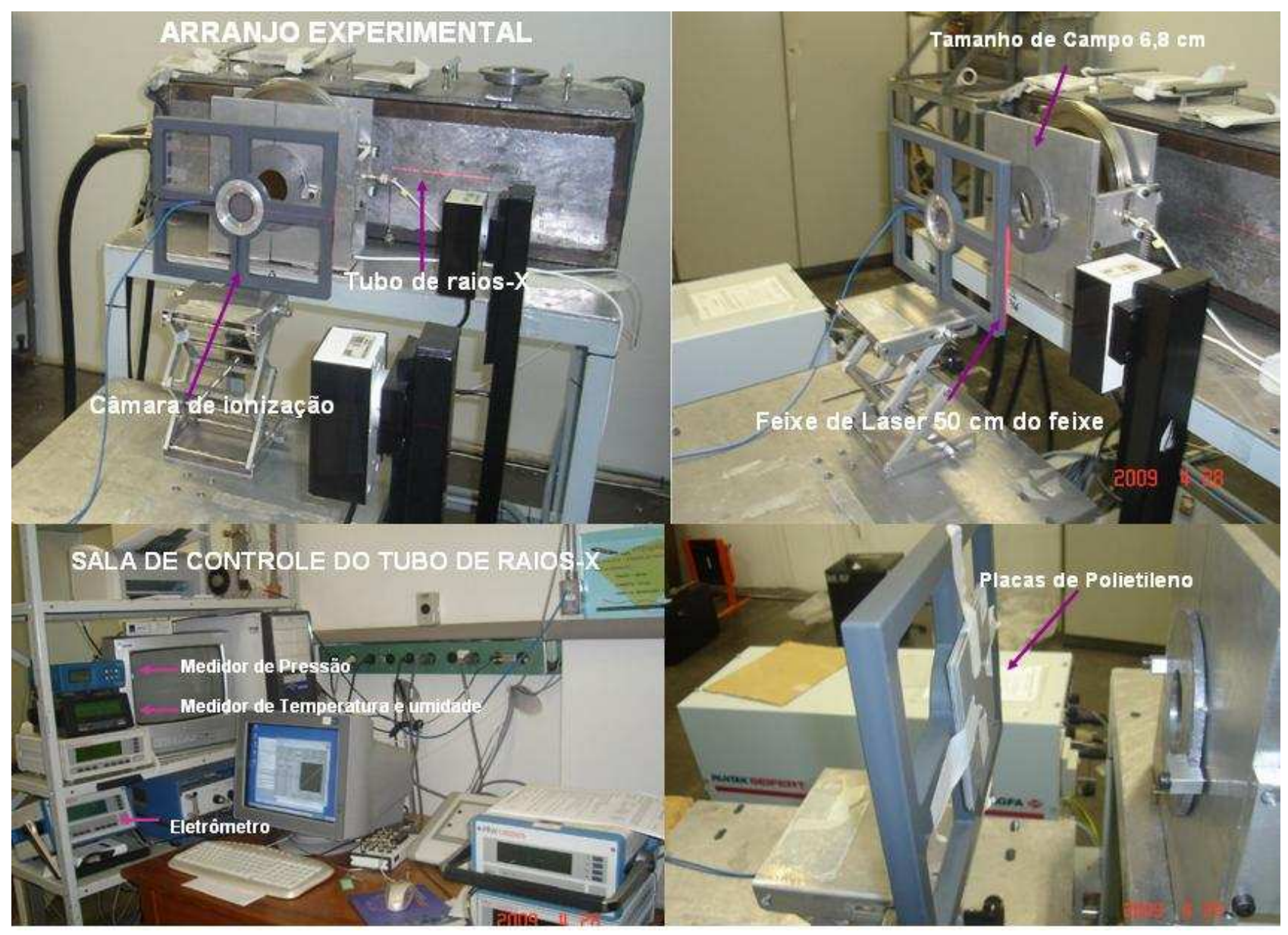

Figura 4.21: Configuração experimental utilizada para as medidas com o equipamento de Raios-X de 90 kVp - Laboratório de Calibração de Instrumentos do IPEN.

A tabela 4.3 mostra as características e configurações utilizadas no experimento com equipamento de raios-X. 
Tabela 4.3 - Características e configurações do experimento com raios-X de $90 \mathrm{kVp}$.

\begin{tabular}{ll}
\hline \hline Parâmetro & Caracteristicas ou valores de Referêcias \\
\hline Sistema de Irradiação & marca Pantak/Seifert, modelo ISOVOLT 160- HS \\
Feixe de raios-X & Raios-X $90 \mathrm{kVp}$ \\
Sistema de Medida & \\
Câmara de ionização de Placas Paralelas & marca PTW, modelo 77334 \\
Eletrômetro & marca PTW, modelo Unidos \\
Tamanho de Campo & $6,8 \mathrm{~cm}$ de diâmetro \\
Filtro Adicional & $2,5 \mathrm{mmAl}$ \\
Distância Fonte-superfície & $50 \mathrm{~cm}$ \\
Dose & $50 \mathrm{cGy}$ \\
Tempo de Irradiação & $1,25 \mathrm{~min}$ \\
Energia Efetiva & $33,05 \mathrm{keV}$ \\
número de placas atenuadoras & 10 \\
\hline
\end{tabular}

Para modelagem da geometria do experimento do raios-X no MCNP4C, utilizaram-se elipsóides representando a região de interesse. Para cálculo da dose, posicionou-se cada elipsóide nas posições referentes as profundidades de cada placa. O filtro de alumínio também foi modelado utilizando-se planos. A figura 4.22 mostra a geometria utilizada para simulação do experimento do feixe de raios-X.

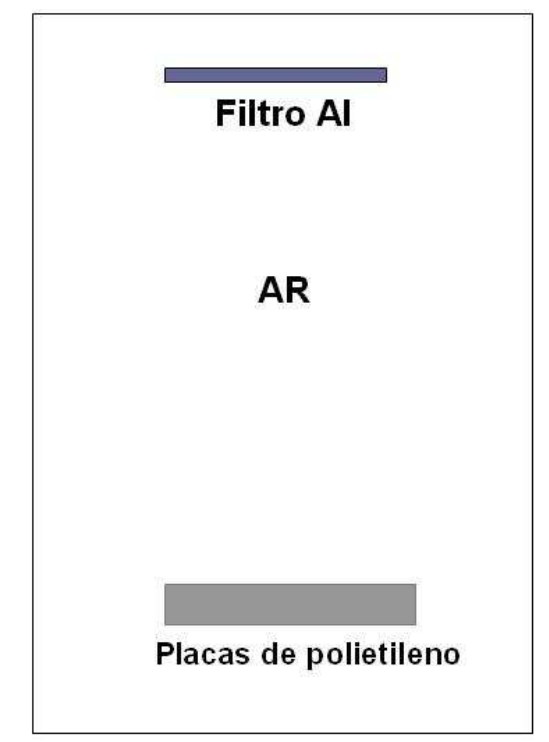

Figura 4.22: Geometria modelada no MCNP4C referente ao arranjo experimental das medidas com equipamento de raios- $\mathrm{X}$ de $90 \mathrm{kVp}$. 
A determinação do espectro do feixe de raios-X utilizado no código de Monte Carlo MCNP, foi feita pela espectrometria do feixe realizada pelo pessoal qualificado do Laboratório de Calibração de Instrumentos do IPEN. A figura 4.23 mostra o espectro de raios-X usado no MCNP para simulação. O cálculo de dose foi realizado com o uso do tally F6:P que fornece a energia média depositada por unidade de massa do volume alvo considerado.

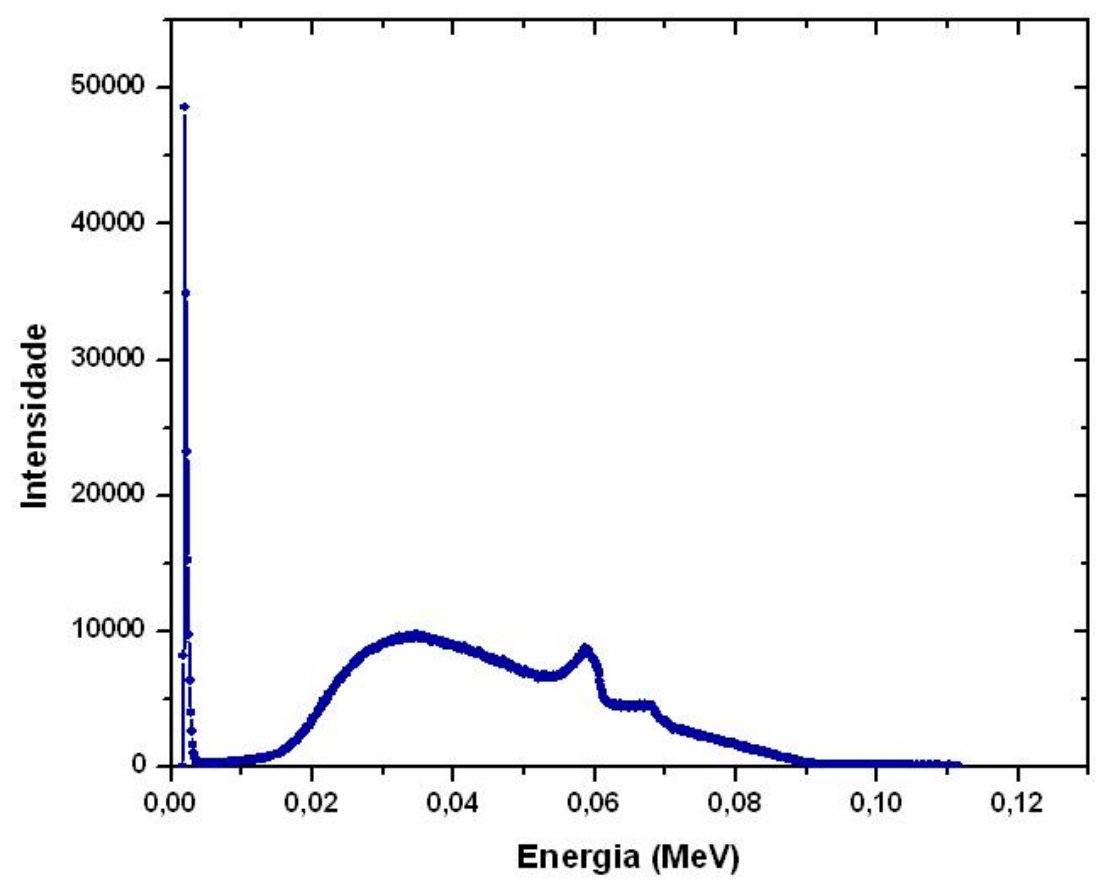

Figura 4.23: Espectro do feixe de raios-X de $90 \mathrm{kVp}$ usado no MCNP4C para simulação

\subsubsection{Casos Clínicos}

Uma vez caracterizadas e validadas as fontes dos feixes das radiações é possível realizar simulações de casos clínicos em radioterapia de pacientes que se submetem a esse tipo de tratamento.

Inicialmente foram fornecidos 26 casos clínicos de tumores de pele para simulações pelo departamento de Dermatologia e Radioterapia do Hospital das Clínicas da UNESP de Botucatu. Apenas alguns casos clínicos foram selecionados para simulação de tratamento no MCNP. A escolha dos casos clínicos baseou-se em alguns parâmetros tais como, dimensões das lesões; energia de tratamento e tamanho de campo e que mais se aproximavam das características observadas na revisão bibliográfica realizada neste trabalho. A tabela 4.4, apresenta as cacarcterísticas dos casos clínicos selecionados para simulação. 
Tabela 4.4 - Casos Clínicos de tratamento de lesões de pele com feixes de elétrons.

\begin{tabular}{ccccc}
\hline \hline & & & & \\
Caso & Energia $(\mathrm{MeV})$ & Dimensões das Lesões X/Y & DFS & Aplicador \\
\hline 1 & 4 & $6 \mathrm{~cm} \times 6 \mathrm{~cm}$ & $100 \mathrm{~cm}$ & $10 \mathrm{~cm} \times 10 \mathrm{~cm}$ \\
2 & 9 & $9 \mathrm{~cm} \times 6 \mathrm{~cm}$ & $100 \mathrm{~cm}$ & $10 \mathrm{~cm} \times 10 \mathrm{~cm}$ \\
3 & 9 & $6 \mathrm{~cm} \mathrm{\times} 6 \mathrm{~cm}$ & $103 \mathrm{~cm}$ & $10 \mathrm{~cm} \times 10 \mathrm{~cm}$ \\
4 & Raios-X $90 \mathrm{kVp}$ & $6 \mathrm{~cm} \times 6 \mathrm{~cm}$ & $50 \mathrm{~cm}$ & $6,8 \mathrm{~cm}$ diâmetro \\
\hline
\end{tabular}

A modelagem geométrica dos tumores no código MCNP seguiu um padrão simples e que se constitui de camadas de diferentes espessuras representadas por diferentes planos. Quanto à composição dos tumores, considerou-se tecido mole com densidade da água, i.e., $1 \mathrm{~g} / \mathrm{cm}^{3}$, tendo em vista que a histologia dos tumores apresenta uma grande variabilidade em literatura e uma grande complexidade. A figura 4.24b mostra a geometria modelada no MCNP.

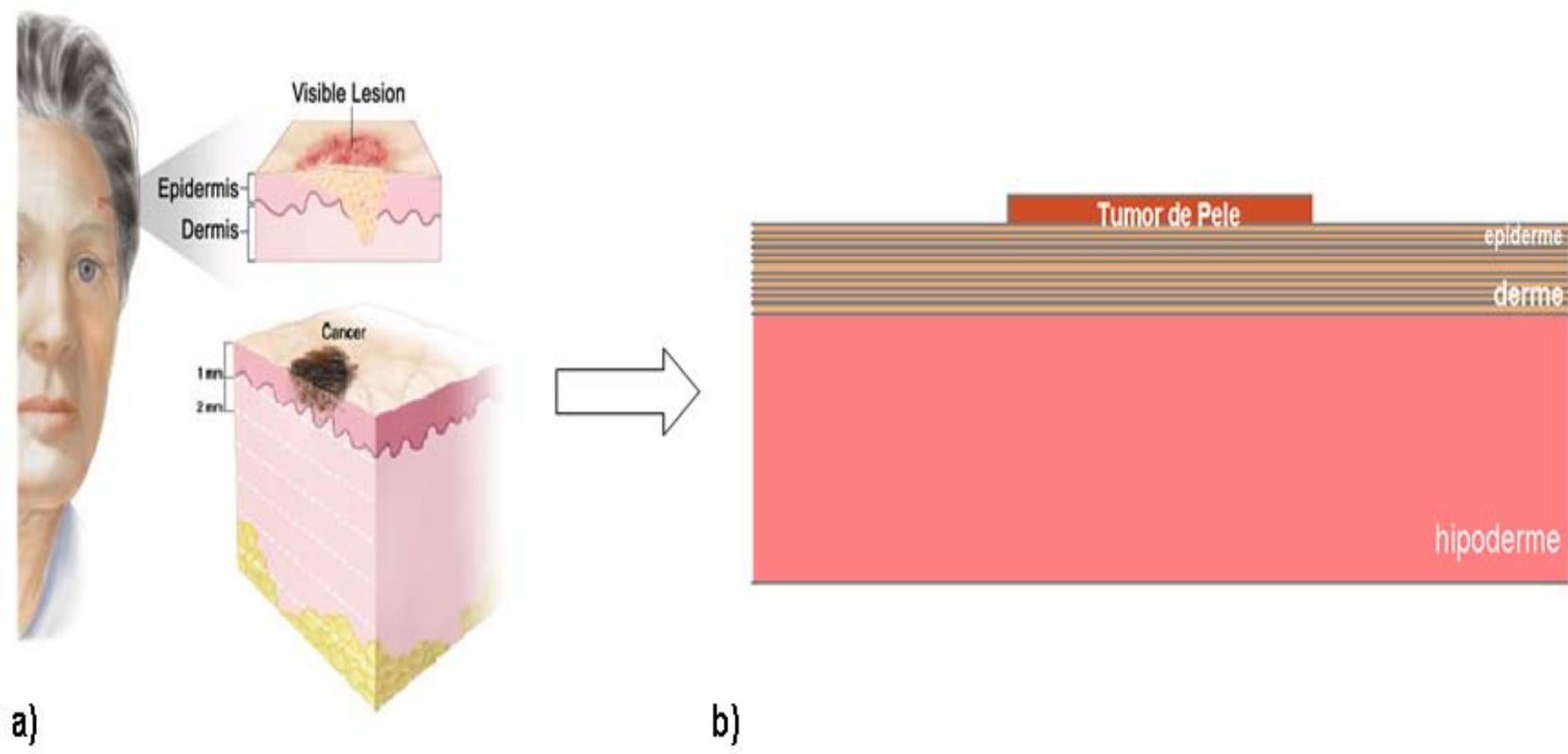

Figura 4.24: a) Desenho ilustrativo de uma lesão de pele, b) Geometria do tumor de pele no MCNP4C. 


\section{Capítulo 5}

\section{RESULTADOS E DISCUSSÕES}

Este capítulo apresenta os resultados e as discussões das medidas experimentais e dos cálculos obtidos pelo código MCNP4C, descritos no capítulo anterior, assim como, a comparação dosimétrica entre as fontes de radiação e as simulações dos casos clínicos.

\subsection{Reconstruções dos Espectros Energéticos e Espaciais com o MCNP4C para os Feixes de Elétrons de $4 \mathrm{MeV}$ e $9 \mathrm{MeV}$}

Através das curvas de PDP obtidas experimentalmente determinou-se as regiões de doses máximas. Para o feixe de $4 \mathrm{MeV}$ a região de dose máxima foi localizada a 0,75 $\mathrm{cm}$ de profundidade, figura 5.1a, e para o feixe de $9 \mathrm{MeV}$ foi localizada a 2,10 $\mathrm{cm}$ de profundidade, figura 5.1b.

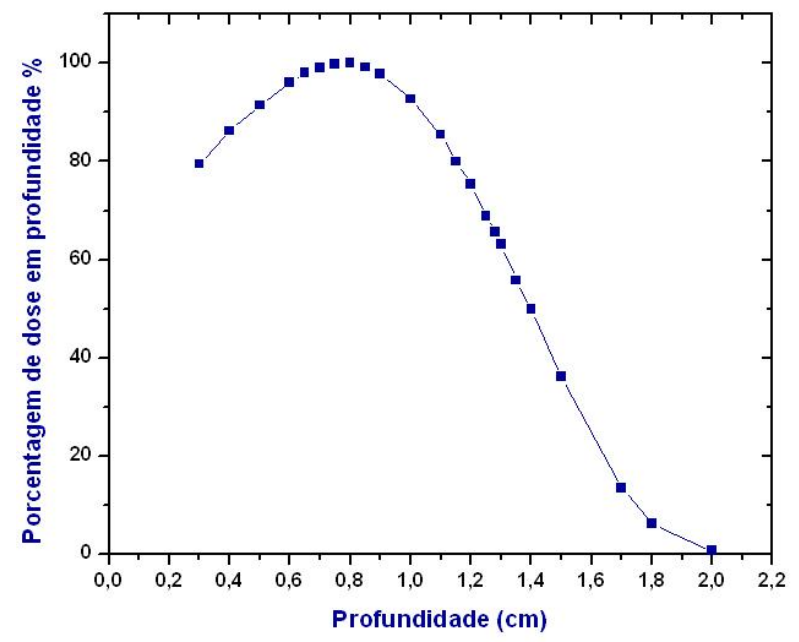

a)

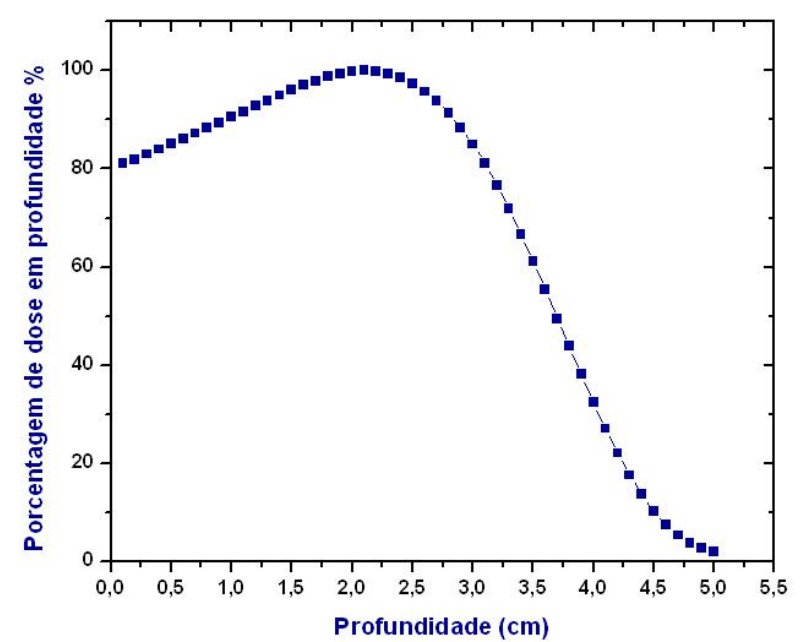

b)

Figura 5.1: Curvas de PDPs a) $4 \mathrm{MeV}$, b) $9 \mathrm{MeV}$. 


\subsubsection{Reconstrução do Espectro: Parte Axial}

Após o levantamento das PDPs foi possível realizar as reconstruções dos espectros com o MCNP4C.

O espectro simulado de $4 \mathrm{MeV}$ apresentou uma distribuição energética entre 0 a 4,2 $\mathrm{MeV}$, dividido em regiões com diferentes intensidades, como mostra figura 5.2. Já o espectro simulado de $9 \mathrm{MeV}$, pode ser observado na figura 5.3, apresentou uma distribuição entre 0 a $9,8 \mathrm{MeV}$.

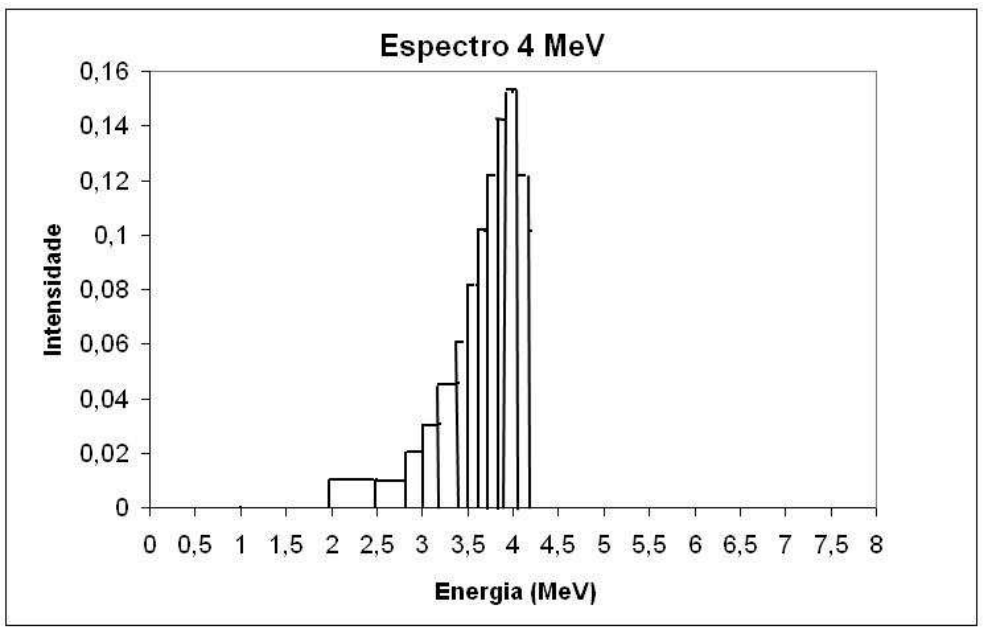

Figura 5.2: Espectro reconstruído do feixe clínico de elétrons de $4 \mathrm{MeV}$ no MCNP4C.

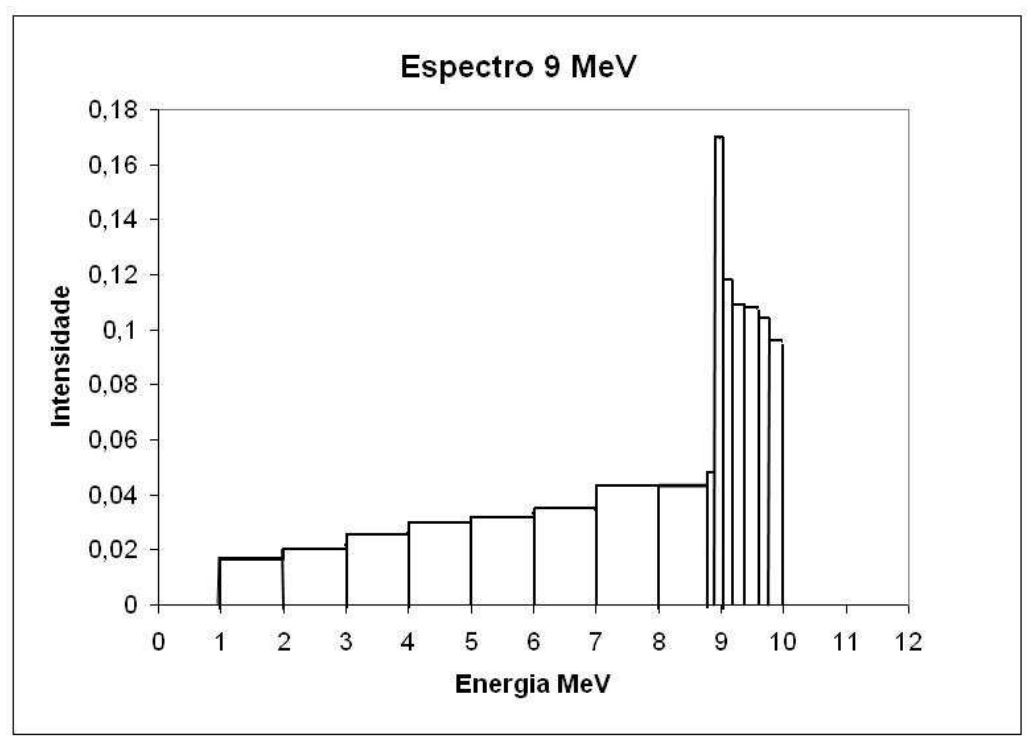

Figura 5.3: Espectro reconstruído do feixe clínico de elétrons de 9 MeV no MCNP4C. 
A figura 5.4a mostra a curva de porcentagem de dose profunda obtida experimentalmente com feixe de elétrons de $4 \mathrm{MeV}$ e a comparação com a curva obtida após a reconstrução do espectro energético obtida através das simulações no MCNP4C. A figura 5.4b mostra a diferença percentual (erro\%) entre a curva de PDP obtida experimentalmente versus simulada para energia de $4 \mathrm{MeV}$. Na figura 5.4a observa-se que as duas curvas apresentam o mesmo comportamento.

A incerteza da curva experimental é estimada em $2 \%$ em todos os pontos. Já as incertezas das simulações no MCNP variam para cada ponto, sendo que nos pontos mais profundos a incerteza é maior, e nos pontos menos profundos a incerteza é menor que $1 \%$. Na figura 5.4b observa-se que a diferença percentual entre o simulado e o experimental aumenta nos pontos mais profundos. Há uma diferença percentual maior para profundidades maiores ou iguais a $1,50 \mathrm{~cm}$, entretanto, para essas profundidades a dose já é menor que $30 \%$ da dose máxima.

O gráfico da diferença percentual mostra o quanto quantitativamente a incerteza estimada é satisfatória, pois mais de dois terços dos dados estão dentro da incerteza estimada.

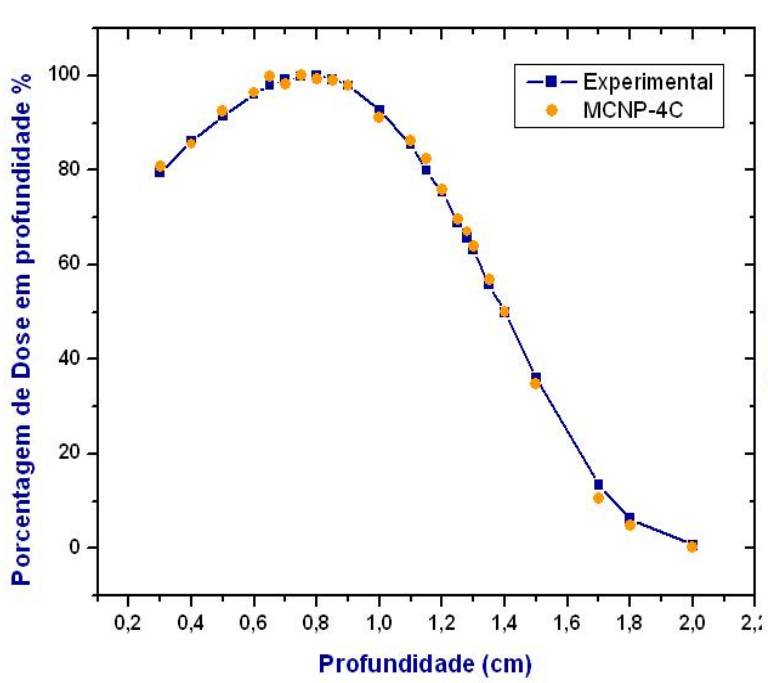

a)

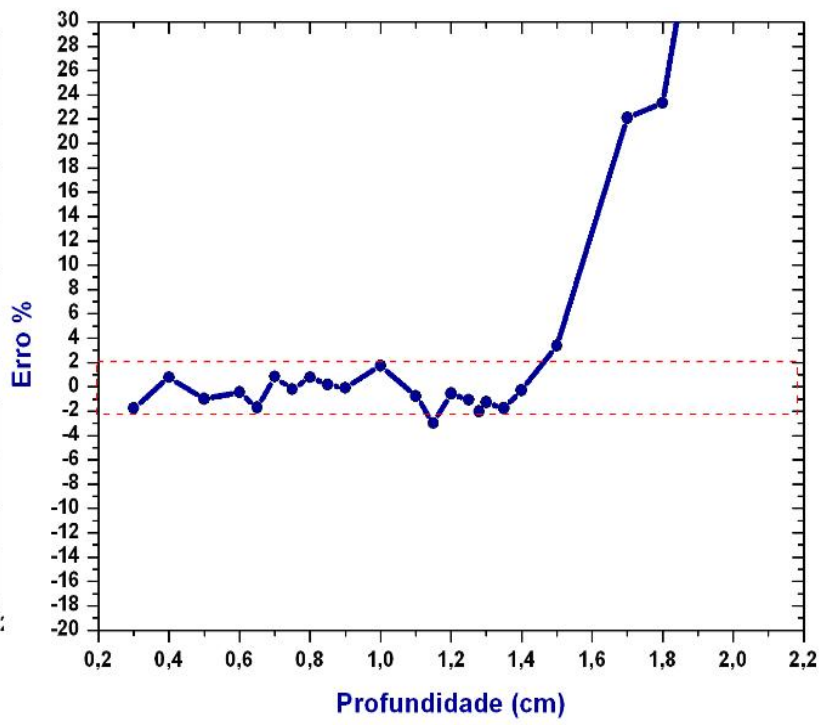

b)

Figura 5.4: a) Comparação entre PDP obtida com a câmara de ionização e a simulada com espectro energético reconstruído para energia de $4 \mathrm{MeV}$, b) Diferença percentual entre a curva de PDP obtida experimentalmente e simulada no MCNP4C para energia de $4 \mathrm{MeV}$ 
Já para uma análise comparativa entre o espectro de energia de $9 \mathrm{MeV}$ experimental e o reconstruído pode-se notar, na figura 5.5a, também que as duas curvas apresentam os mesmo comportamento.

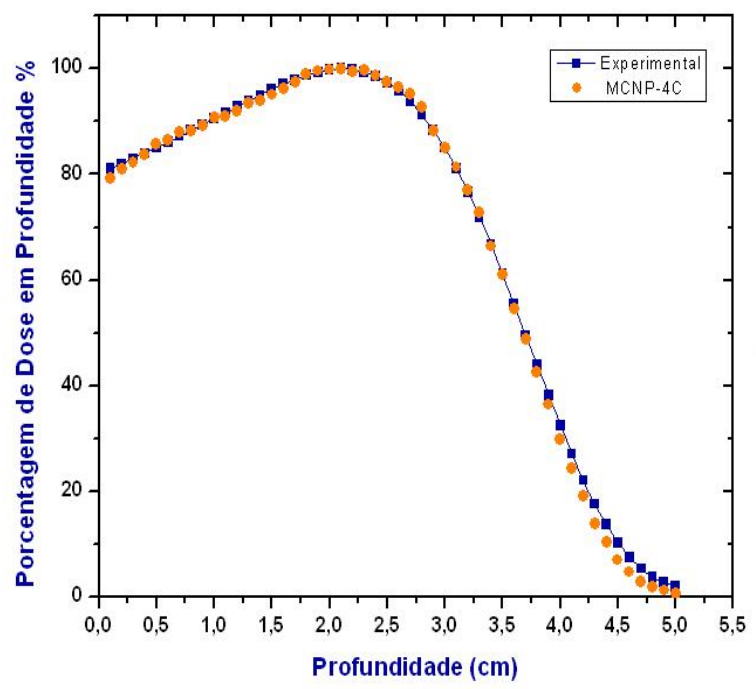

a)

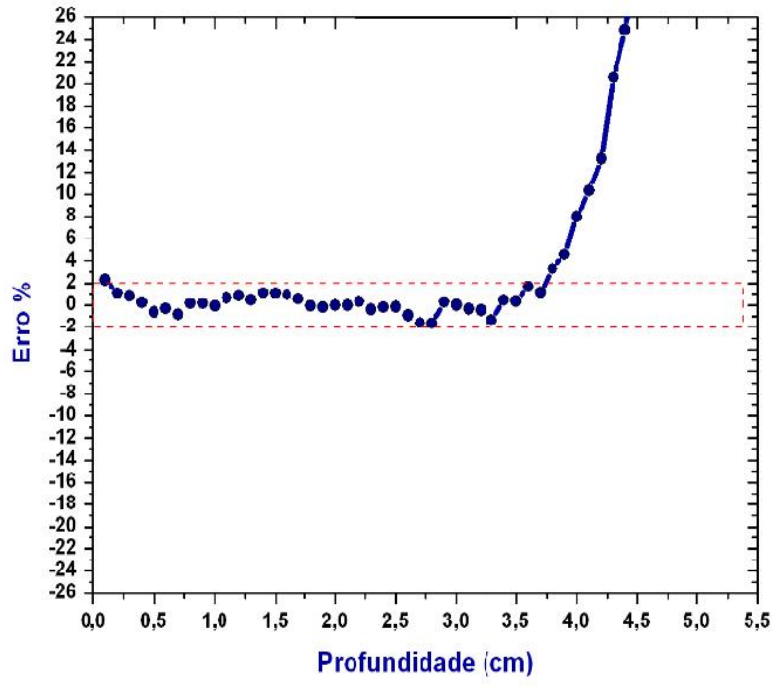

b)

Figura 5.5: a) Comparação entre PDP obtida com a câmara de ionização e a simulada com espectro energético reconstruído para energia de $9 \mathrm{MeV}$; b) Diferença percentual entre a curva de PDP obtida experimentalmente e simulada no MCNP4C para energia de $9 \mathrm{MeV}$.

As incertezas experimentais são as mesmas com o experimento de $4 \mathrm{MeV}$, ou seja, $2 \%$. Ao analisar o gráfico da diferença percentual, figura 5.5b, nota-se que a diferença percentual entre o valor observado experimentalmente e o valor simulado está dentro de $1 \%$ na maioria dos pontos. A partir da profundidade de $4,2 \mathrm{~cm}$, que é a profundidade do alcance prático do feixe de elétrons de $9 \mathrm{MeV}$, a diferença percentual aumenta crescentemente. Porém, a partir dessa profundidade, já não faz parte da região de interesse.

Pode-se notar através das figuras 5.4a e 5.5a uma excelente concordância dos resultados, mostrando que os espectros energéticos de fonte foram adequadamente reconstruídos para a parte axial da distribuição.

Se considerarmos o feixe monoenergético para simulação no MCNP pode-se ter uma diferença acima de $11 \%$ entre experimental e simulado para o feixe de elétrons de $9 \mathrm{MeV}$ como mostrado na figura 5.6. Com a técnica de reconstrução do espectro temos uma diferença percentual máxima de $2 \%$. 


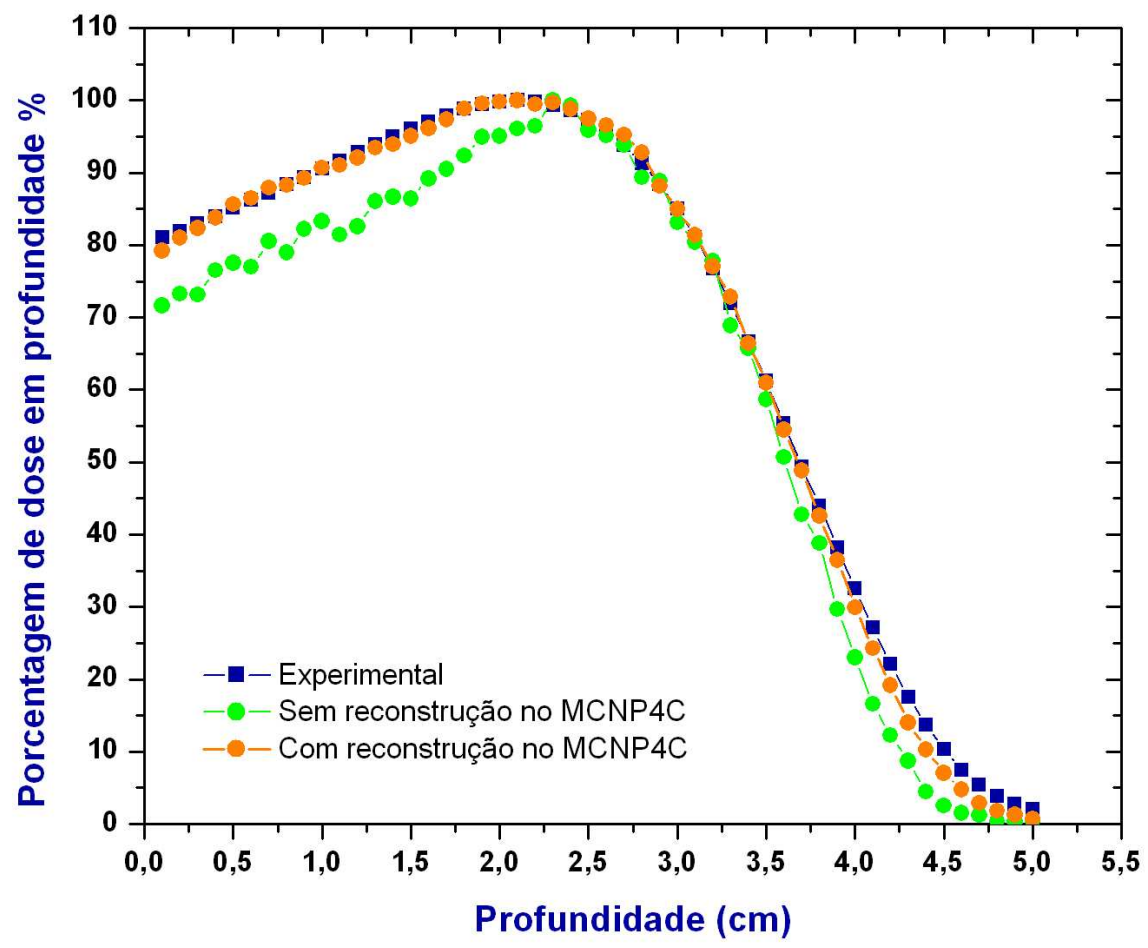

Figura 5.6: PDP $9 \mathrm{MeV}$ - Curva de PDP experimental versus PDP considerando o feixe monoenergético versus PDP com espetro energético reconstruído no MCNP.

\subsubsection{Reconstrução do Espectro: Parte Radial}

As reconstruções das distribuições espaciais dos feixes de $4 \mathrm{MeV}$ e $9 \mathrm{MeV}$ no MCNP, foram obtidas a partir das medidas experimentais radiais dos feixes.

Para caracterização da parte radial dos feixes de $4 \mathrm{MeV}$ e $9 \mathrm{MeV}$, inicialmente ,utilizouse uma distribuição homogênea em todas as regiõe. Os resultados simulados foram comparados com as medidas experimentais e as subdivisões, assim como suas intensidades, foram ajustadas até que se obtivesse um resultado simulado próximo ao experimental. Dividiu-se o campo de radiação em regiões quadradas, conforme mostra a figura 5.7. Foram considerados 3 regiões que formam quadrados concêntricos. Para cada região foi atribuído peso que representa a intensidade naquela região. O quadrado que corresponde a região da área A1, por exemplo, possui $10 \mathrm{~cm}$ de lado e tem peso de 0,017475 , a área A2 corresponde a região entre A1 e A3, possui peso 0,59417 e assim por diante tal que a soma dos pesos é igual a 1. 


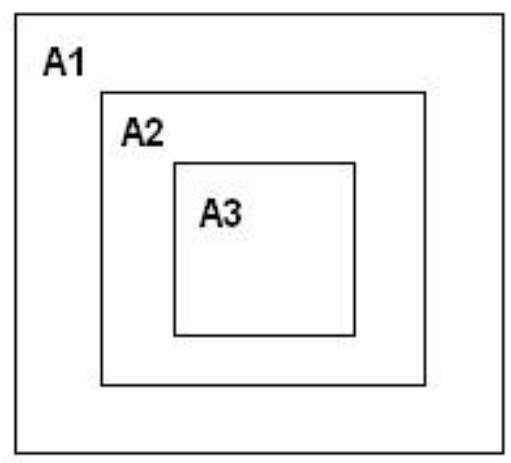

Figura 5.7: Caracterização geométrica do campo de radiação com 3 regiões com pesos distintos

Nas tabelas 5.1 e 5.2 estão apresentados os valores dos pesos atribuídos e as dimensões após algumas simulações no MCNP4C para os feixes de elétrons de $4 \mathrm{MeV}$ e $9 \mathrm{MeV}$ para o tamanho de campo $10 \mathrm{~cm}$ X $10 \mathrm{~cm}$.

Tabela 5.1 - Valores das dimensões de cada região do campo de radiação e os respectivos pesos obtidos pelo MCNP4C para o feixe de $4 \mathrm{MeV}$.

\begin{tabular}{ccc}
\hline \hline Área & Dimensão $(\mathrm{cm})$ & Peso \\
\hline A1 & 10 & 0,017475 \\
A2 & 9 & 0,59417 \\
A3 & 7 & 0,38835 \\
\hline
\end{tabular}

Tabela 5.2 - Valores das dimensões de cada região do campo de radiação e os respectivos pesos obtidos pelo MCNP4C para o feixe de $9 \mathrm{MeV}$.

\begin{tabular}{ccc}
\hline \hline Área & Dimensão $(\mathrm{cm})$ & Peso \\
\hline A1 & 10 & 0,150753 \\
A2 & 9,6 & 0,011725 \\
A3 & 9 & 0,837520 \\
\hline
\end{tabular}

Nas figuras 5.8 e 5.9, estão mostrados os perfis radiais reconstruídos para energias de 4 $\mathrm{MeV}$ e $9 \mathrm{MeV}$ nas profundidades de dose máxima de cada feixe e os perfis experimentais. 


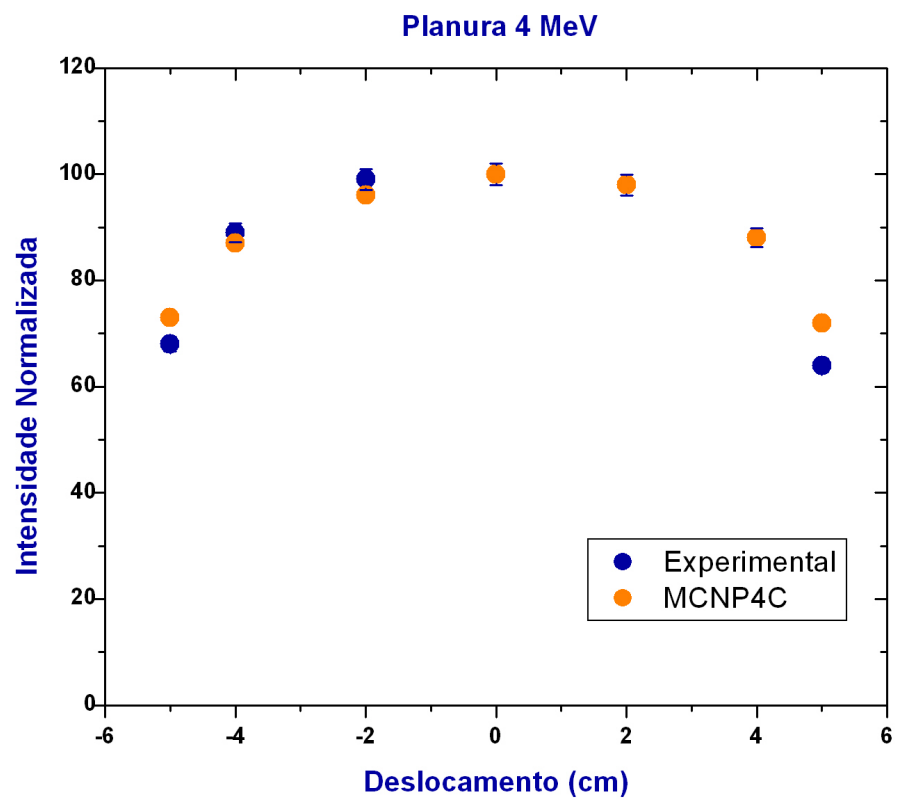

Figura 5.8: Curvas da planura obtida experimentalmente e reconstruída com MCNP do feixe $4 \mathrm{MeV}$ na profundidade de dose máxima do feixe.

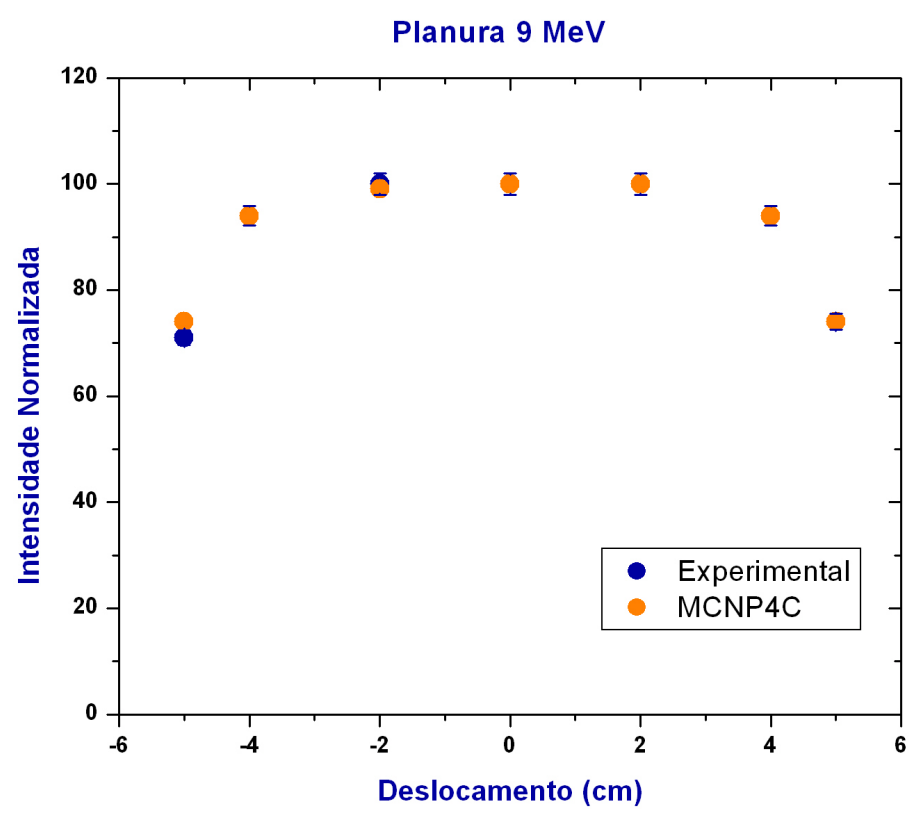

Figura 5.9: Curvas da planura obtida experimentalmente e reconstruída com MCNP4C do feixe $9 \mathrm{MeV}$ na profundidade de dose máxima do feixe. 
Observa-se que os perfis radiais simulados após reconstruções espaciais aproximam-se dos perfis radiais experimentais demonstrando uma boa concordância entre si. As incertezas das curvas experimentais são estimadas em $2 \%$ em todos os pontos, já as incertezas das simulações no MCNP estão dentro de 1\%. As diferenças percentuais entre as curvas estão ente $0 \%$ e $4 \%$ na maioria dos pontos, nas extremidades dos perfis radiais há uma diferença maior.

\subsection{Resultados dos Experimentos e Cálculos com o MCNP4C do Perfil Axial de Dose dos Feixes de Elétrons em Função de Atenuadores}

\subsubsection{Resultados para Feixe de Elétrons $4 \mathrm{MeV}$.}

A figura 5.10 mostra a comparação entre a curva de perfil de distribuição de dose com bólus obtida com câmara de ionização e o cálculo baseado no método de Monte Carlo para energia de $4 \mathrm{MeV}$ em função de atenuadores. Para os dois primeiros pontos, o resultado calculado no Monte Carlo mostrou uma diferença de 0,5\% do valor experimental, para os demais pontos a diferença entre os resultados experimentais e os resultados simulados, estão entre $1 \%$ e $4 \%$. As incertezas estatísticas para os cálculos com MCNP4C, considerando 20 milhões de partículas, estão em torno de $0,5 \%$.

Os resultados da simulação foram satisfatórios, pois apresentaram boa concordância em relação ao comportamento da curva experimental e as incertezas estão dentro da faixa exigidas pelo TEC DOC 1151. ${ }^{1}$. Com o objetivo de comparar a curva de perfil de atenuação de dose com diferentes detectores, o mesmo experimento foi realizado utilizando dosímetros termoluminescente. As curvas apresentadas na figura 5.11 permite comparar os resultados obtidos com os dosímetros termoluminescentes TLD LiF-100 e os resultados obtidos com a câmara de ionização.

A figura 5.11 mostra uma boa concordância entre as curvas, pois todas apresentam o mesmo comportamento. Os desvios padrões de cada ponto das curvas levantada com os TLDs, foram obtido por uma média de leitura de 9 TLDs. O maior desvio observado foi de $5 \%$.

\footnotetext{
${ }^{1}$ Protocolo de controle da qualidade -Aspectos físicos da garantia da qualidade da Radioterapia
} 


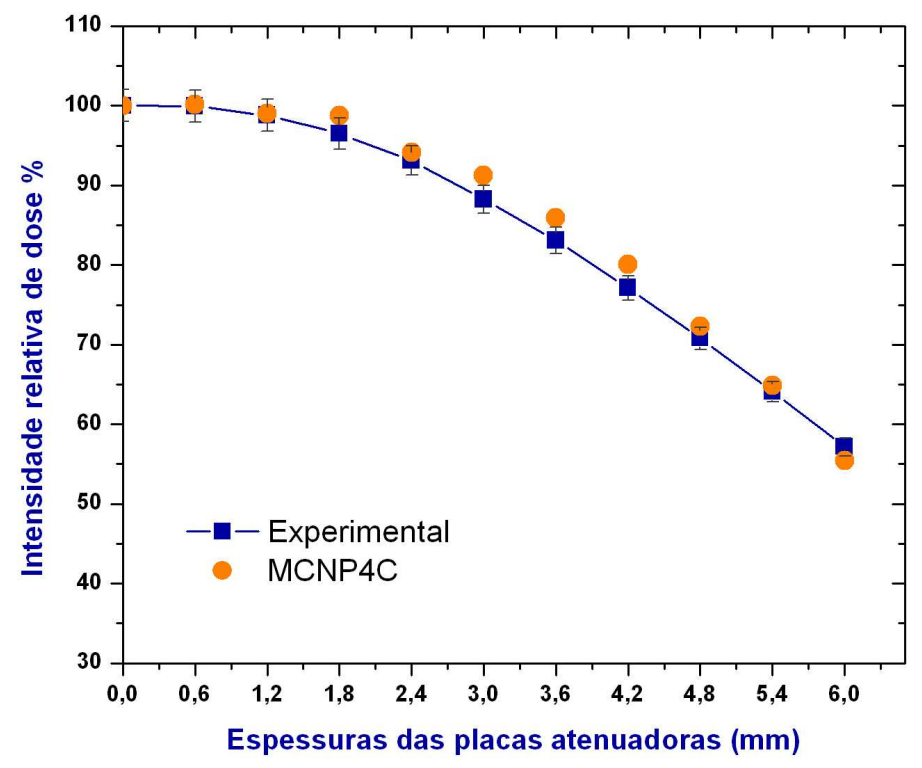

Figura 5.10: Intensidade de dose relativa obtida com câmara de ionização em função das espessuras de placas atenuadoras para o feixe de elétrons de $4 \mathrm{MeV}$.

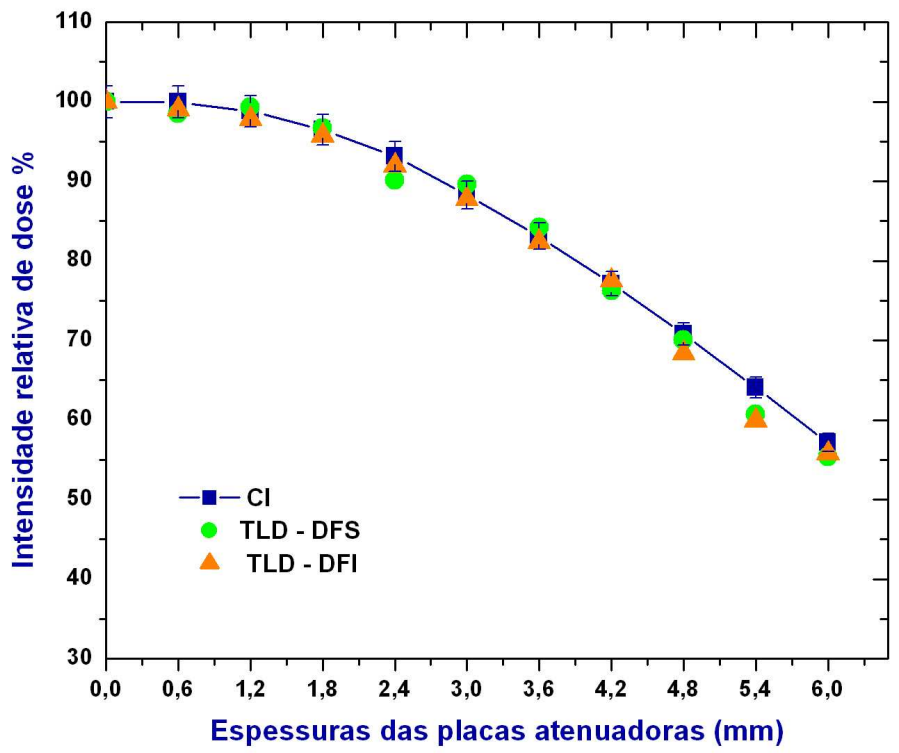

Figura 5.11: Intensidade de dose relativa obtida com câmara de ionização e TLD em função das espessuras de placas atenuadoras para o feixe de elétrons de $4 \mathrm{MeV}$ 
As diferenças percentuais nas medidas de dose com TLDs em comparação com a câmara de ionização não passaram de $2 \%$ até a profundidade de $1,78 \mathrm{~cm}$ nas demais profundidades a diferença máxima não ultrapassa 5\%. As curvas obtidas com tipos de detectores diferentes apresentaram o mesmo comportamento. Os resultados mostraram que é possível obter medidas experimentais usando TLDs com precisão entre $0,5 \%$ e $5 \%$.

\subsubsection{Resultados para o Feixe de Elétrons de $9 \mathrm{MeV}$.}

A figura 5.12 apresenta as curvas de distribuição de dose axial com bólus obtida com câmara de ionização e com o cálculo baseado no método de Monte Carlo para energia de $9 \mathrm{MeV}$ em função de placas atenuadoras.

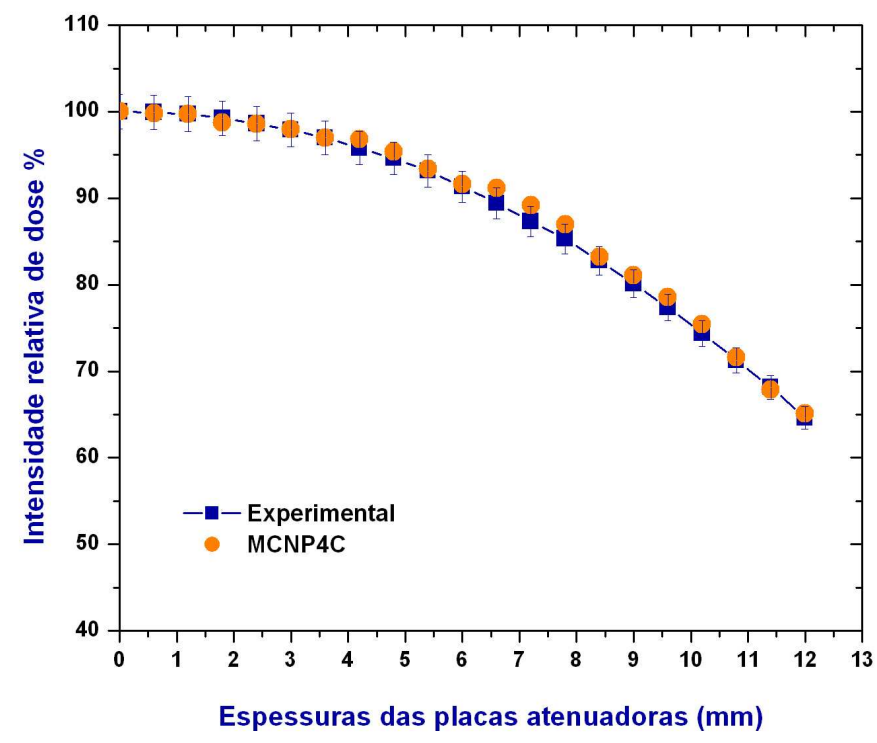

Figura 5.12: Intensidade de dose relativa obtida com câmara de ionização em função das espessuras de placas atenuadoras para o feixe de elétrons de $9 \mathrm{MeV}$

A diferença máxima percentual entre as medidas experimentais e os valores simulados, é de $2 \%$. As incertezas estatísticas para os cálculos com MCNP4C considerando o número de 20 milhões partículas estão em torno de 0,5\% e as incertezas das medidas experimentais estão estimadas em $2 \%$. As comparações entre as curvas apresentaram uma boa concordância entre si. 


\subsection{Resultados dos Experimentos e Cálculos com o MCNP4C do Perfil Radial de Dose (planura) dos Feixes de Elétrons em Função de Atenuadores}

Os resultados das medidas experimentais referentes as planuras de $4 \mathrm{MeV}$ e $9 \mathrm{MeV}$ em função de atenuadores podem ser observados através dos gráficos mostrados nas figuras 5.13 e 5.14 .

Os gráficos 5.13 e 5.14 demonstram-se coerentes em termos de atenuação (quantidade de placas) e em termos dos perfis radiais com a prática clínica. Observa-se também que as planuras estão dentro da tolerância de $3 \%$ conforme estabelicidas pelo protocolo (TEC DOC 1151). As profundidades $0 \mathrm{~mm}, 1,2 \mathrm{~mm}, 3 \mathrm{~mm}$ e $6 \mathrm{~mm}$ das planuras de $4 \mathrm{MeV}$ refere respectivamente a 100\%,71\%,31\% e 2\% da dose. As profundidades $0 \mathrm{~mm}, 3 \mathrm{~mm}, 6 \mathrm{~mm}$ e $9 \mathrm{~mm}$ das planuras de $9 \mathrm{MeV}$ refere respectivamente a 100\%, 92\%, $80 \%$ e $63 \%$ da dose.

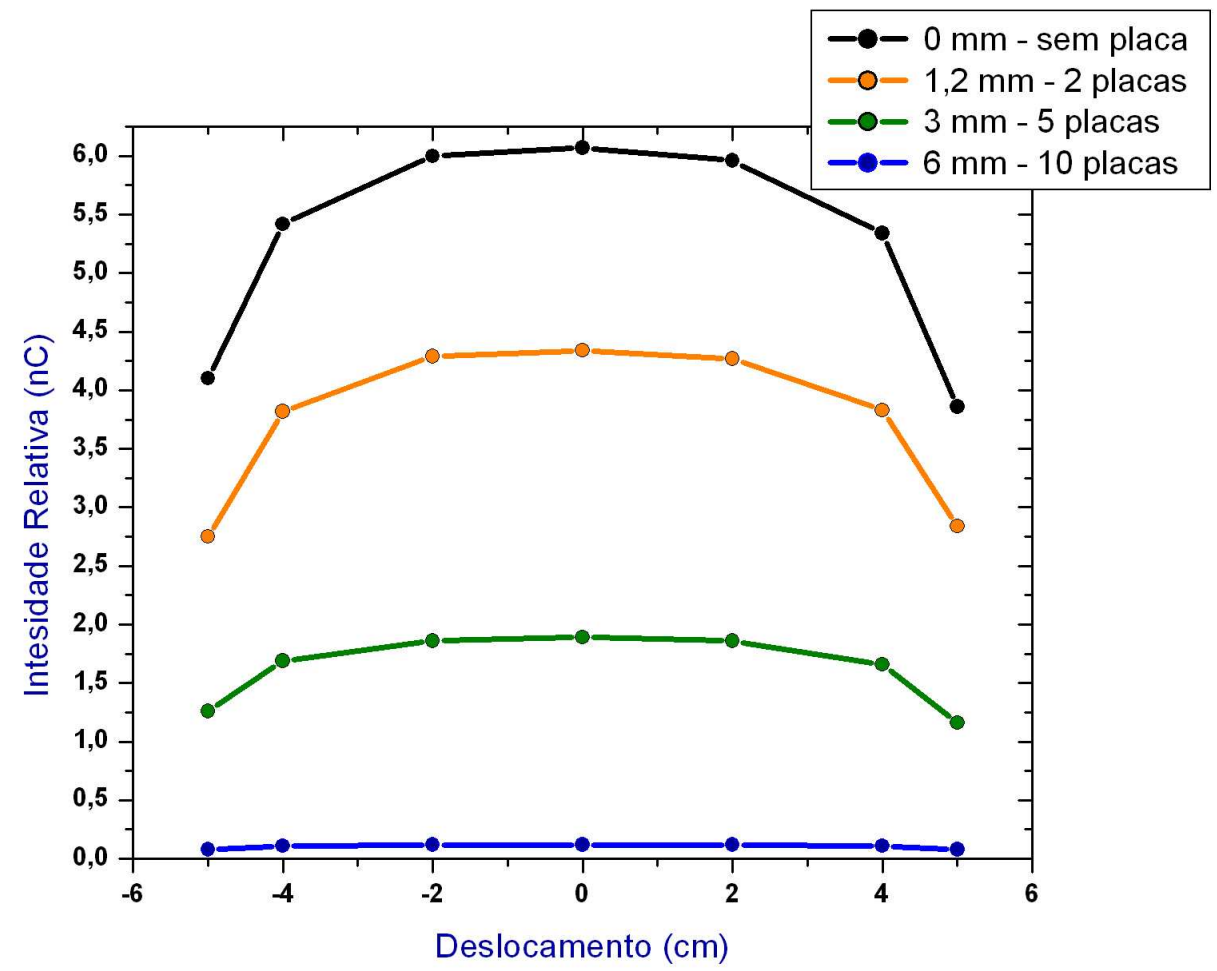

Figura 5.13: Medidas experimentais da planura do campo $10 \mathrm{~cm} \mathrm{X} 10 \mathrm{~cm}$ do feixe de $4 \mathrm{MeV}$ em 4 profundidades. 


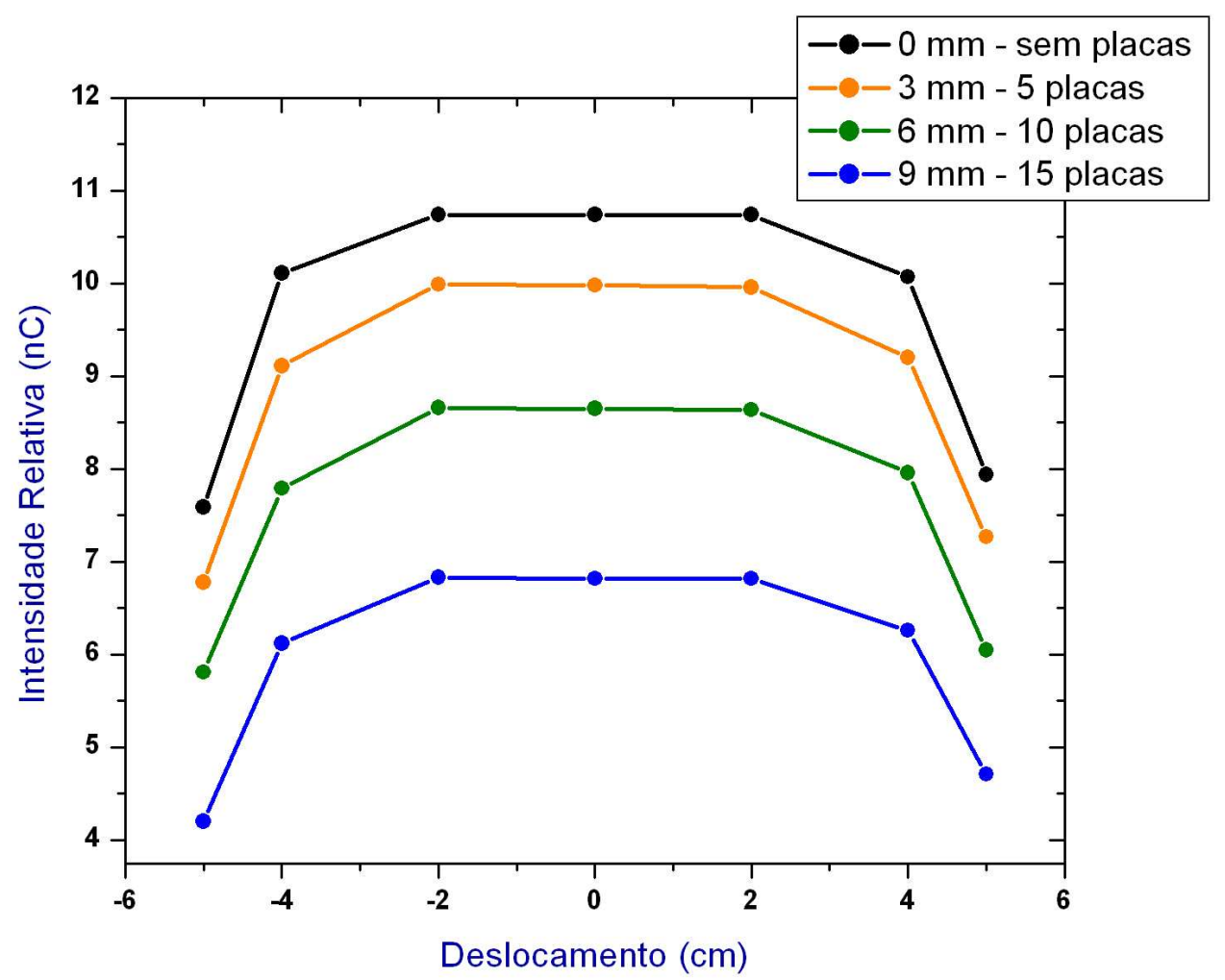

Figura 5.14: Medidas experimentais da planura do campo $10 \mathrm{~cm} \mathrm{X} 10 \mathrm{~cm}$ do feixe de $9 \mathrm{MeV}$ em 4 profundidades.

\subsubsection{Resultados das Planuras do Feixe de Elétrons de $4 \mathrm{MeV}$.}

As comparações dos resultados entre a planura do feixe de $4 \mathrm{MeV}$ obtida experimentalmente e através da simulação MCNP-4C estão apresentados nas figuras 5.15 e 5.16. Somente duas profundidades foram simuladas no MCNP4C com base na região de interesse, pois como citado no item anterior a profundidade $0 \mathrm{~mm}$ (sem placa) se refere a 100\% e a profundidade $1,2 \mathrm{~mm}$ se refere a $71 \%$ da dose.

Os gráficos das figuras 5.15 e 5.16 dão uma ilustração do comportamento das duas curvas.

A incerteza da medida experimental é estimada em $2 \%$, já as incertezas estimadas no MCNP4C para 20 milhões de histórias varia para cada ponto, mas a incerteza máxima é inferior a $2 \%$. Esse número de partículas foi o suficiente para garantir uma boa estatística do método.

As diferenças percentuais das planuras nas profundidades $0 \mathrm{~mm}$ e $1,2 \mathrm{~mm}$ podem ser 


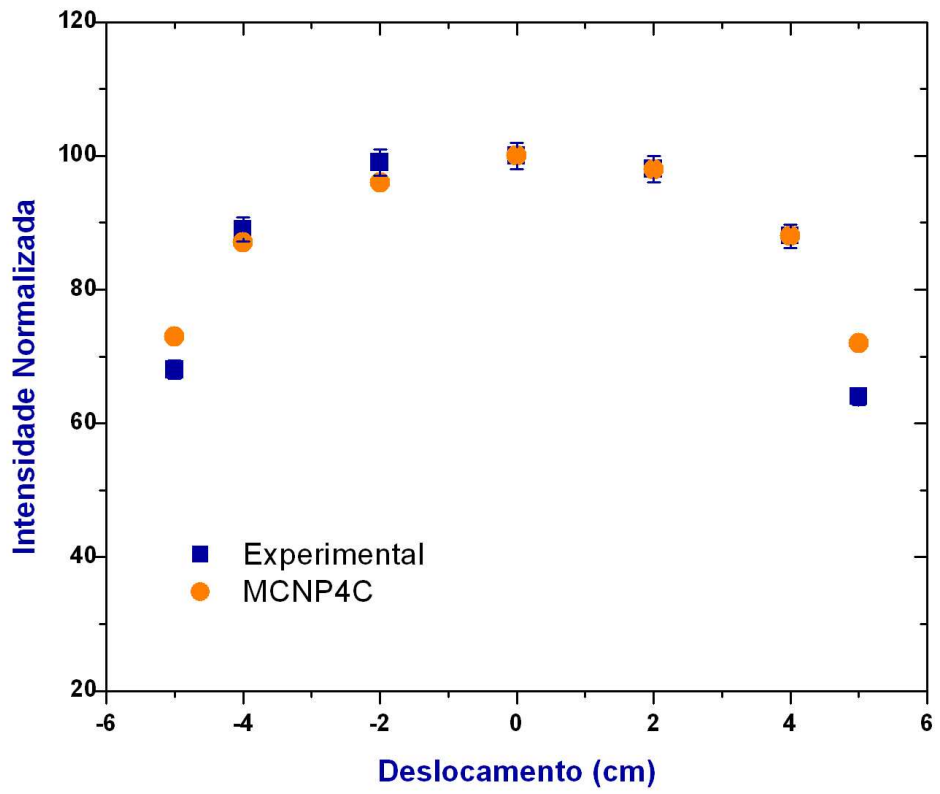

Figura 5.15: Planura do feixe de $4 \mathrm{MeV}$ na profundidade de $0 \mathrm{~mm}$ sem placas atenuadoras.

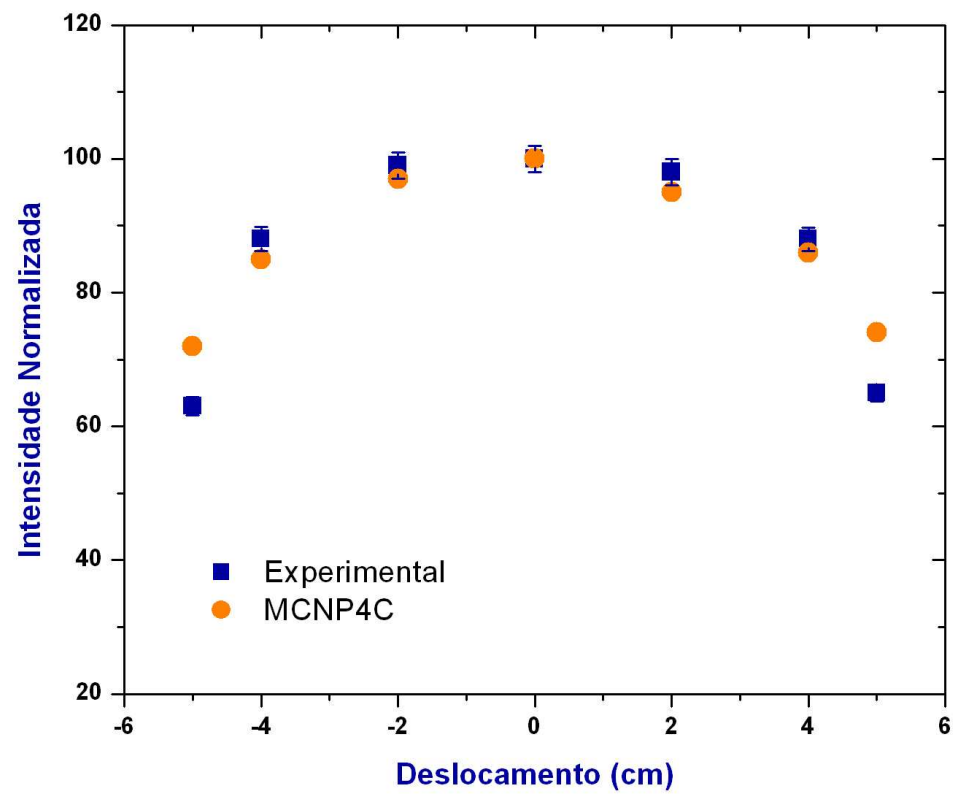

Figura 5.16: Planura do feixe de $4 \mathrm{MeV}$ na profundidade de $1,2 \mathrm{~mm}$ referente à 2 placas atenuadoras. 
observadas, respectivamente, nas tabelas 5.3 e 5.4 para cada deslocamento.

Tabela 5.3 - Dados normalizados obtidos da planura do feixe de $4 \mathrm{MeV}$ e a diferença Percentual para profundidade $0 \mathrm{~mm}$ referente a $100 \%$ de dose relativa.

\begin{tabular}{cccccccccc}
\hline \hline & & & & & & \\
& Esquerda & \multicolumn{3}{c}{ Centro } & \multicolumn{3}{c}{ Direita } \\
\hline Deslocamento $(\mathrm{cm})$ & -5 & -4 & -2 & 0 & 2 & 4 & 5 \\
Dados experimentais normalizados & 68 & 89 & 99 & 100 & 98 & 88 & 64 \\
Dados Simulados MCNP-4C normalizados & 73 & 87 & 96 & 100 & 98 & 88 & 72 \\
Diferença \% & -8 & 3 & 3 & 0 & 0 & 0 & -13 \\
\hline
\end{tabular}

Tabela 5.4 - Dados normalizados obtidos da planura do feixe de $4 \mathrm{MeV}$ e a diferença Percentual para profundidade $1,2 \mathrm{~mm}$ referente a $71 \%$ de dose relativa.

\begin{tabular}{cccccccccc}
\hline \hline & & & & & & & \\
& Esquerda & \multicolumn{3}{c}{ Centro } & \multicolumn{3}{c}{ Direita } \\
\hline Deslocamento (cm) & -5 & -4 & -2 & 0 & 2 & 4 & 5 \\
Dados experimentais normalizados & 63 & 88 & 99 & 100 & 98 & 88 & 65 \\
Dados Simulados MCNP-4C normalizados & 72 & 85 & 97 & 100 & 95 & 86 & 74 \\
Diferença \% & -14 & 4 & 2 & 0 & 4 & 3 & -13 \\
\hline
\end{tabular}

O aumento da diferença percentual nas extremidades do campo pode estar associado com a configuração experimental utilizada e também com a reconstrução espacial no MCNP que pode ser melhorada.

\subsubsection{Resultados das Planuras do Feixe de Elétrons de $9 \mathrm{MeV}$.}

As comparações dos resultados entre a planura do feixe de $9 \mathrm{MeV}$ obtida experimentalmente e através da simulação MCNP4C estão apresentados nas figuras 5.17; 5.18; 5.19 e 5.20 . 


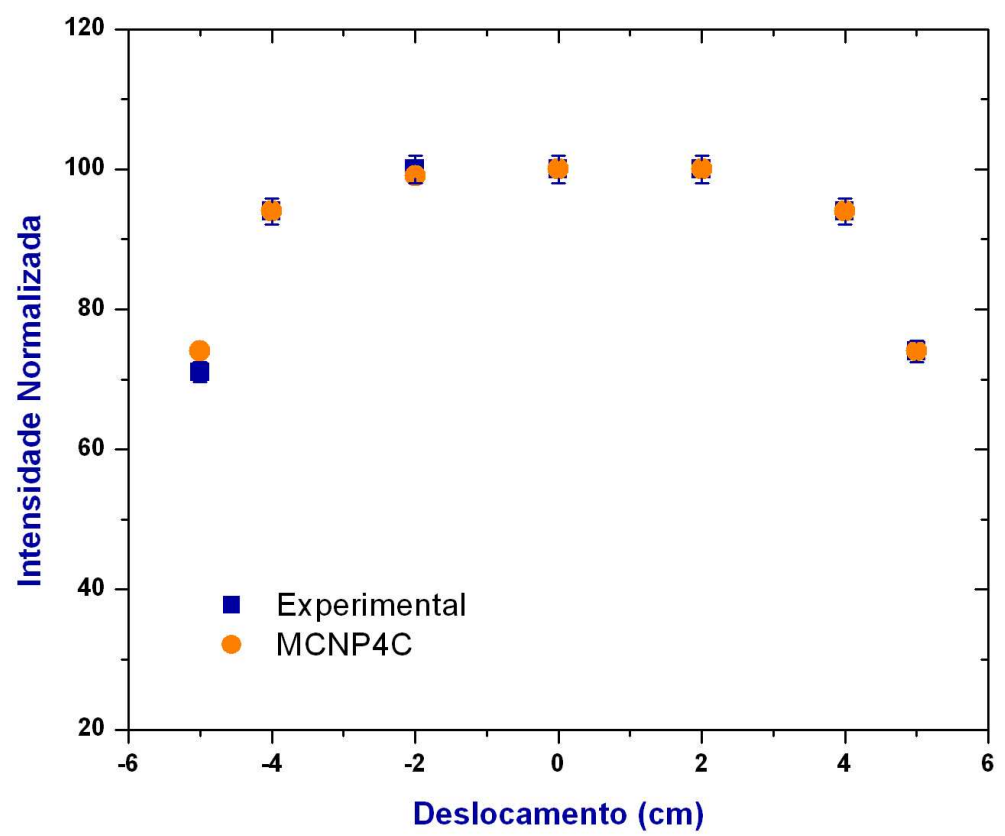

Figura 5.17: Planura do feixe de $9 \mathrm{MeV}$ na profundidade de $0 \mathrm{~mm}$ sem placas atenuadoras.

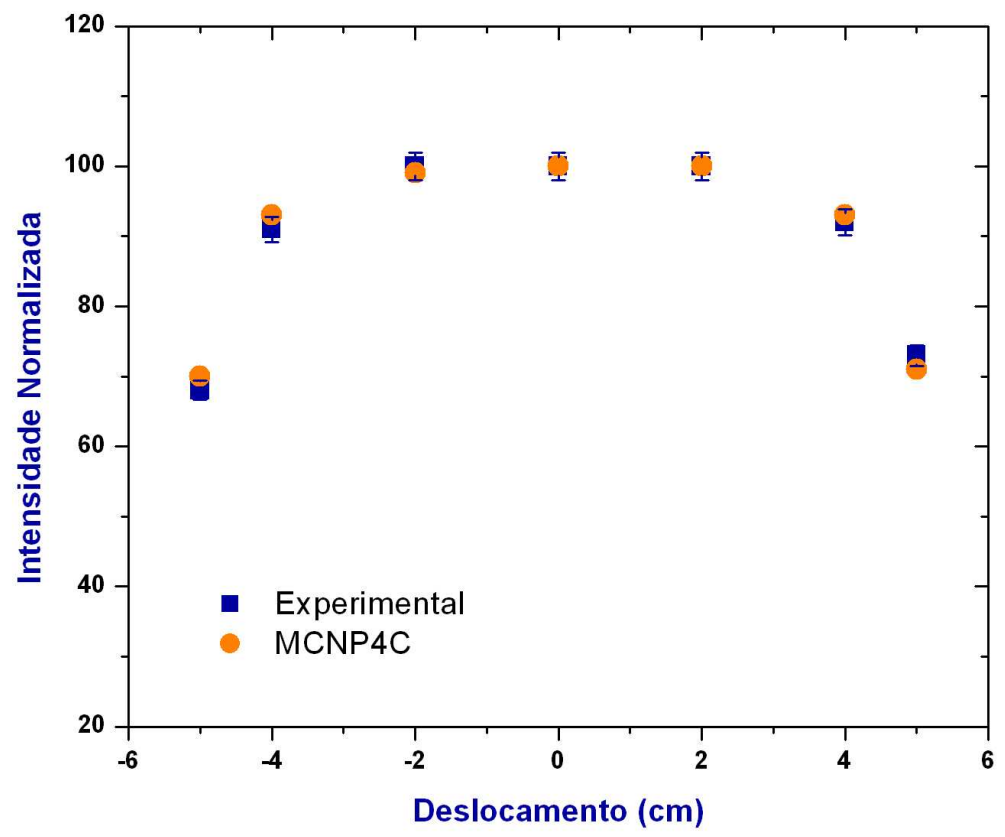

Figura 5.18: Planura do feixe de $9 \mathrm{MeV}$ na profundidade de $3 \mathrm{~mm}$ referente à 5 placas atenuadoras. 


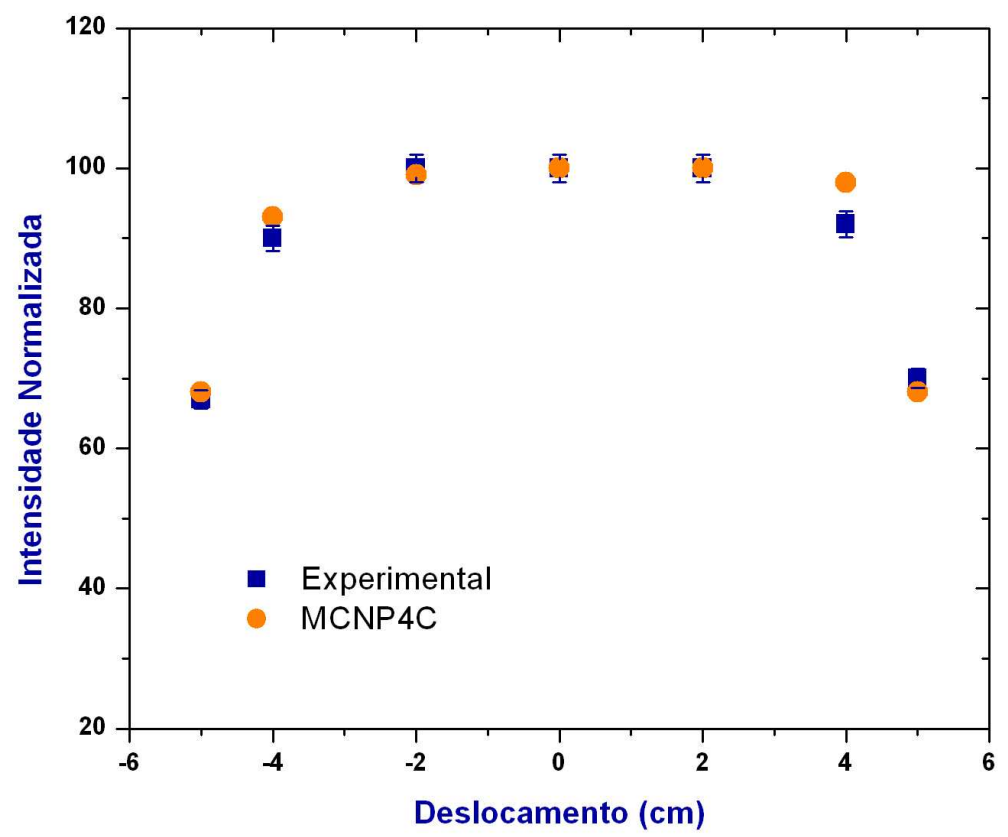

Figura 5.19: Planura do feixe de $9 \mathrm{MeV}$ na profundidade de $6 \mathrm{~mm}$ referente à 10 placas atenuadoras.

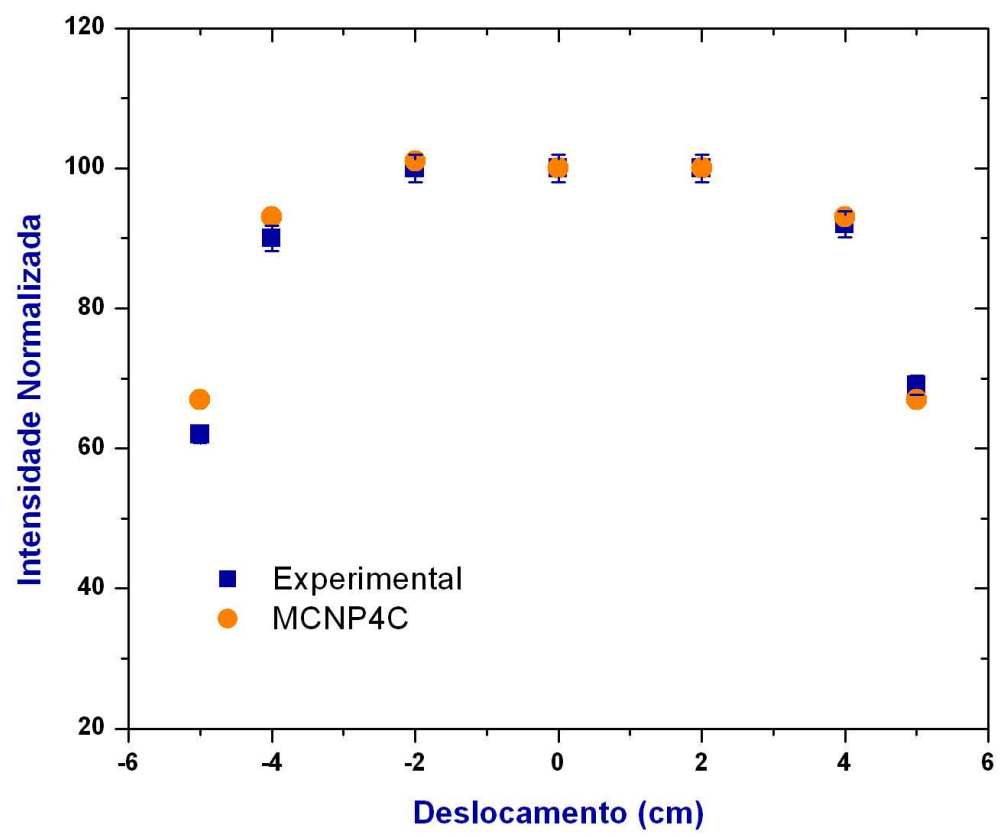

Figura 5.20: Planura do feixe de $9 \mathrm{MeV}$ na profundidade de $9 \mathrm{~mm}$ referente à 15 placas atenuadoras. 
Pelos resultados obtidos observa-se que as incertezas estimadas para as medidas experimentais e para os cálculos no MCNP4C são similares as incertezas dos resultados da planura de $4 \mathrm{MeV}$. A diferença percentual entre o simulado e o experimental nas extremidades da planura de $9 \mathrm{MeV}$ não são superiores a $8 \%$.

Nas tabelas 5.5, 5.6, 5.7 e 5.8 podem ser observados as diferenças percentuais em cada ponto em diferentes profundidades. As incertezas para cada ponto no MCNP4C são inferiores $1 \%$ para 50 milhões histórias.

Tabela 5.5 - Dados normalizados obtidos da planura do feixe de $9 \mathrm{MeV}$ e a diferença percentual para profundidade $0 \mathrm{~mm}$ referente a $100 \%$ de dose relativa.

\begin{tabular}{cccccccccc}
\hline \hline & & & & & & \\
& Esquerda & & Centro & & \multicolumn{2}{c}{ Direita } \\
\hline Deslocamento $(\mathrm{cm})$ & -5 & -4 & -2 & 0 & 2 & 4 & 5 \\
Dados experimentais normalizados & 71 & 94 & 100 & 100 & 100 & 94 & 74 \\
Dados Simulados MCNP4C normalizados & 74 & 94 & 99 & 100 & 100 & 94 & 74 \\
Diferença \% & -4 & 0 & 1 & 0 & 0 & 0 & 0 \\
\hline
\end{tabular}

Tabela 5.6 - Dados normalizados obtidos da planura do feixe de $9 \mathrm{MeV}$ e a diferença percentual para profundidade $3 \mathrm{~mm}$ referente a $92 \%$ de dose relativa.

\begin{tabular}{cccccccccc}
\hline \hline & & & & & & \\
& Esquerda & & Centro & & \multicolumn{2}{c}{ Direita } \\
\hline Deslocamento $(\mathrm{cm})$ & -5 & -4 & -2 & 0 & 2 & 4 & 5 \\
Dados experimentais normalizados & 68 & 91 & 100 & 100 & 100 & 92 & 73 \\
Dados Simulados MCNP4C normalizados & 70 & 93 & 99 & 100 & 100 & 93 & 71 \\
Diferença \% & -3 & 2 & 1 & 0 & 0 & -1 & 3 \\
\hline
\end{tabular}


Tabela 5.7 - Dados normalizados obtidos da planura do feixe de $9 \mathrm{MeV}$ e a diferença percentual para profundidade $6 \mathrm{~mm}$ referente a $80 \%$ de dose relativa.

\begin{tabular}{cccccccccc}
\hline \hline & & & & & \\
& Esquerda & & Centro & & \multicolumn{2}{c}{ Direita } \\
\hline Deslocamento $(\mathrm{cm})$ & -5 & -4 & -2 & 0 & 2 & 4 & 5 \\
Dados experimentais normalizados & 67 & 90 & 102 & 100 & 100 & 92 & 70 \\
Dados Simulados MCNP4C normalizados & 68 & 93 & 99 & 100 & 100 & 92 & 68 \\
Diferença \% & -1 & -3 & 3 & 0 & 0 & 0 & -3 \\
\hline
\end{tabular}

Tabela 5.8 - Dados normalizados obtidos da planura do feixe de $9 \mathrm{MeV}$ e a diferença percentual para profundidade $9 \mathrm{~mm}$ referente a $63 \%$ de dose realativa.

\begin{tabular}{ccccccccccc}
\hline \hline & & & & & & & \\
& Esquerda & & Centro & & \multicolumn{2}{c}{ Direita } \\
\hline Deslocamento $(\mathrm{cm})$ & -5 & -4 & -2 & 0 & 2 & 4 & 5 \\
Dados experimentais normalizados & 62 & 90 & 100 & 100 & 100 & 92 & 69 \\
Dados Simulados MCNP4C normalizados & 67 & 93 & 101 & 100 & 100 & 93 & 67 \\
Diferença \% & -8 & -3 & -1 & 0 & 0 & -1 & 3 \\
\hline
\end{tabular}

O aumento da diferença percentual nas extremidades do campo pode estar associado com a configuração experimental utilizada e também com a reconstrução espacial no MCNP que pode ser melhorada.

\subsection{Resultados dos Experimentos e Cálculos com o MCNP4C do Perfil de Dose do Feixe de Raios-X de $90 \mathrm{kVp}$}

O gráfico da figura 5.21 apresenta a atenuação obtida com as placas atenuadoras com o feixe de raios-X de $90 \mathrm{kVp}$. Pode-se observar, através da curva experimental que a $6 \mathrm{~mm}$ temos aproximadamente $90 \%$ de atenuação.

Observa-se também que as curvas se divergem em profundidade, tal divergência pode estar associada com o espectro fornecido. As incertezas para o cálculo com MCNP4C considerando 20 milhões partículas, estão em torno de $0 \%$ a 3\%. As incertezas das medidas experimentais estão estimadas em $1 \%$, e a diferença máxima entre o valor calculado e o experimental é de $3 \%$. Os desvios encontrados são considerados aceitáveis para garantir que 
o Código MCNP4C seja uma ferramenta adequada para o cálculo de perfil de profundidade de dose relativa.

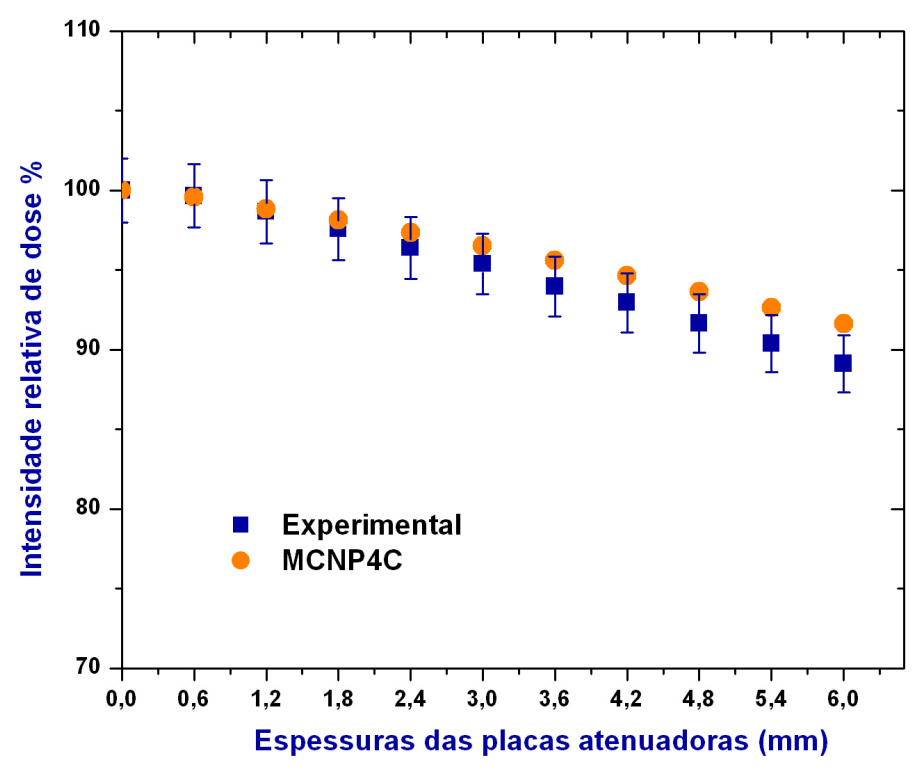

Figura 5.21: Intensidade de dose relativa obtida com câmara de ionização em função das espessuras de placas atenuadoras para o feixe de raios-X de $90 \mathrm{kVp}$.

\subsection{Comparação Dosimétrica entre os Feixe de Elétrons de 4 MeV, Elétrons de $9 \mathrm{MeV}$, Raios-X de $90 \mathrm{kVp}$ e Fonte de ${ }^{90} \boldsymbol{S r}+{ }^{90} \boldsymbol{Y}$.}

Na figura 5.22 pode-se comparar as curvas experimentais obtidas com feixe de elétrons de $4 \mathrm{MeV}, 9 \mathrm{MeV}$ e raios-X de $90 \mathrm{kVp}$ e fonte de ${ }^{90} \mathrm{Sr}+{ }^{90} \mathrm{Y}$ do ponto de vista clínico

A análise dessas curvas do ponto de vista clínico é bastante importante, pois através delas analisam-se quais são os feixes mais apropriados para um determinado tipo de planejamento de radioterapia. É importante ressaltar que, para o levantamento dessas curvas utilizou-se a colocação de bólus para superficializar a dose, afim de obter a dose máxima na pele.

No caso de lesões de pele superficiais, observa-se que todos os feixes conseguem liberar uma boa cobertura de dose na superfície e assegura dose até o fim das lesões nas profundi- 
dades desejadas para lesões de pele (as profundidades dos CBC e CEC normalmente não passam de $5 \mathrm{~mm}$ ). Como os tumores são muito variáveis em suas dimensões (profundidade, tamanho, geometria) é preciso analisar o comportamento de cada feixe e escolher uma energia adequada para cada uma das condições.

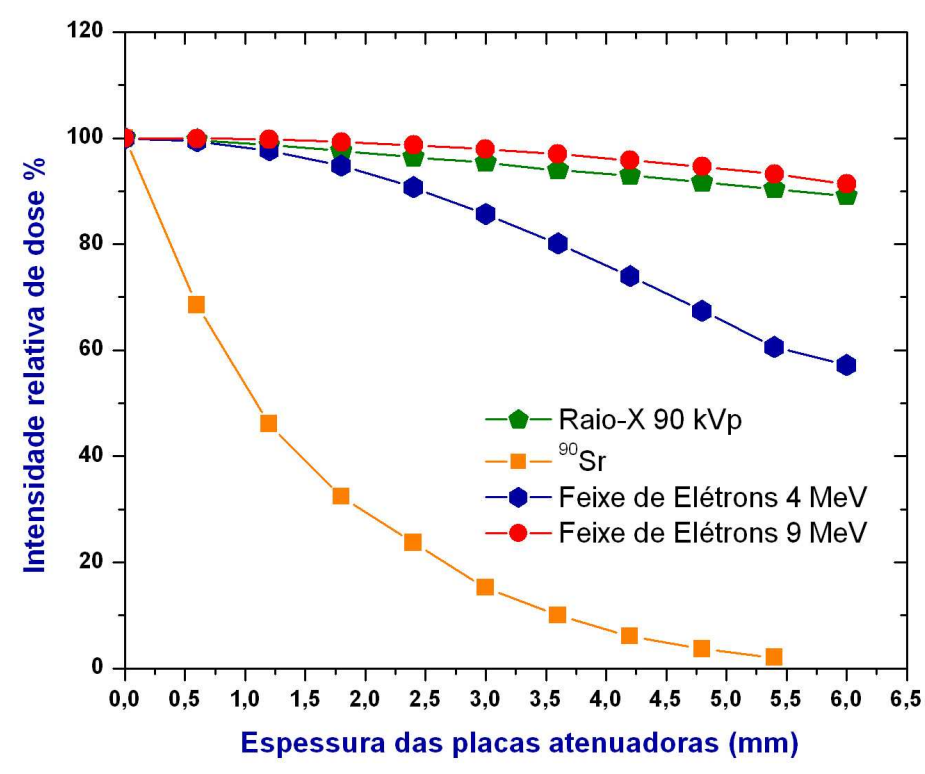

Figura 5.22: Análise dosimétrica entre as curvas experimentais dos feixes de elétrons de 4 $\mathrm{MeV}$ e $9 \mathrm{MeV}$, Raios-X de $90 \mathrm{kVp}$ e fonte de ${ }^{90} \mathrm{Sr}+{ }^{90} \mathrm{Y}$.

Observa-se que o feixe de elétrons, principalmente de $4 \mathrm{MeV}$, têm absorção rápida pelos tecidos, com queda rápida em profundidade, resultando em exposição mínima dos tecidos mais profundos, além da área de interesse. Comparando a curva de ${ }^{90} \mathrm{Sr}+{ }^{90} \mathrm{Y}$ com o feixe de elétrons de $4 \mathrm{MeV}$, que são usualmente utilizadas no tratamento de quelóides, observase que o feixe de elétrons de $4 \mathrm{MeV}$ apresenta uma melhor distribuição de dose. As curvas do feixe de elétrons de $9 \mathrm{MeV}$ e a curva do feixe de raios-X de $90 \mathrm{kVp}$ apresentam um comportamento semelhante.

Conforme mostra o gráfico 5.22 observa-se que as fontes de ${ }^{90} \mathrm{Sr}+{ }^{90} \mathrm{Y}$ são recomendadas para lesões bastante superficiais. A dose absoluta nos pontos de máximos foram de 50 cGy para os feixes de elétrons de $4 \mathrm{MeV}$ e $9 \mathrm{MeV}$ e para o feixe de raios-X $90 \mathrm{kVp}$, para o aplicador de ${ }^{90} \mathrm{Sr}+{ }^{90} \mathrm{Y}$ a dose absoluta foi de $300 \mathrm{cGy}$. 


\subsection{Resultados das Simulações dos Casos Clínicos}

Uma vez feita as validações dos resultados de cálculo mediante comparação com dados experimentais foram realizadas simulações de casos clínicos típicos. Mais especificamente, foram realizadas cálculos de dose para quatro casos clínicos de lesões de pele, conforme citados na seção 4.4.6.

As figuras 5.23, 5.24, 5.25 e 5.26 apresentam os resultados das simulações para cada caso clínico, mostrando a porcentagem de dose absorvida em cada região da camada da pele e na região do tumor.

As incertezas estatísticas para o cálculo com MCNP4C considerando 2 milhões partículas, estão em torno de 0,5\%. Pode-se observar através destes resultados que em todos os casos $80 \%$ da dose estão dentro de $1 \mathrm{~cm}$ de profundidade corroborando com as prescrição médica citada no item 3.2.4.

No primeiro caso clínico simulado considerou-se a espessura do tumor de $0,75 \mathrm{~cm}$ acima da superfície da pele. Tal espessura coincide com a profundidade de dose máxima do feixe de elétrons de $4 \mathrm{MeV}$. Observa-se que a região do tumor recebe aproximadamente $87 \%$ da dose e a primeira camada da pele recebe 100\%, neste caso recomenda-se o uso de um bólus para superficializar a dose máxima no tumor. O $\mathrm{R}_{85 \%}$ está a 3,6 mm de profundidade abaixo da superfície da pele. Em comparação com os outros feixes simulados verifica-se que o feixe de elétrons de $4 \mathrm{MeV}$ tem uma absorção maior.

O segundo e o terceiro casos clínicos foram simulados com feixe de elétrons de $9 \mathrm{MeV}$, considerou-se nesses dois casos uma espessura de 2,10 $\mathrm{cm}$ para o tumor, coincidindo assim com a profundidade de dose máxima do feixe de elétrons de $9 \mathrm{MeV}$. A diferença entre o segundo e o terceiro casos clínicos são as dimensões dos tumores e a DFS que variou de $100 \mathrm{~cm}$ para $103 \mathrm{~cm}$ de um caso para o outro. No caso 2 tem-se $100 \%$ da dose do tumor utilizando DFS $103 \mathrm{~cm}$ e no caso 3 o tumor recebe aproximadamente 99\%, em ambos os casos o $\mathrm{R}_{85 \%}$ está aproximadamente a 7,2 $\mathrm{mm}$ da superfície da pele.

Para a simulação do quarto caso que é o caso clínico tratado com feixe de Raios-X foi necessário considerar dimensões próximas aos casos realísticos. Observa-se na figura 5.26 que a $R_{85 \%}$ está dentro da região do tumor, e a região da epiderme recebe aproximadamente $75 \%$ da dose. 


\begin{tabular}{|c|c|c|c|c|}
\hline \multirow[b]{2}{*}{ Célula } & Dimensões da lesão & \multirow{2}{*}{$\begin{array}{c}\text { Espessura da lesão } \\
Z(\mathrm{~cm})\end{array}$} & \multirow[t]{2}{*}{ Distruição da dose $\%$} & \multirow[t]{2}{*}{ Profundidade } \\
\hline & $X(\mathrm{~cm}) \quad Y(\mathrm{~cm})$ & & & \\
\hline REGIAO DO TUMOR & 6 & 0,75 & 86,88 & \\
\hline & & & & SUPERFIOIE DA PELE \\
\hline REEIÂO DA EPIDERME & & & 100,00 & $0,6 \mathrm{~mm}$ \\
\hline & & & 99,12 & $1,2 \mathrm{~mm}$ \\
\hline REEIĀO DA DERME & & & 96,64 & $1,8 \mathrm{~mm}$ \\
\hline & & & 94,03 & $2,4 \mathrm{~mm}$ \\
\hline & & & 90,19 & $3,0 \mathrm{~mm}$ \\
\hline & & & 85,79 & $3,6 \mathrm{~mm}$ \\
\hline & & & 79,92 & $4,2 \mathrm{~mm}$ \\
\hline & & & 73,49 & $4,8 \mathrm{~mm}$ \\
\hline & & & 66,11 & $5,4 \mathrm{~mm}$ \\
\hline & & & 58,37 & $6,0 \mathrm{~mm}$ \\
\hline RECIAO DAHIPODERME & & & 49,80 & $6,6 \mathrm{~mm}$ \\
\hline & & & 41,22 & $7,2 \mathrm{~mm}$ \\
\hline & & & 33,33 & $7.8 \mathrm{~mm}$ \\
\hline & & & 25,78 & $8,4 \mathrm{~mm}$ \\
\hline & & & 18,86 & $9,0 \mathrm{~mm}$ \\
\hline & & & 13,15 & $9,6 \mathrm{~mm}$ \\
\hline & & & 8,47 & $1 \mathrm{~cm}$ \\
\hline
\end{tabular}

Figura 5.23: Resultado da simulação no MCNP4C do Caso clínico 1 - Lesão de pele com dimensões $6 \mathrm{~cm}$ X $6 \mathrm{~cm} \mathrm{X} \mathrm{0,75} \mathrm{cm;} \mathrm{Energia} \mathrm{de} \mathrm{tratamento} 4 \mathrm{MeV}$; Tamanho de campo 10 cm X $10 \mathrm{~cm}$ e DFS $100 \mathrm{~cm}$.

\begin{tabular}{|c|c|c|c|c|}
\hline \multirow[b]{2}{*}{ Célula } & Dimensōes da lesão & \multirow{2}{*}{$\begin{array}{c}\text { Espessura da lesão } \\
Z(\mathrm{~cm})\end{array}$} & \multirow[t]{2}{*}{ Distribuição da dose \% } & \multirow[t]{2}{*}{ Profundidade } \\
\hline & $X(\mathrm{~cm})$ & & & \\
\hline Regiáo do TUMOR & 6 & 2,1 & 100,00 & \\
\hline & & & SUPE & GCEDA PAELE \\
\hline RECIAO DA EPIDERME & & & 99,69 & $0,6 \mathrm{~mm}$ \\
\hline & & & 99,48 & $1,2 \mathrm{~mm}$ \\
\hline REEIAO DA DERME & & & 98,11 & $1,8 \mathrm{~mm}$ \\
\hline & & & 97,37 & $2,4 \mathrm{~mm}$ \\
\hline & & & 96,45 & $3 \mathrm{~mm}$ \\
\hline & & & 95,30 & $3,6 \mathrm{~mm}$ \\
\hline & & & 93,86 & $4,2 \mathrm{~mm}$ \\
\hline & & & 92,70 & $4,8 \mathrm{~mm}$ \\
\hline & & & 91,11 & $5,4 \mathrm{~mm}$ \\
\hline & & & 89,68 & $6 \mathrm{~mm}$ \\
\hline RECIAO DA HIPODERM: & & & 87,57 & $6,6 \mathrm{~mm}$ \\
\hline & & & 85,04 & $7,2 \mathrm{~mm}$ \\
\hline & & & 83,00 & $7.8 \mathrm{~mm}$ \\
\hline & & & 80,17 & $8,4 \mathrm{~mm}$ \\
\hline & & & 77,78 & $9 \mathrm{~mm}$ \\
\hline & & & 74,10 & $9,6 \mathrm{~mm}$ \\
\hline & & & 68,49 & $1 \mathrm{~cm}$ \\
\hline
\end{tabular}

Figura 5.24: Resultado da simulação no MCNP4C do Caso clínico 2 - Lesão de pele com dimensões $6 \mathrm{~cm}$ X $6 \mathrm{~cm}$ X 2,1 cm; Energia de tratamento $9 \mathrm{MeV}$; Tamanho de campo 10 cm X $10 \mathrm{~cm}$ e DFS $103 \mathrm{~cm}$. 


\begin{tabular}{|c|c|c|c|c|}
\hline \multirow[b]{2}{*}{ Célula } & Dimensões da lesão & \multirow{2}{*}{$\begin{array}{c}\text { Espessura da lesão } \\
Z \mathrm{Z}(\mathrm{cm})\end{array}$} & \multirow[t]{2}{*}{ Distribuição da dose $\%$} & \multirow[t]{2}{*}{ Profundidade } \\
\hline & $X(\mathrm{~cm})$ & & & \\
\hline \multirow[t]{2}{*}{ RECIAO DO TUMOR } & 9 & 2,1 & 98,63 & \\
\hline & & & & ERFICIE DA PELE \\
\hline \multirow{2}{*}{\multicolumn{2}{|c|}{ Regito da EPIDERME }} & & 100,00 & $0,6 \mathrm{~mm}$ \\
\hline & & & 99,68 & $1,2 \mathrm{~mm}$ \\
\hline \multirow[t]{2}{*}{ Regita da DERME } & & & 98,99 & $1,8 \mathrm{~mm}$ \\
\hline & & & 98,17 & $2,4 \mathrm{~mm}$ \\
\hline \multirow{13}{*}{ Regitio da HiPOBERME } & & & 97,51 & $3,0 \mathrm{~mm}$ \\
\hline & & & 96,21 & $3,6 \mathrm{~mm}$ \\
\hline & & & 94,95 & $4,2 \mathrm{~mm}$ \\
\hline & & & 93,91 & $4,8 \mathrm{~mm}$ \\
\hline & & & 92,46 & $5,4 \mathrm{~mm}$ \\
\hline & & & 90,72 & $6,0 \mathrm{~mm}$ \\
\hline & & & 89,00 & $6,6 \mathrm{~mm}$ \\
\hline & & & 86,77 & $7,2 \mathrm{~mm}$ \\
\hline & & & 84,53 & $7,8 \mathrm{~mm}$ \\
\hline & & & 81,97 & $8,4 \mathrm{~mm}$ \\
\hline & & & 78,86 & $9,0 \mathrm{~mm}$ \\
\hline & & & 75,02 & $9,6 \mathrm{~mm}$ \\
\hline & & & 69,49 & $1,0 \mathrm{~cm}$ \\
\hline
\end{tabular}

Figura 5.25: Resultado da simulação no MCNP4C do Caso clínico 3 - Lesão de pele com dimensões $9 \mathrm{~cm}$ X $6 \mathrm{~cm}$ X 2,1 cm; Energia de tratamento $9 \mathrm{MeV}$; Tamanho de campo 10 $\mathrm{cm}$ X $10 \mathrm{~cm}$ e DFS $100 \mathrm{~cm}$.

\begin{tabular}{|c|c|c|c|c|c|}
\hline \multirow[b]{2}{*}{ Célula } & \multicolumn{2}{|c|}{ Dimensōes da lesão } & \multirow{2}{*}{$\begin{array}{l}\text { Espessura da lesão } \\
Z Z(\mathrm{~cm})\end{array}$} & \multicolumn{2}{|c|}{ Distribuiçao de Dose\% Profundidade } \\
\hline & $X(\mathrm{~cm})$ & $Y(\mathrm{~cm})$ & & & \\
\hline \multirow[t]{2}{*}{ REEIAOO DO TUMOR } & 6 & 6 & 2,1 & 100,00 & \\
\hline & & & & \multicolumn{2}{|c|}{ SUPERFICIEDAPELE } \\
\hline \multirow{2}{*}{ RECAOO DA EPDDERME } & & & & 74,04 & $0,6 \mathrm{~mm}$ \\
\hline & & & & 73,70 & $1,2 \mathrm{~mm}$ \\
\hline \multirow[t]{2}{*}{ REEIAOO DA DERME } & & & & 72,98 & $1.8 \mathrm{~mm}$ \\
\hline & & & & 71,27 & $2,4 \mathrm{~mm}$ \\
\hline \multirow{13}{*}{ RECIAO DA HIPODERME } & & & & 70,67 & $3,0 \mathrm{~mm}$ \\
\hline & & & & 67,89 & $3,6 \mathrm{~mm}$ \\
\hline & & & & 67,84 & $4,2 \mathrm{~mm}$ \\
\hline & & & & 66,77 & $4,8 \mathrm{~mm}$ \\
\hline & & & & 63,88 & $5,4 \mathrm{~mm}$ \\
\hline & & & & 63,95 & $6,0 \mathrm{~mm}$ \\
\hline & & & & 62,05 & $6,6 \mathrm{~mm}$ \\
\hline & & & & 60,09 & $7,2 \mathrm{~mm}$ \\
\hline & & & & 58,75 & $7,8 \mathrm{~mm}$ \\
\hline & & & & 56,50 & $8,4 \mathrm{~mm}$ \\
\hline & & & & 55,74 & $9,0 \mathrm{~mm}$ \\
\hline & & & & 54,58 & $9,6 \mathrm{~mm}$ \\
\hline & & & & 51,66 & $1,0 \mathrm{~cm}$ \\
\hline
\end{tabular}

Figura 5.26: Resultado da simulação no MCNP4C do Caso clínico 4 - Tumor de pele com dimensões $6 \mathrm{~cm}$ X 6 cm X 2,1 cm; Feixe de Tratamento Raios-X de 90 kVp; Tamanho de campo 6,8 cm e DFS $50 \mathrm{~cm}$ (Caso Fictício). 


\begin{tabular}{|c|c|c|c|c|c|c|c|c|c|}
\hline \multirow[b]{2}{*}{ Célula } & \multicolumn{2}{|c|}{ Elétrons 4MeV } & \multicolumn{2}{|c|}{ Elétrons $9 \mathrm{MeV}$} & \multicolumn{2}{|c|}{ Raio-X $90 \mathrm{kVp}$} & \multicolumn{2}{|c|}{${ }^{90} \mathrm{Sr}+{ }^{90} \mathrm{Y}$} & \multirow[b]{2}{*}{ Profundidade } \\
\hline & $\mathrm{Cl}$ & MCNP4C & $\mathrm{Cl}$ & MCNP4C & $\mathrm{Cl}$ & MCNP4C & $\mathrm{Cl}$ & MCNP4C & \\
\hline Superficie da Pele & 100,00 & 100,00 & 100,00 & 100,00 & 100,00 & 100,00 & 100,00 & 100,00 & $0 \mathrm{~mm}$ \\
\hline Regliko da Epiderme & 99,38 & 100,14 & 99,91 & 99,77 & 99,65 & 99,59 & 68,49 & 67,92 & $0,6 \mathrm{~mm}$ \\
\hline \multirow{3}{*}{ Regizo da Derme } & 97,65 & 98,99 & 99,73 & 99,70 & 98,66 & 98,84 & 46,06 & 47,06 & $1,2 \mathrm{~mm}$ \\
\hline & 94,82 & 98,75 & 99,27 & 98,74 & 97,57 & 98,16 & 32,35 & 32,59 & $1,8 \mathrm{~mm}$ \\
\hline & 90,70 & 94,09 & 98,63 & 98,55 & 96,39 & 97,36 & 23,70 & 22,24 & $2,4 \mathrm{~mm}$ \\
\hline \multirow{6}{*}{ Reglio da Hipoderme? } & 85,66 & 91,28 & 97,90 & 97,96 & 95,38 & 96,51 & 15,19 & 14,75 & $3 \mathrm{~mm}$ \\
\hline & 80,10 & 85,88 & 96,99 & 96,97 & 93,97 & 95,60 & 9,94 & 9,55 & $3,6 \mathrm{~mm}$ \\
\hline & 73,96 & 80,08 & 95,80 & 96,82 & 92,95 & 94,64 & 6,06 & 55,87 & $4,2 \mathrm{~mm}$ \\
\hline & 67,43 & 72,33 & 94,62 & 95,35 & 91,65 & 93,62 & 3,65 & 3,44 & $4,8 \mathrm{~mm}$ \\
\hline & 60,62 & 64,89 & 93,16 & 93,39 & 90,38 & 92,64 & 2,04 & 1,88 & $5,4 \mathrm{~mm}$ \\
\hline & 57,17 & 55,47 & 91,33 & 91,66 & 89,11 & 91,62 & - & - & $6 \mathrm{~mm}$ \\
\hline
\end{tabular}

Figura 5.27: Medidas experimentais das fontes de radiação para uso de lesões dermatológicas e simulações no MCNP4C, mostrando a porcentagem de dose absorvida em cada região da camada da pele até $6 \mathrm{~mm}$.

A figura 5.27 apresenta o resumo dos resultados das medidas experimentais das fontes de radiação para uso de lesões dermatológicas e os resultados simulados com o MCNP4C, mostrando a porcentagem de dose absorvida em cada região da camada da pele até $6 \mathrm{~mm}$, já apresentado nesse trabalho em forma de gráficos. 


\section{Capítulo 6 \\ CONCLUSÕES}

As conclusões deste trabalho podem ser apresentada pelos seguintes tópicos:

A) Análises Dosimétricas: foi possível alcançar o objetivo do trabalho realizando a análise dosimétrica de diferentes fontes de radiação utilizadas em procedimentos radioterápicos em lesões superficiais da pele. A comparação da análise dosimétrica, entre as diferentes fontes de radiação, apresentada pode fornecer auxílio nas decisões médicas quanto à forma mais adequada para um determinado tratamento. Através deste trabalho foi possível a realização de uma série de estudos relacionados a importantes parâmetros clínicos e físicos utilizados na radioterapia em lesões dermatológicas.

B) Caracterização dos Feixes: os feixes de elétrons de $4 \mathrm{MeV}$ e $9 \mathrm{MeV}$ do acelerador linear do HC/UNESP-Botucatu foram caracterizados, na parte axial e radial, tanto experimentalmente como no código MCNP4C. Os resultados dessas caracterizações dos feixes no MCNP4C basearam-se na metodologia da reconstrução dos espectros, que apresentaram uma excelente concordância entre as curvas experimentais e as curvas obtidas pelas simulações no MCNP, mostrando que os espectros tanto na parte axial e radial foram adequadamente reconstruídos.

C) Medidas Experimentais e os Cálculos no MCNP4C: os resultados das medidas experimentais comparados com os cálculos no MCNP apresentaram uma boa concordância entre si. A diferença percentual entre as curvas na parte axial foram inferiores a $2 \%$, já a diferença entre as curvas na parte radial foram inferiores a $4 \%$ na maioria dos 
pontos, desconsiderando a região fora de interesse. Os pontos de maior discordância entre os valores calculados e experimentais concentram-se nas medidas do perfil radial nas extremidades do tamanho de campo, verificando uma diferença percentual de até $14 \%$. Tendo em vista que a dosimetria com a CI não oferece muitas vantagens quanto à resolução espacial. Para validação das reconstruções dos espectros realizou-se medidas experimentais em função de placas atenuadoras, pelos resultados obtidos com os cálculos MCNP4C considera que os resultados foram coerentes com as medidas experimentais. A concordância entre as curvas de atenuação experimental e simulada com o MCNP4C mostra que este método é ferramenta valiosa para validação dos experimentos dos feixes de elétrons e raios-X de $90 \mathrm{kVp}$. As medidas comparando os TLDs e CI apresentaram uma diferença percentual máxima na ordem de $5 \%$.

D) Casos Clínicos: as simulações dos casos clínicos permitiram comprovar a viabilidade de simulações por Monte Carlo para o cálculo de distribuição de dose que podem auxiliar nas decisões médicas quanta forma mais adequada para um determinado tratamento. Neste sentido, conclui-se que os resultados dos cálculos com o método de Monte Carlo, utilizando o código MCNP4C podem ser utilizados no auxílio aos cálculos dosimétricos na rotina médica em tratamentos de lesões de pele com diferentes fontes radioativas.

Os resultados aqui apresentados também sugerem a possibilidade de desenvolvimento de protocolos baseados nas medidas experimentais e valores que auxiliem os físicos-médicos nos planejamentos para o tratamento de forma geral. 


\section{Referências Bibliográficas}

AIEA, AGÊNCIA INTERNACIONAL DE ENERGIA ATÔMICA. "Absorved Dose Determination in External Beam Radiotherapy. An International Code of Practice for Dosimetry Based on Standards of Absorved Dose to Water". Technical Reports Serie no. 398. Vienna. 2000.

AIEA, AGÊNCIA INTERNACIONAL DE ENERGIA ATÔMICA. "Dosimetry in Diagnostic Radiology: An International Code of Practice". Technical Reports Serie no. 457. Vienna. 2007.

ABNT, ASSOCIAÇÃO BRASILEIRA DE NORMAS TÉCNICAS. "NBR 6023: Informação e documentação - Referências - Elaboração". Rio de Janeiro, 2002.

ABNT, ASSOCIAÇÃO BRASILEIRA DE NORMAS TÉCNICAS. "NBR 10520: Informação e documentação - Citações em documentos - Apresentação". Rio de Janeiro, 2002.

ARAÚJO, A. M; VIEGAS, C. C; RODRIGUES, L. N; GUIZZARDI, M. L; JUNIOR, P. P E SOUZA, R.S. "O elétron na radioterapia": curso a distância/Fundação Oswaldo Cruz. Escola Nacional de Saúde Publica Sérgio Arouca. Programa de Educação a distância Rio de Janeiro INCA,2005.

ATTIX, F. H. "Introduction to Radiological Physic and Radiation Dosimetry", 1986. New York. 
BENTEL, G. C. "Radiation Therapy Planning”. Mc Graw-Hill. New York. 2a ed, 1996.

BIRAL, A. R. "Radiações ionizantes para médicos, físicos e leigos". Editora Insular. Ano 2002. Florianópolis.

BRIESMEISTER, J. F. “MCNP: A general Monte Carlo N-particle transport code, version 4 C", LA-13709-M, Los Alamos Scientific Laboratory, Los Alamos, New Mexico,2000.

CASTRO, L. G. M; TOYAMA, C. L; GOMES. A.; FREIRE, M. A; BRITO, T. F. "Investigação clínica, epidemiológica, laboratorial e terapêutica. Câncer de pele em clínica particular em São Paulo" - SP . Anais Brasileiros de de dermatologia Volume 71 - № $6,1996$.

CUCE,L. C; NETO FESTA, C; "Manual de Dermatologia".. Editora Atheneu. 2a edição.

FERNANDES, M. A. R. "Utilização de Moldes Radioativos Especiais de Folhas de Ouro-198 para Braquiterapia em Tumores de Pele". Tese de Doutorado, Instituto de Pesquisas Energéticas e Nucleares (IPEN/CNEN-SP), 2000.

FERNANDES, M. A. R.; TADA.A.; YORIAYAZ, H. "Determinação da curva de atenuação da radiação em feixes de elétrons de alta energia." Universitas- Revista Científica do Unisalesiano de Araçatuba V.I, n. 2, p.155-159. Ano 2009.

FONSECA, G. P; FURNARI, L.; YORIYAZ, H.; SIQUEIRA, P. T. D, RUBO, R.; POLI, M. E.. "Metodologia para caracterização de dosímetros termoluminescentes (TLD-100) para dosimetria em radioterapia". International Nuclear Atlantic Conference - INAC, 2007 Santos, SP, Brazil.

GOLEMAN; B. FRIEDHOFER; H.' RIVITTI, E.; ANGER, M.; SOUZA, L. “Carcinomas basocelular e espinocelular da pele". Anais Brasileiros de dermatologia, volume 53 número 4. 
ICRP 89, "Basic anatomical and physiological data for use in radiological protection: reference values .Integumentary System. International Commission on Radiological Protection".

INCA - Instituto Nacional do Câncer. "Câncer de Pele".Rio de Janeiro. Disponível em http://www.inca.gov.br. Acessado em janeiro/2010.

KOPKE, L. F. F; SCHMIDT, S. M, "Carcinoma basocelular". Anais Brasileiro de dermatologia, volume 77, número 3,educação contínua, Rio de Janeiro, 2002

LEMOS, H. L. "Caracterização e Dosimetria de feixe de Raios-X de 100 e 140 kVp usados em radioterapia". 2006. Centro de Desenvolvimento da Tecnologia Nuclear. Belo Horizonte-MG.

MARIN, A. V. Tese de Mestrado "Desenvolvimento de um sistema dosimétrico postal para uso e programas de qualidade em radioterapia com feixes de fótons em condições de não referência”, 2003. Tese (mestrado). Instituto Nacional do Câncer.

MICHALANY, J; MICHALANY, N. S. “Anatomia e Histologia da Pele". São Paulo, Lemos Editorial 2002.

MORLOTI, M. "Verificação de Tratamentos Radioterápicos diversos com dosimetria termoluminescentes". 2007. Tese (mestrado) - Universidade de São Paulo. São Paulo.

NANDI, D.M "Estudo de funcionalidade e segurança para Aceleradores Lineares utilizados em Radioterapia". - Uma contribuição para gestão de Tecnologia Médico-Hospitalar. 2004. Tese (Mestrado). Universidade Federal de Santa Catarina. Florianópolis.

NOBREGA; A. I. “Tecnologia Radiológica e Diagnóstico por imagem".. 3 ed. São Caetano do Sul-SP, Difusão Editora- Série Curso de Radiologia Volume 2. 
OKUNO; E., CONSTANTINO; M. A. V. "Radiação Ultravioleta:Características e efeitos".. 1 Edição- São Paulo: Editora Livraria da Física, Sociedade Brasileira de Física, 2005.

OLIVEIRA, B.J. "Estudo comparativo entre o tratamento radioterápico com elétrons e Betaterapia após Cirurgia de quelóide”. 2007. - Universidade Estadual Paulista "Julio Mesquita Filho - UNESP. Botucatu-SP.

PODGORSAK; E.B. "Radiation Oncology Physics: A Handbook for Teachers and Students".Technical Editor [et al.]. -International Atomic Energy Agency.

POLI, M. A. R. "Definição do Alvo e seu efeito na Radioterapia". 2007. Tese (doutorado) - Instituto de Pesquisas Energéticas e Nucleares.

SANCHES, A. "Projeto e confecção de simuladores oftalmológicos para aplicações clínicas". 2006. Tese (doutorado) - Instituto de Pesquisas Energéticas e Nucleares. São Paulo

SALVAJOLI, J. C; SOUHAMI, L; FARIA. S.L. " "Radioterapia em Oncologia"., editora MDSI, São Paulo 1999.

SALLES, T. C; TADA. A; FERNANDES, M. A. R; YORIYAZ; H.; ANTONIO, P. L. "Dosimetric comparison of electron beam and ${ }^{90} \mathrm{Sr}+{ }^{90} \mathrm{Y}$ applicator for keloids treatment". 2009 International Nuclear Atlantic Conference - INAC 2009.

SANTOS, G. P. "Desenvolvimento de um Sistema Dosimétrico Multidiodos para Garantia da Qualidade em Equipamentos Radioterapêuticos". 2002. Tese (Mestrado) - Instituto de Pesquisas Energéticas e Nucleares. São Paulo.

SALOMON, R. "A história da Radioterapia”. Mini-curso de radioproteção. SBRT. Programa da qualidade em radioterapia . trabalhos técnicos cientifico Aulas e apresentações. Aula 1, 2006. Disponível em http://www.inca.gov.br/pqrt/download/trab/minicurso_radioprotecao_aula1.pdf. 
SALEMME, F. "Aceleradores Lineares". In: CONGRESSO BRASILEIRO DE FÍSICA MÉDICA, 2005, Salvador-BA. Disponível em http://www.abfm.org.br/c2005/palestras/palestra98.pdf. Acessado em janeiro de 2010.

SCAFF, L. A. M. “Física da Radioterapia”. São Paulo: Sarvier, 1997.

STOLL, B. A. "Radioterapia - Conhecimento Gerais para médicos e estudantes de medicina" - Savier -Editora da Universidade de São Paulo- 1968.

SHUlTIS, J. K. AN MCNP - PRIMER. 2006. Dept. of Mechanical and Nuclear Engineering Kansas State University Manhattan, KS 66506.

TADA, A.; FERNANDES, M.A.R.; YORIYAZ,H. "Uso do Código MCNP para Análise da Curva de Atenuação em Feixes de Eletróns de $4 \mathrm{MeV}$ ". Revista Brasileira de Cancerologia. Volume 56, número 2, Ano 2010. ISSN 2176945.

TADA, A.; SALLES,T.; FERNANDES, M.A.R.; YORIYAZ,H. Uso do Código MCNP para Análise da Atenuação da Radiação Produzida por Fontes Radioativas Utilizadas em Radioterapia em Tumores de Pele.".XV Congresso Brasileiro de Física Médica.

TEIXEIRA; P. B "Simulação por monte Carlo de Dose em Radiografia Industrial”..2009. Tese (Doutorado). Universidade Federal do Rio de Janeiro-UFRJ.

TELLES, L. F.K. "Simulação Monte Carlo da dosimetria clinica em Radioterapia usando aceleradores lineares". 2008. Tese (Doutorado). Universidade Federal do Rio de Janeiro -UFRJ.

VIERA, A. M. "Dosimetria dos Sistemas de Radiocirurgia Estereotáxica com Aceleradores lineares equipados com colimadores micro multi-lâminas". 2008. Tese (Doutorado). Instituto de Pesquisas Energéticas e Nucleares. São Paulo. 
YORIYAZ, H. "Método de Monte Carlo: princípios e aplicações na área de Física Médica”. Revista Brasileira de Física Médica, p141-149. Ano 2009.

YORIYAZ, H; SIQUEIRA, P. T. D; ANDRADE, D. A; FONSECA, G. P; GUIMARÃES, P. A; SOUZA, G. "Estudos dos Parâmetros Clínicos em Radioterapia com Feixes de Elétrons" . Relatório Técnico PeD. Centro de Engenharia Nuclear CEN/IPEN, 2007.

YOSHIZUMI, M. T; YORIYAZ, H. CALDAS, L. V. "Backscattered Radiation into a Transmission Ionization Chamber: Measurement and Monte Carlo Simulation"IPEN, 2007. 